\title{
ORNL Fusion Power Demonstration Study: The Concept of the Cassette Blanket
}

\author{
Richard W. Werner
}

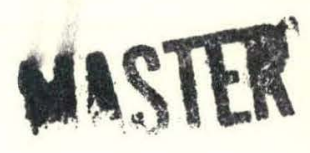

\section{OAK RIDGE NATIONAL LABORATORY}




\section{DISCLAIMER}

This report was prepared as an account of work sponsored by an agency of the United States Government. Neither the United States Government nor any agency Thereof, nor any of their employees, makes any warranty, express or implied, or assumes any legal liability or responsibility for the accuracy, completeness, or usefulness of any information, apparatus, product, or process disclosed, or represents that its use would not infringe privately owned rights. Reference herein to any specific commercial product, process, or service by trade name, trademark, manufacturer, or otherwise does not necessarily constitute or imply its endorsement, recommendation, or favoring by the United States Government or any agency thereof. The views and opinions of authors expressed herein do not necessarily state or reflect those of the United States Government or any agency thereof. 


\section{DISCLAIMER}

Portions of this document may be illegible in electronic image products. Images are produced from the best available original document. 
Printed in the United States of America. Available from National Technical Information Service

U.S. Department of Commerce 5285 Port Royal Road, Springfield, Virginia 22161

Price: Printed Copy $\$ 5.25$; Microfiche $\$ 3.00$

This report was prepared as an account of work sponsored by the United States Government. Neither the United States nor any of its employees, nor any of its contractors, subcontractors, or their employees, makes any warranty, express or implied, or assumes any legal liability or responsibility for the accuracy, completeness or usefulness of any information, apparatus, product or process disclosed, or represents that its use would not infringe privately owned rights. 
Contract No. W-7405-eng-26

FUSION ENERGY DIVISION

ORNL FUSION POWER DEMONSTRATION STUDY:

THE CONCEPT OF THE CASSETTE BLANKET

Richard W. Werner

Lawrence Livermore Laboratory

Livermore, California

Date Publishod - October 1977

NOTICE

This report was prepared as an account of wotk consored hy the United States Government. Neither the United States not the United States Energy Research and Development Adrisistration, nor any or their employeas. nor any of hes contractors. warranty, express or implied, or assumes any legal lizbility of responsibility for the accuracy, completeness or usefulness of any information, apparatus, product or process disclosed, of represents that its use would no infringe privitely nomed rights.

Prepared by the OAK RIDGE NATIONAL LABORATORY Oak Ridge, Tennessee 37830 operated by

UNION CARBIDE CORPORATION for the DEPARTMENT DF FNFRGY 
THIS PAGE

\section{WAS INTENTIONALLY LEFT BLANK}




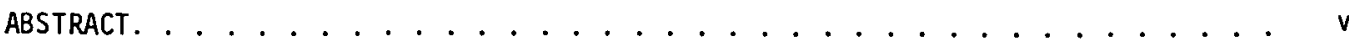

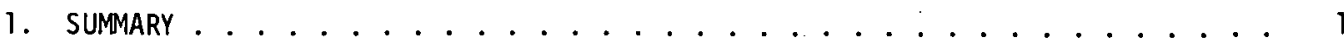

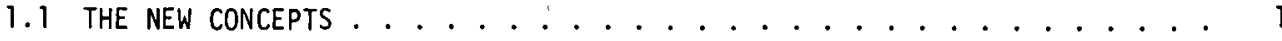

1.1.1 The Cassette................... 1

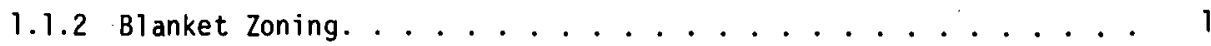

1.1 .3 Rectangular Blanket ................ 1

1.1 .4 Internal Tritium Recovery ............... 1

1.1 .5 The Blanket Assembly. ................ 1

1.2 THE CASSETtE CONCEPT IN THE FUSION PROGRAM ............ 1

2. THE USE OF CASSETTES IN A FUSION REACTOR BLANKET. ............ 2

2.1 A TYPICAL CASSETTE UNIT. . . . . . . . . . . . . 2

2.2 StRUCTURAL AND THERMAL-HYDRAULiC CHARACTERISTICS OF CASSETtES. . . . . 2

2.3 THE CASSETTE BlANKET ................... 2

2.3.1 Fusion Reactor Blankets in General............. 2

2.3.2 The Idea of Zoning. ............... 6

2.3.3 Details of the Rectangular Blanket. ...........66 6

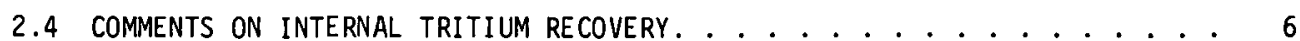

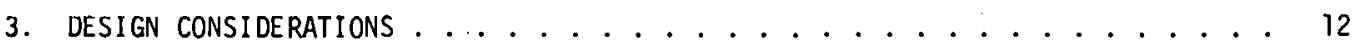

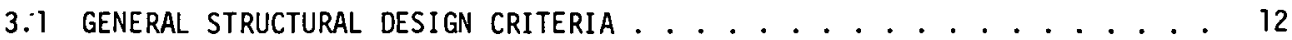

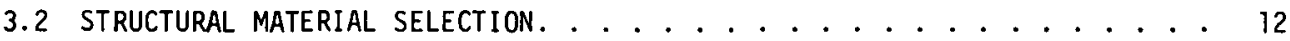

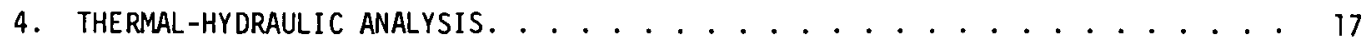

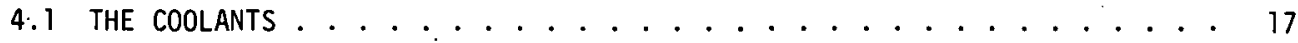

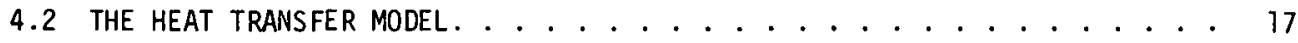

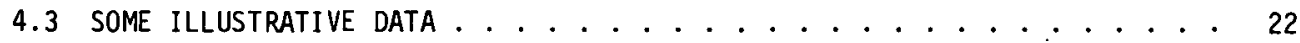

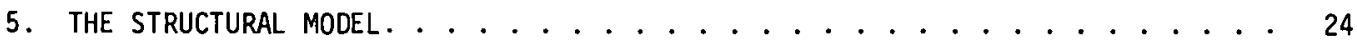

5.1 GENERAL COMMENTS ON STRESS ANALYSIS. . . . . . . . . . . 24

5.2 DEFORMATION AND BENDING STRESS IN NONUNIFORMLY HEATED TUBES. . . . . . 24

5.2 .1 The Stress Leveis. . . . . . . . . . . . . . 25

5.2 .2 Cyclic Stress Intensities ............... 25

5.3 STRESSES IN THE TUBE AS A UNIT ................ 28

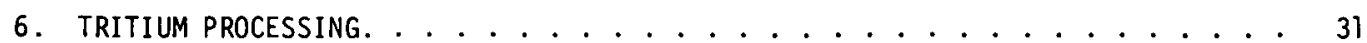

6.1 HEATING OF THE LITHIUM . . . . . . . . . . . . . 31

6.2 TRITIUM PRODUCTION AND RECOVERY. . . . . . . . . . . . 31

6.2.1 An Example: Partial Pressure Requirements. . . . . . . . 34

6.2.2 Removing the Tritium to an External Region.......... 34 


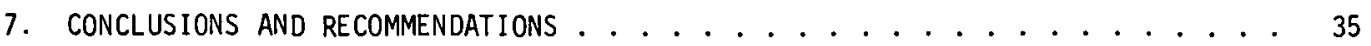

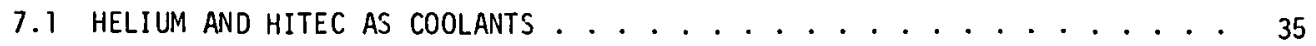

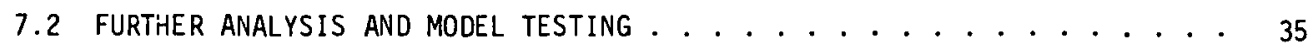

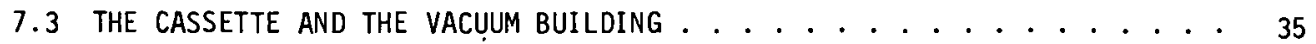

7.4 A final CAVEAT: THE NEEd fOR A FaIL-SAFE BlANKET. . . . . . . . . 36 REFERENCES. . . . . . . . . . . . . . . . . . 37

APPENDIX 1. PROPERTIES OF HELIUM AND HITEC .............. 38

APPENDIX 2. CALCULATIONAL PROCEDURE FOR HEAT TRANSFER. . . . . . . . . . 39

APPENDIX 3. OUTPUT DATA FOR HELIUM AND HITEC AT DIFFERENT WALL

LOADINGS AND TUBE DIAMETERS . . . . . . . . . . . 44

APPENDIX 4. SELECTIONS FROM THE ASME BOILER CODE ON ALTERNATING STRESSES . . . 47

APPENDIX 6 . STRESSES AT THE BEND OF À U-SHAPED TIIBE. . . . . . . . . . . . 53

APPENDIX 6. EQUATION FOR TEMPERATURE PROFILES IN THE LITHIUM . . . . . . 57 
The cassette blanket introduces four major improvements in fusion reactor blanket design. These are:

1) the cassette itself which by design furnishes the key unit for simplification of bianket replacement and maintenance and also isolates the lithium moderator from the plasma by enveloping it in the coolant;

2) the concept of blanket zoning, which uses to advantage the fact that radiation damage to structure decreases exponentially with distance. With the use of cassettes in series, only the front fraction of the blanket, the first cassette, need be changed due to damage over the life of the plant;

3) the rectangular blanket concept, which recognizes that blankets must envelop the plasma but need not conform to plasma shape. With this rectangular geometry, cassettes may be installed or removed by simple linear motion between magnet colls;

4) internal tritium recovery, whtch uses a favorable temperature gradient and "MHD-frozen" lithium to diffuse tritium out of the cassette.

Supporting calculations and illustrative cases are provided for these four areas using two coolants: helfum and HITEC, a eutectic mixture of inorganic salts (potassium nitrate, sodium nitrate, and sodium nitrite). 


\subsection{THE NEW CONCEPTS}

This report describes a number of new ideas in fusion reactor blanket design centering on one principal concept - that of the cassette module. The design incorporates a number of innovative features and has been developed in an attempt to satisfy all criteria of assembly, disassembly, integrity, tritium breeding, use of existing materials technology, and integration with plasma physics, based on today's understanding of the problem. The design introduces and combines in a beneficial way four major new features: the cassette, the concept of blanket zoning, the rectangular blanket concept, and internal tritium recovery.

\subsubsection{The Cassette}

The cassette itself is an elementary, simple structure which is designed to furnish the key unit for simplification of blanket replacement and maintenance. It also isolates the lithium moderator from the plasma by enveloping it in the coolant.

\subsubsection{Blanket Zoning}

The concept of blanket zoning uses to advantage the fact that radiation damage to structure decreases exponentially with distance. With the use of cassettes in series, only the front fraction of the blanket, the first cassette, will need to be changed due to radiation damage over the life of the plant.

\subsubsection{Rectangular Blanket}

The rectangular blanket concept recognizes that blankets must envelop the plasma but need not conform to plasma shape. With this geometry, cassettes may be installed or removed by simple linear motion between toroidal and poloidal coils.

\subsubsection{Internal Tritium Recovery}

Internal tritium recovery uses a favorable temperature gradient and "MHD-frozen" lithium to diffuse tritium out of the cassette. 1

\section{1 .5 The Blanket Assembly}

The combination of these four major design ideas produces a blanket assembly which eases the total design problem, is relatively simple, and can be serviced and maintained with a minimum of difficulty. The basic cassette module, the assembly of cassettes in a sector of a reactor, and the cross section of a completed reactor with cassettes in place are fully discussed and illustrated in the following sections.

\subsection{THE CASSETTE CONCEPT IN THE FUSION PROGRAM}

The concept of the cassette blanket came about as a result of the Oak Ridge National Laboratory (ORNL) Fusion Power Demonstration Study, the purpose of which was to develop a plan for demonstrating in this century the commercial feasibility of fusion power based on the tokamak concept. ${ }^{2}$ A major part of the plan involves highlighting and discussing key engineering problems to focus attention on them and to ensure that they receive the necessary technological support. In order for fusion to enter the marketplace at the earliest possible time, the physics and the technology for fusion must proceed concurrently and with equal vigor. It would be a serious blunder if failing to recognize the compression of time and acceleration of progress now occurring in plasma physics, we found ourselves not in a state of technological readiness when scientific feasibility was unequivocally demonstrated. 


\section{THE USE OF CASSETTES IN A FUSION REACTOR BLANKET}

\subsection{A TYPICAL CASSETTE UNIT}

We have found that a typical cassette has the general characteristics given in Table 1 . Figure 1 illustrates the general design features of a cassette blanket module. The cassette's assembly of individual coolant tubes completely encapsulates the lithium moderator, providing good isolation from the plasma. Figure 2 illustrates a method for producing the coolant tubes by fussing together scalloped sheets. The benefits of this method are:

- the welds need not be completely leaktight, because a leak will produce only cross flow between adjacent tubes;

- the welds are isolated from both the plasma and the lithium; and

- the welds are on the neutral axis (zero stress) for tube bending.

The balance of the tube uses $20 \%$ cold worked material. A method of fusing the two sheets is illustrated in Fig. 3 .

The cassette may be relatively slender to factlitate assembly and disassembly. Its thicknesss is determined by the desired decrease in radiation damage from front to back, usually about $25 \mathrm{~cm}$ for a damage reduction of five to ten, and by the temperature profile within the module. The module is $\sim 4 \mathrm{~m}$ long and $<1 \mathrm{~m}$ wide. The module assembly includes supply and return headers for the coolant and a noncirculating lithium moderator complete with an expansion plenum to accommodate the volumetric change of the lithium during the operating cycle. This bellows-type expansion plenum also acts as a pressure transducer or stress transducer that senses pressure changes in the event of a leak between coolant and moderator. The cassette also incorporates a method for tritium recovery.

\subsection{STRUCTURAL AND THERMAL-HYDRAULIC CHARACTERISTICS OF CASSETTES}

We have examined in reasonable depth the structural and thermal-hydraulic characteristics of an individual cassette for two coolants: helium and the commercial inorganic salt HITEC. Although more detailed calculations will eventually be in order, we have found that there is an ample thermal-hydraulic-structural operating regime when helium is the coolant. Using the constraints of $1 \%$ of the thermal power for pumping and allowing a 32,000-psi cyclic stress for 316 stainless steel at temperatures less than $500^{\circ} \mathrm{C}$, we have found the roquirod coolant tube diameters Tor he ifum to be belween 2 and 5 lii ini vider to accommodate wall loadings of $2-4.5 \mathrm{MW} / \mathrm{m}^{\text {? }}$. This high wall load capability with helium is a very encouraging result. The structural limits on the salt HITEC as a coolant are less severe than those for helium. However, the salt has inescapable problems of thermal and radiation stability, melting point, start-up, and freezing on shutdown. It is our opinion that helium is the preferred coolant. Also, with helium encapsulating the lithium in a cassette, there is a much lower probability of venting lithlum lu bie plasilla.

\subsection{THE CASSETTE BLANKET}

\subsubsection{Fusion Reactor Blankets in Cieneral}

The blanket of a fusion reactor is a complicated, multifunctional unit enveloping the reacting plasma. In a deuterium-tritium (D-T) system it must

1) moderate the 14-MoV noutrone to therma energy levels,

2) breed the required tritium fuel via neutron reactions with lithluin or lithium r.nmpounds,

3) provide for thermal energy transfer to an external turbogenerator so that useful clectrical power is produced, and

4) envelop the plasma and yet allow flux penetration so that current may be induced in the plasma.

These tasks must be accomplished in a relatively flimsy structure - the flimsiness is 
ORNL / OWG/FED - 77373R
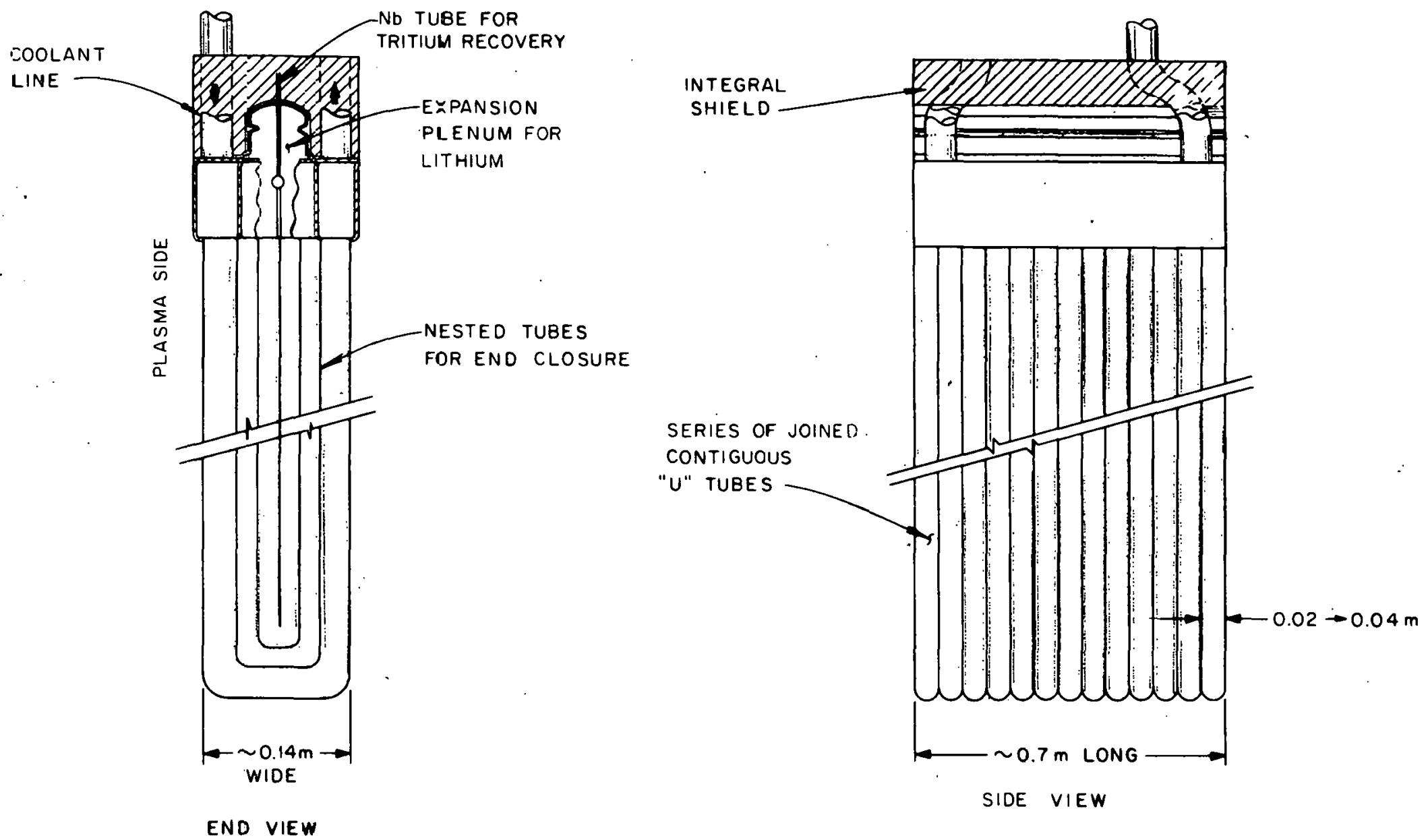

Fig. 1. General design features of a cassette blanket module. 
ORNL / DWG / FED - 77359

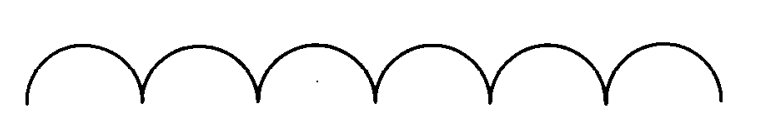

SCALLOPED

SHEET 1

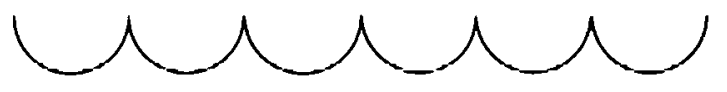

SCALLOPED

SHEET?

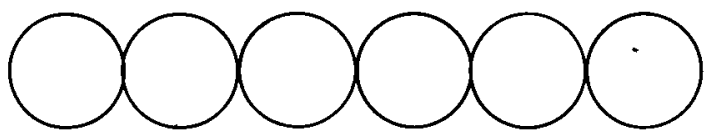

SHEETS 1 AND 2 JOINED

Fig. 2. Scalloped sheets joined to form coolant tubes for cassette.

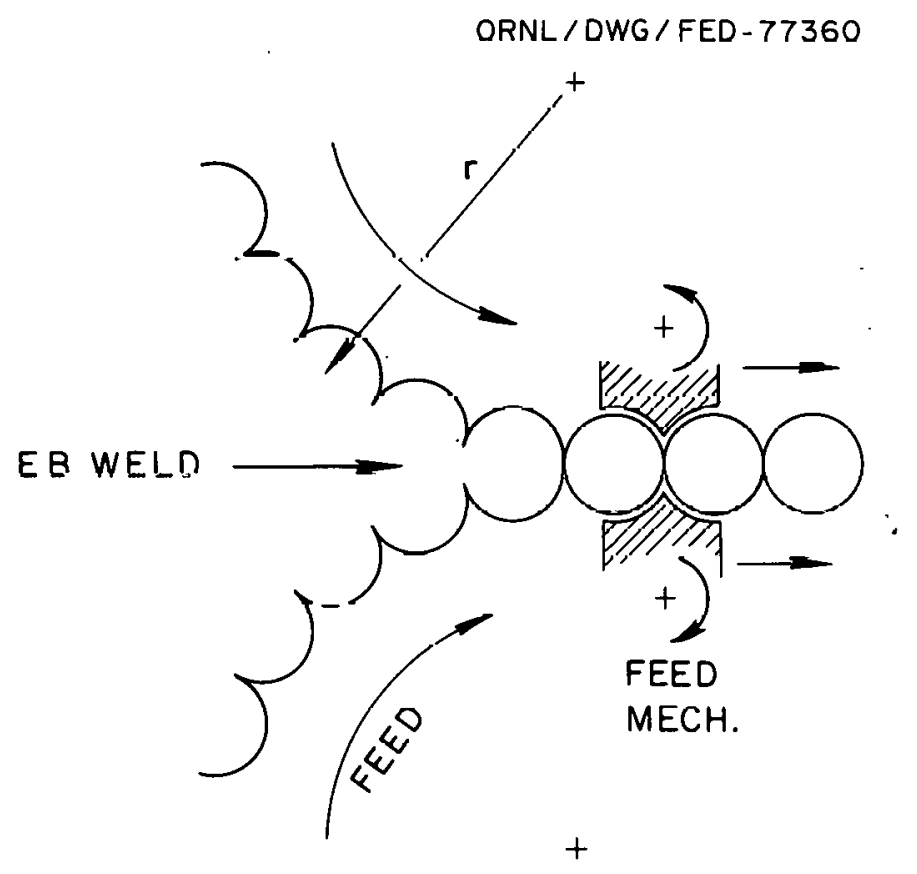

Fig. 3. Curved scalloped sheets are fed to a convergent line where joining is accomplished by electron beam welding. 
Table 1. Cassette characteristics

Structural material
Coolant
Coolant temperature
Maximum material temperature
in high radiation zone
Wall loading capability
Probable lifetime
Moderator
Tritium recovery
Cassette thickness
Cassette length
Cassette width
Coolant disconnect location
Removal method
Tritium partial pressure
HeLi leak detection '
Fail-safe feature
Cost
Changing time
In situ repairs
Compatibility with plasma
Resistance to magnetic field forces

necessary to ensure adequate tritium breeding. The ratio of reacting volume to structural volume is about 20:1 ideally and 15:1 practically. Because of its thermodynamic function as an energy store, the blanket is quite hot $-400-500^{\circ} \mathrm{C}$ is representative. (It is, after all, the heat source of a power plant.) Because of its proximity to the plasma, it is subjected to the ravages of radiation and other fusion environmental effects: atomic displacements, heliuminduced swelling, sputtering, spalling, cyclic fatigue, and thermal stress. Consequently, its Iife expectancy may be less than that of the total plant. It must be designed in small units because it has to be assembled in some reasonable way and also because if it were a single homogeneous unit, flux penetration to the plasma would be impaired. It is disagreeably inaccessible, situated immediately next to the plasma and surrounded by such things as shields, poloidal coils, vertical field coils, toroidal coils,
316 stainless steel, $20 \%$ cold worked Helium at $60 \mathrm{~atm}$

$\mathrm{T}_{\text {in }} \simeq 350 \mathrm{~K} ; \mathrm{T}_{\text {out }} \simeq 750 \mathrm{~K}$

$700 \mathrm{~K}$

$\sim 4.5 \mathrm{MW} / \mathrm{m}^{2}$

2 years

Noncirculating lithium sealed in place

Niobium or vanadium window

$20.14 \mathrm{~m}$

$\sim 4.0 \mathrm{~m}$

$21 \mathrm{~m}$.

Outside shield

Linear motion

210-6 torr

Pressure sensor in plenum

Helium-encapsulated $1 \mathrm{i}$ thium

Appears reasonable; not calculated

Appears short; not analyzed

Not necessary; cassette would be replaced

Wall of front cassette may be treated with low $Z$ coating

Not calculated

injectors, coolant piping, divertors, structure, instrumentation, and miscellany. Yet access is necessary because the blanket - at least the first $12-25 \mathrm{~cm}$ - is likely to be the shortestlived reactor component and must be replaced periodically. A 5-year lifetime projection is probably optimistic. Furthermore, some number of faults in the blanket modules would seem almost inevitable during their life span, and it is highly probable that replacement of single blanket modules rather than in situ repair would have to be planned. The blanket must be economical to fabricate and maintain. Of utmost importance is that it must be as fault-free and as fail-safe as possible. Simplicity must be strived for both in method of manufacture and in the use of contemporary structural materials. Above all, there must exist a credible method of blanket module assembly, disassembly, and maintenance under (more than likely) remote operating conditions. 


\subsubsection{The Idea of Zoning}

In the cassette design approach, we take advantage of the fact that radiation damage decreases as a function of depth into the blanket. For a reference design, a spatial distribution of damage characterized by atomic displacement rate and helium generation rate is illustrated in Fig. $4{ }^{3}$ It may be observed from Fig. 4 that in a distance of about $25 \mathrm{~cm}$, the atomic displacement rate decreases by a factor of five and the helium generation rate decreases by a factor of seven. We define this region, which represents volumetrically about $25 \%$ of the total blanket, as the first blanket zone (FBZ). The FBZ is that part of the blanket which would be changed routinely when radiation effects dictated or when surface effects such as sputtering erosion required it. All other things being equal, the second blanket zone, i.e., the remaining $75 \%$ of the blanket, would last 5-10 times longer, or about the $\sim 30$ year life of the plant. This zoning approach to blanket maintenance is markedly superior to the more common approach of a main blanket and a separable first wall. There is little to be gained by changing a thin first wall and leaving behind other material that also has had significant damage.

The coolant circuit for the FBZ may be one which is completely independent of the remainder of the blanket, or the outlet duct may feed to the second blanket zone. Piping connections for coolant in either case would be outside the shield where access is relatively simple. There is no lithium flow. The cassette within the zone may be a single or a double unit, as shown in Fig. 5. The choice of unit is dictated by temperature profiles and temperature limits on structural materials of the total cassette, by adequate temperatures at the niobium capillaries to assure tritium recovery, by the level of wall loading, and also by requirements for assembly and ease of replacement.

\subsubsection{Details of the Rectangular Blanket}

Tokamak plasmas were initially developed or created in toroidal shells with circular cross sections, a logical design geometry at that time. As understanding of plasmas has increased, the drive towards optimum system physics has dictated the plasma shape to improve and enhance the performance of the plasma. Plasma shape is now frequently elliptical or elongated, with the major axis in the vertical plane, and is no longer dictated by the surrounding walls.

It should follow that freed from the constraint of shaping the plasmas, the shape of the blanket would be dictated by engineering requirements, including fabricability, ease of maintenance, eculumly, arid deperidatility, tut parlicularly assembly and disassembly. The rectangular blanket using cassette modules is a step in this direction.

The cassette modules which make up the blanket are designed as long, relatively thin, boxlike volumes. The walls of these volumes are a series of $U$-shaped tubes containing the coolant which completely envelops the lithium-moderating fluld contained within. The cassettes are removed and replaced by remote means with linear motions, passing the cassettes between the coils and other obstructions. Figure 5 is a schematic illustration of one subassembly of cassette modules occupying the space between adjacent toroidal field (TF) coils. The number of subassemblies is equal to the number of TF coils. Each subassembly may be divided radially into three "slices." Figure 7 shows how cassettes are positioned for removal through the middle reglon so as to clear the TF coils.

Figure 8 shows the cross section of a completed tokamak reactor equipped with the cassette blanket. It can be seen that a simple linear motion will permit the removal of any of the innermost cassettes through the vertical field (VF) coils without interference. The individual cassettes slip out between the VF coils without disturbing them.

\subsection{COMMENTS ON INTERNAL TRITIUM RECOVERY}

The lithium volume contained in the U-shaped envelope of the cassette module has roughly centered within it an independent, nonstructural 
ORNL.DWG 77.4989

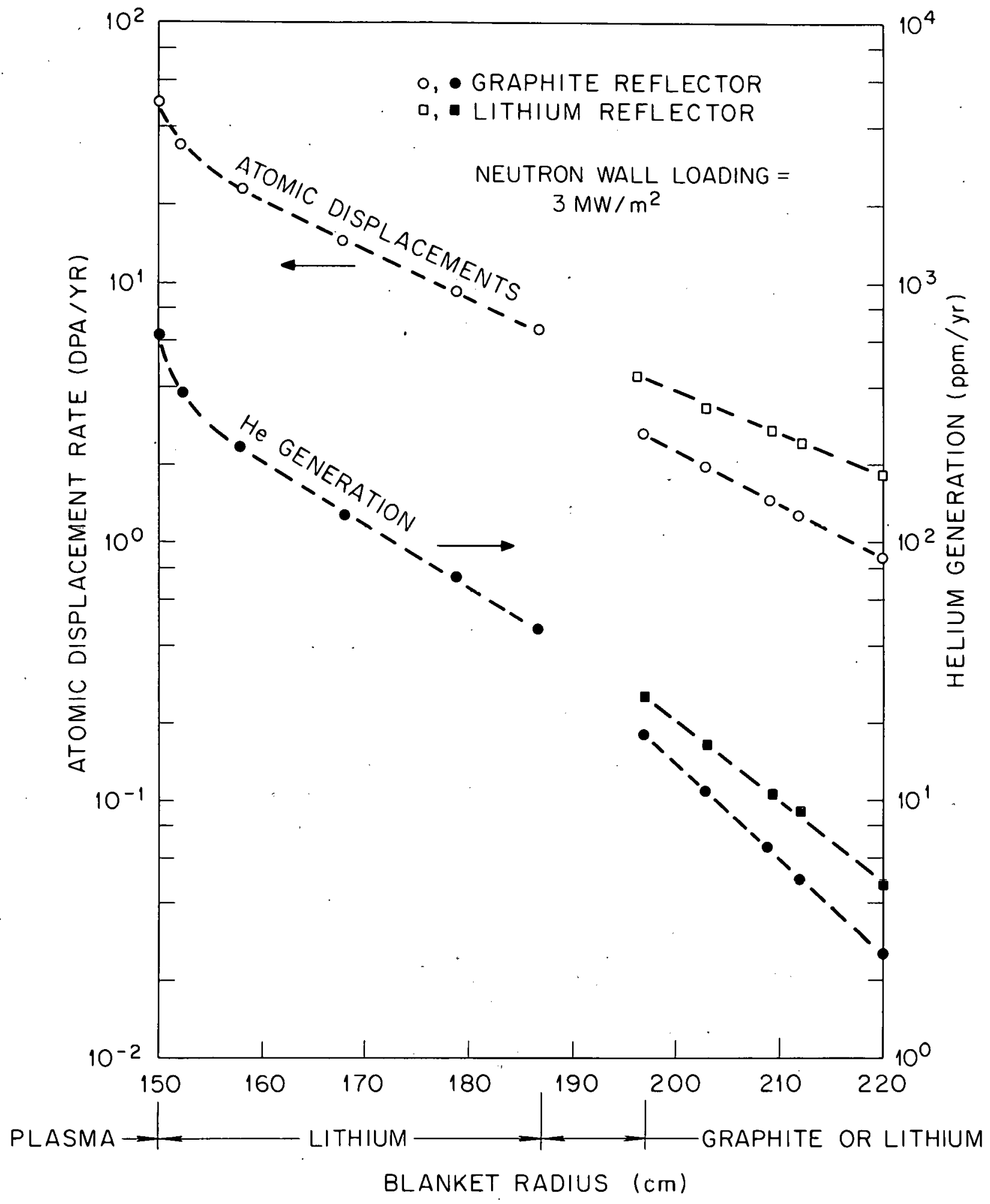

Fiy. 4. Radialiun darnage vs blanket thickness. 


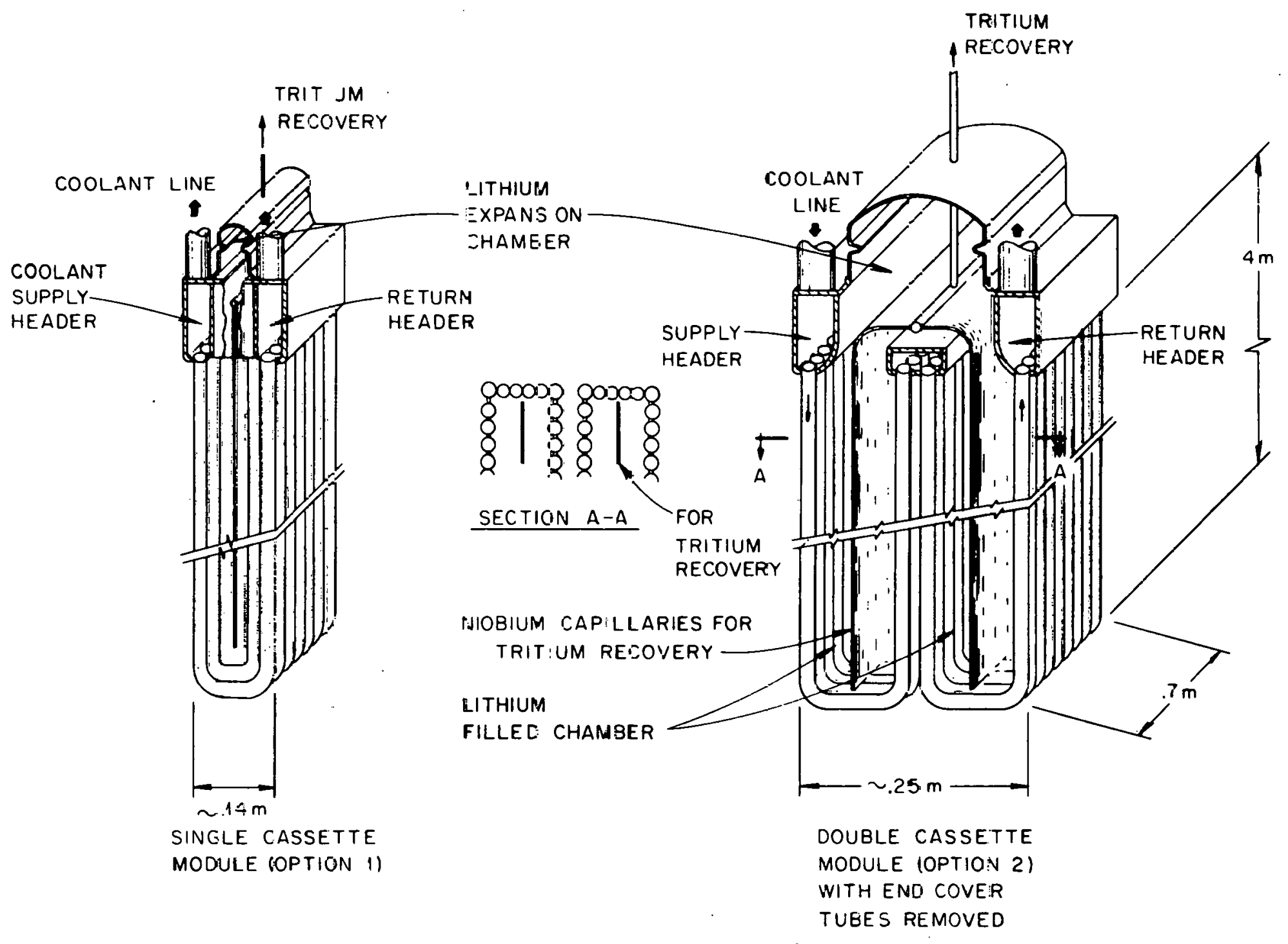

Fig. 5. The cassette mocule for a fusion reactor blanket. 


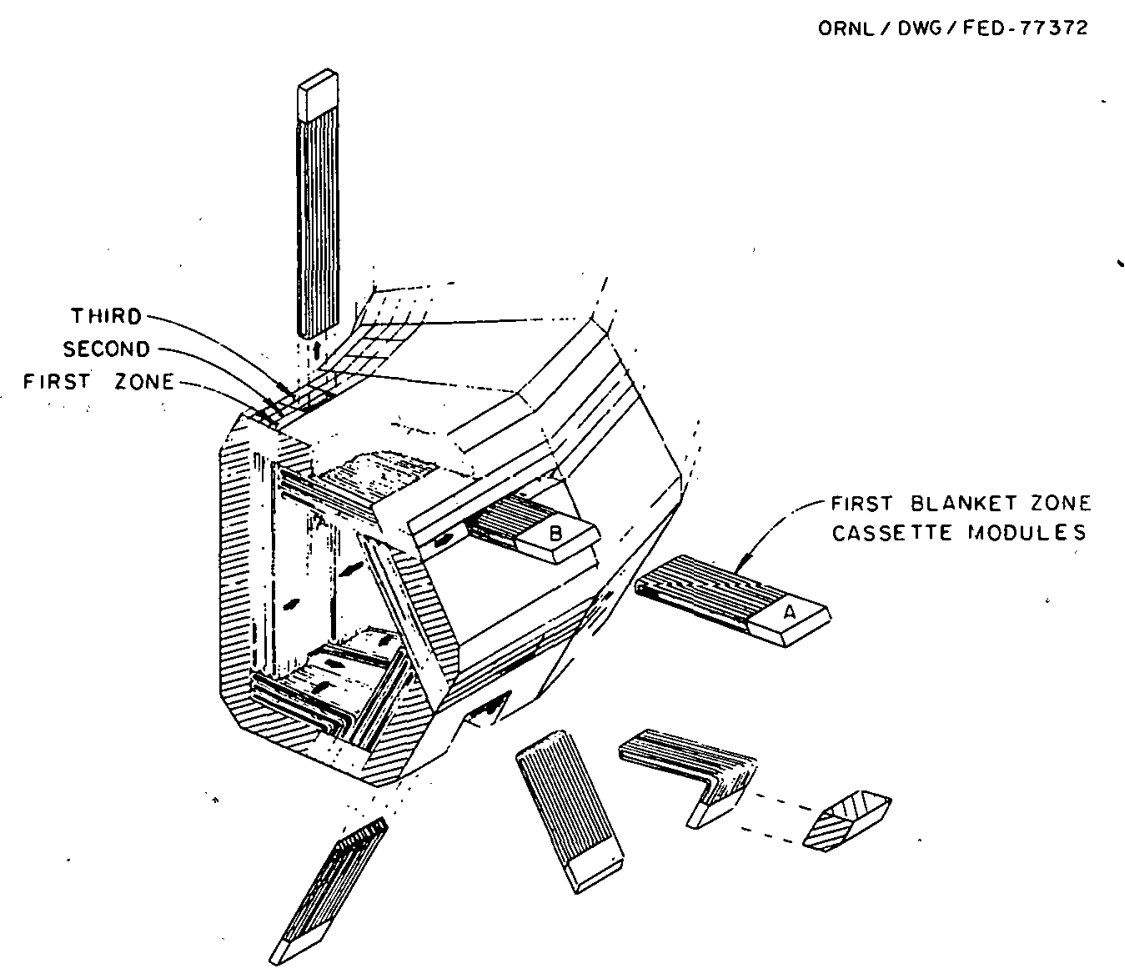

Fig. 6. The zoning approach to blanket design using replaceable cassettes. The figure illustrates the removal of cassettes in the first zone damaged by radiation. With this arrangement, the re would be a five-step sequence to remove the middle cassettes ( $A$ ) of the first zone. The outer cassettes (B) would then be moved to the free space and the sequence repeated. 


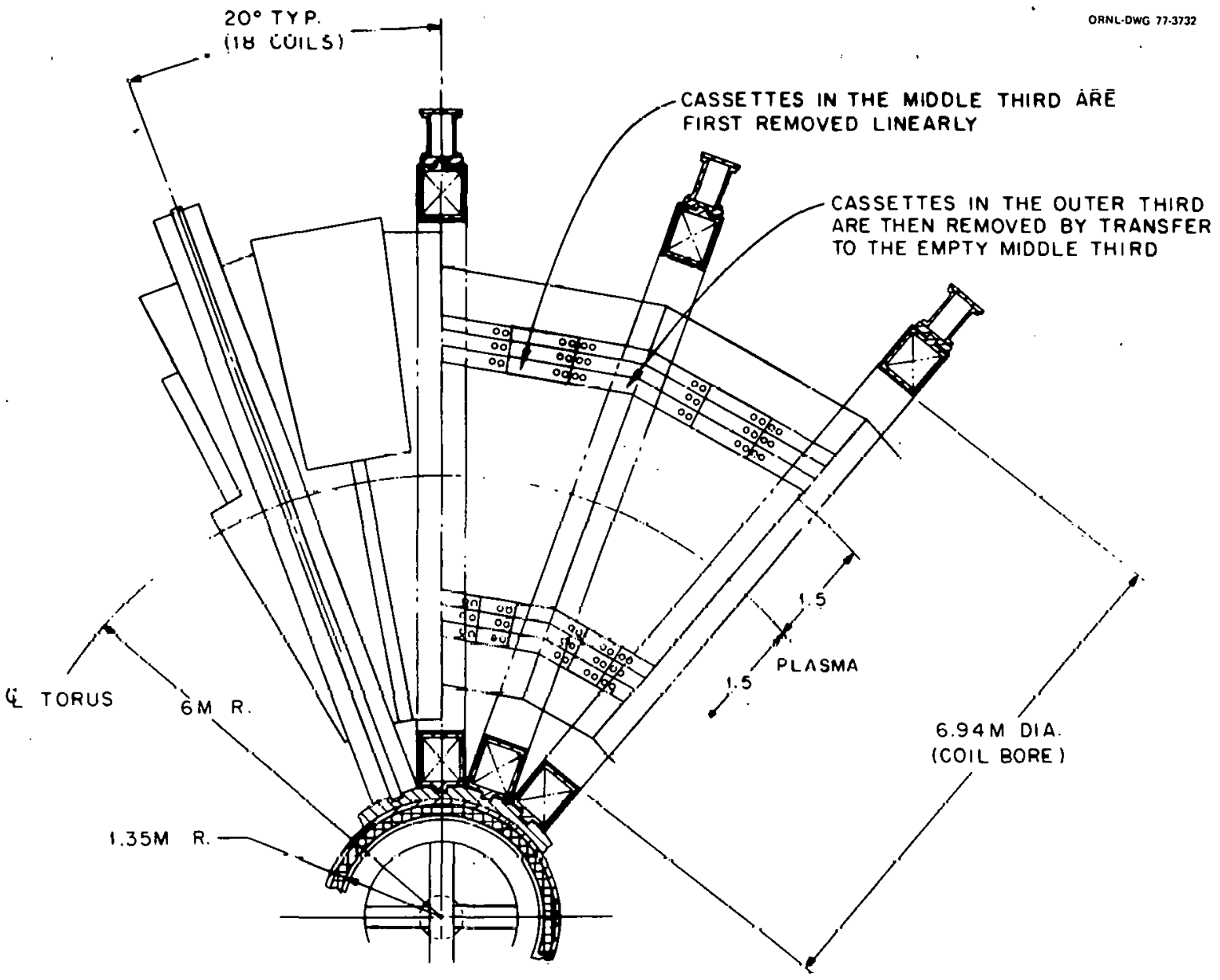

Fig. 7. Plan view of cassette blanket for a tokamak. 
barrier wall that serves a dual role: (1) it acts as an adiabatic, energy-isolating surface between the half of the coolant tubes facing the plasma and the other half of the U-shaped tubes facing the secondary blanket zone, and (2) it is a means of tritium recovery. This barrier wall is made of capillary tubes of niobium or vanadium. Tritium is recovered by diffusion in the lithium and permeation through the niobium. The location of the barrier wall (see Fig. 5) is determined by heat transfer considerations, by the desired flux attentuation, by the gradient in temperature within the lithium, and by the diffusion of tritium in lithium that is assumed to have zero fluid circulation due to magnetic field effects.

Because the magnetohydrodynamic (MHD) effects strongly inhibit the convective mixing of the lithium, the temperature profile in this fluid contained within the module is determined by conduction heat transfer. Thus, we are able to determine appropriate values of $t_{1}$ and $t_{2}$, the distances between coolant tubes and the adiabatic surface. To determine an acceptable value of $t$, we specify that the temperature at the coolant tubes must be low enough to satisfy radiation damage requirements, while the temperature at the adiabatic surface must be high enough so that the tritium will diffuse and permeate through the niobium at an appropriate rate. Once within the niobium tube, the tritium is removed by vacuum pumping or gas flow. Fortunately, the required temperature profiles occur at a total distance $\left(t_{1}+t_{2}\right)$ that is also appropriate to radiation damage attentuation of 5-10 so that tritium recovery in a cassette is consistent with the need to change only the innermost of the cassettes.

ORNL / DWG / FED - 77361

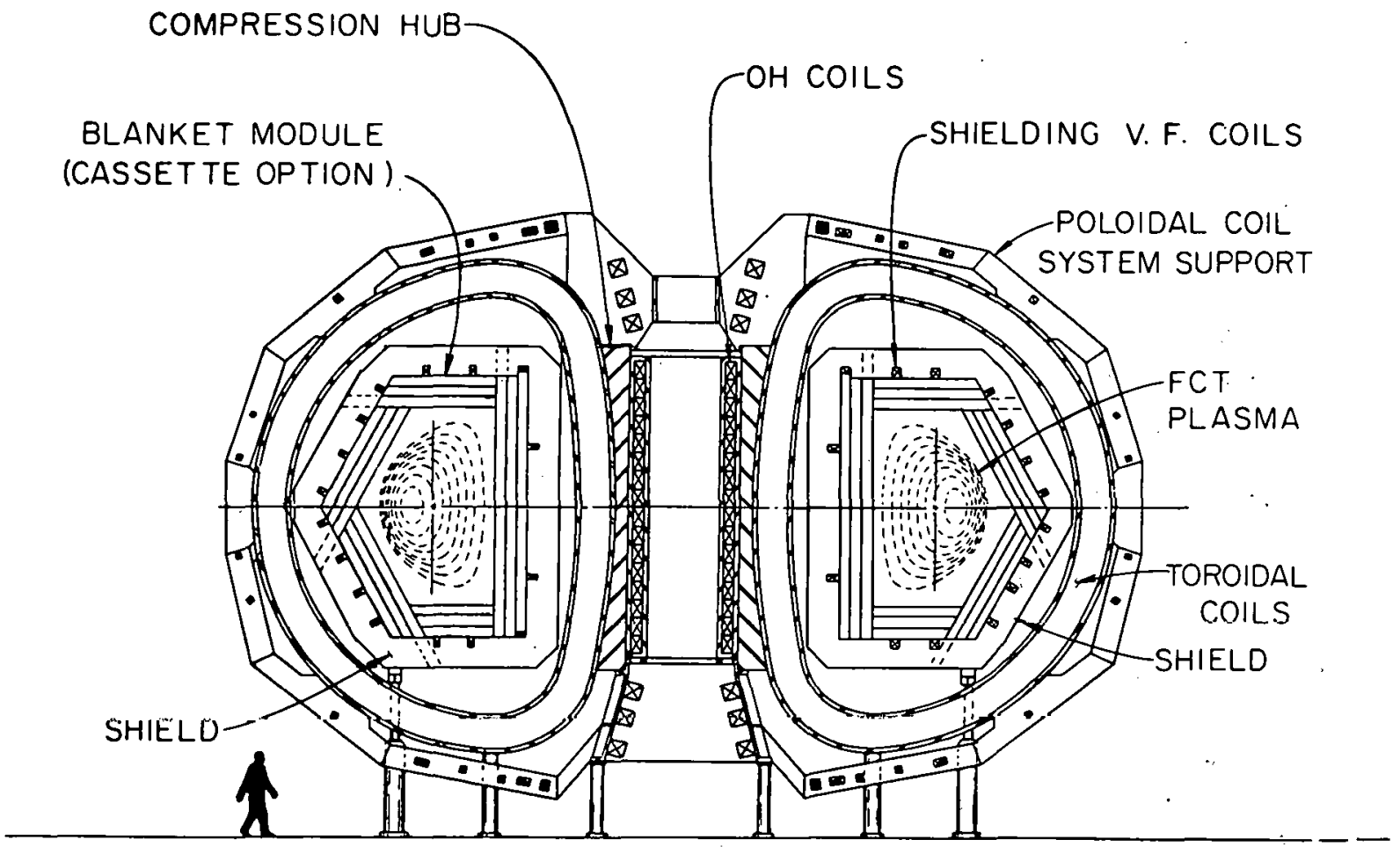

Fig. 8. Tokamak reactor conss section inconrnorating cassettes. 


\section{DESIGN CONSIDERATIONS}

\subsection{GENERAL STRUCTURAL DESIGN CRITERIA}

In the development of a blanket for a demonstration reactor or for the following commercial machines, there are certain criteria that we must try to satisfy. In addition to the previous statement that in a D-T system we must breed tritium in the blanket and are therefore inexorably committed to lithium or lithium compounds as the principal blanket constituent, we must be guided by the following items. ${ }^{4}$

1) Low pressure systems or pressure safe sys tems.

2) Pumping power which is acceptably low compared to thermal power.

3) Conservative limits on structural material, stress, corrosion effects, and temperature.

4) Convenient and efficient blanket module shape and coolant path flow geometry.

5) Simple connectors for remote assembly and disassembly.

6) Small ducting volume, small number of joints and welds, etc.

7) Ease of tritium removal.

8) Economy.

9) The use of current technology materials.

10) Capability of withstanding cyclic thermal stress.

11) Compatib111ty with the plasma.

12) Acceptable replacement frequency.

13) High power density.

14) High wall loading.

\subsection{STRUCTURAL MATERIAL SELECTION}

High power density and high wall loading are likely to be two of the most important economic criteria, simply because capital costs for a reactor are inversely proportional to the power density and wall loading over some operating regime. Countering the requirement for capital cost economy is the fact that the useful life of the first wall and the immediate region of the blanket next to the plasma is inversely proportional to wall loading; therefore, the operating (replacement) costs could be high. We must strive toward a good balance between capital cost and operating cost while achieving high plant availability. Thus, either the first wall and the first $15-25 \mathrm{~cm}$ of the blanket must be replacable quickly, simply, and inexpensively, or the structural, material must have a long life expectancy despite damaging radiation and other hostile conditions.

The cassette module could meet the first option as a "throwaway" blanket if it is carefully designed. Also, a material may be selected and a temperature range used for the cassettes which will minimize radiation damage and therefore lengthen life.

The choice of material and temperature is made difficult by the fact that data are so limited that a simple choice or a highly confident one is not possible. We choose as a primary guide the data in a paper by Bloom et $21 .{ }^{5}$ on austenitic type 316 stainless stee 1 and the data in a survey paper on candidate materials for fusion by J. L. Scott. ${ }^{6}$ These data suggest that $20 \%$ cold worked 316 stainless steel at a temperature of $\angle 530^{\circ} \mathrm{C}$ may have a useful wall lifetime of $\sim 8 \mathrm{MW}-\mathrm{yr} / \mathrm{m}^{2}$ if $25 \%$ swelling is permitted. Also, with a tensile ductility of $22 \%$ at $575^{\circ} \mathrm{C}$ a useful wall lifetime of $210 \mathrm{MW}-\mathrm{yr} / \mathrm{m}^{2}$ is estimated, and if the material temperature can be kept as low as $350-380^{\circ} \mathrm{C}$ (see Fig, 9) a ductility greater than $2 \%$ appears to be retained even with increasing fluence, with the percentage of swelling limiting life. (There are a number of assumptions in these statements and the reader is encouraged to read the references cited.) We use a maximum 5\% swelling and a minimum $2 \%$ ductility at conservative temperatures of $2400-500^{\circ} \mathrm{C}$ (in the coolant tube facing the plasma, where radiation damage is greatest, the temperature is held at $2400^{\circ} \mathrm{C}$; in the other half of the tube, where damage may be a factor of five lower, the temperature may reach $2500^{\circ} \mathrm{C}$ ). The useful wall life in terms of neutron wall loading may then be $8-10 \mathrm{MW}-\mathrm{yr} / \mathrm{m}^{2}$. 


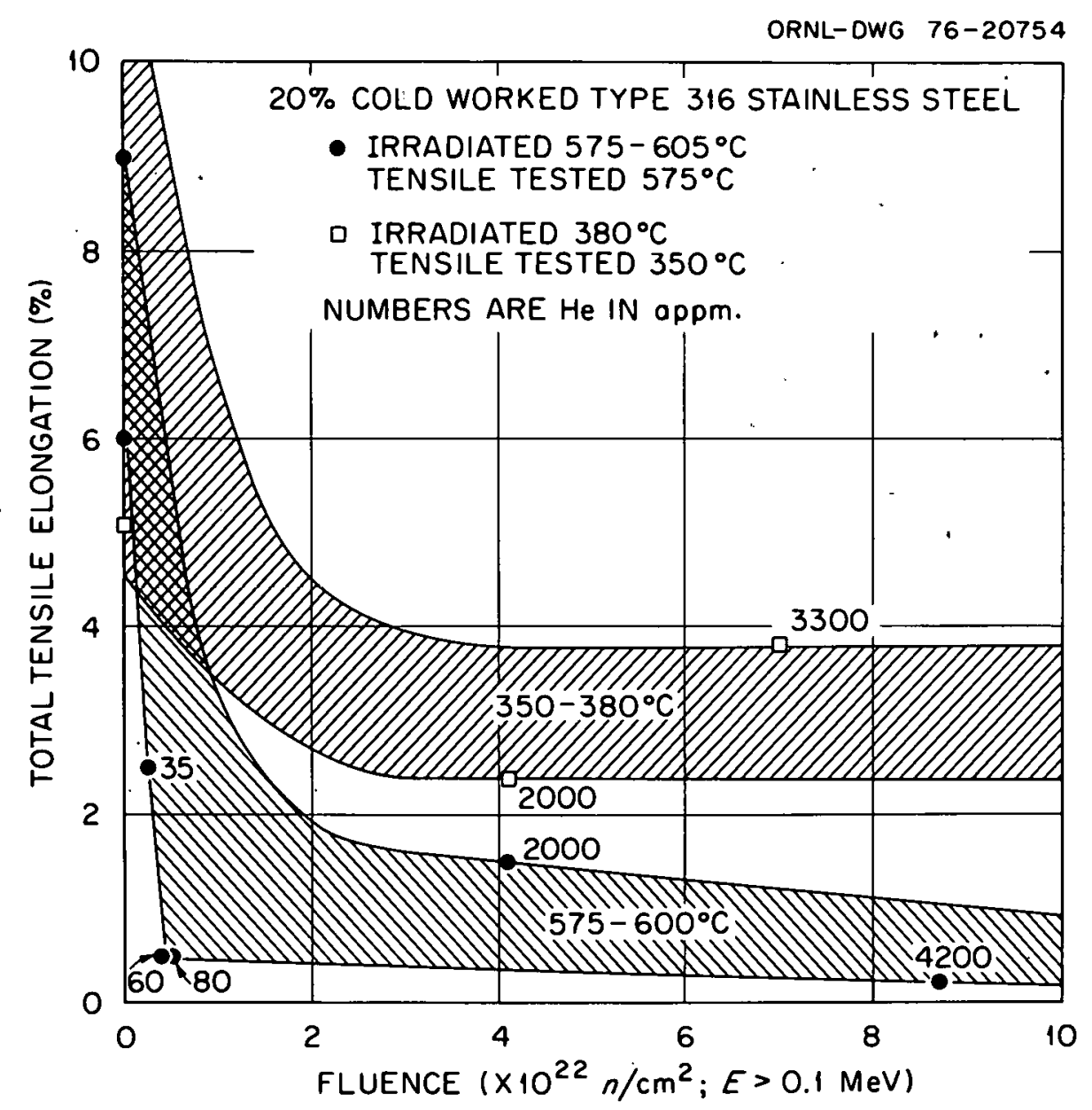

Fig. 9. Fluence-dependence of total elongation in cold worked type 316 stainless steel irradiated in the High Flux Isotope Reactor. Trend curves were drawn based on the data of R. L. Fish et al. ("Swelling and Tensile Property Evaluation of High-Fluence EBR-II Thimbles," p. 149 in Effects of Radiation on Substructure and Mechanical Alloys of Metals and Alloys, ASTMSTP 529, American Society for Testing and Metals, Philadelphia, Pennsylvania, 1973). 
Looking to the future, there is a modified 316 stainless steel (with $0.25 \mathrm{Ti}$ added) that promises to be better than the standard 316 stainless steel. Other compositional variations are also possible; thus, improvements in life expectancy may be expected for the stainless steels. Clearly, much more information is needed - not only on stainless steels, but also on other materials. Stainless steel has two rather severe limitations: poor thermal conductivity, which can result in thermal stresses dominating a blanket design, and a relatively low allowable operating temperature, which limit.s thermndynamic. efficiency. Nevertheless, for a demonstration reactor or an early commercial reactor, we use for our blanket/first wall cold worked 316 stainless steel. This material is chosen over annealed 304 and 316 stainless steel despite the fact that there are more data for the annéaled steels because
1) 316 stainless steel is stronger than 304 ,

2) cold worked 316 swells less than annealed 316 , and

3) cold worked 316 has better ductility than the annealed 316 .

Limited radiation data have been collected for 316 stainless steel, and it has the advantage of being a contemporary material. One of the design constraints will be to maintain temperatures of $400^{\circ} \mathrm{C}$ at the first wall, where the damage rate is highest. Because damage derreases exponentially with radial dist țance into the neutron-moderating blanket, temporaturos will be allowed to increase with radial distance.

Figures 9, 10, and 11 (taken from Ref. 2) provide some data on the properties of cold worked type 316 stainless steel. Radiation data are taken from tests made in the High Flux Isotope Reactor (HFIR). 


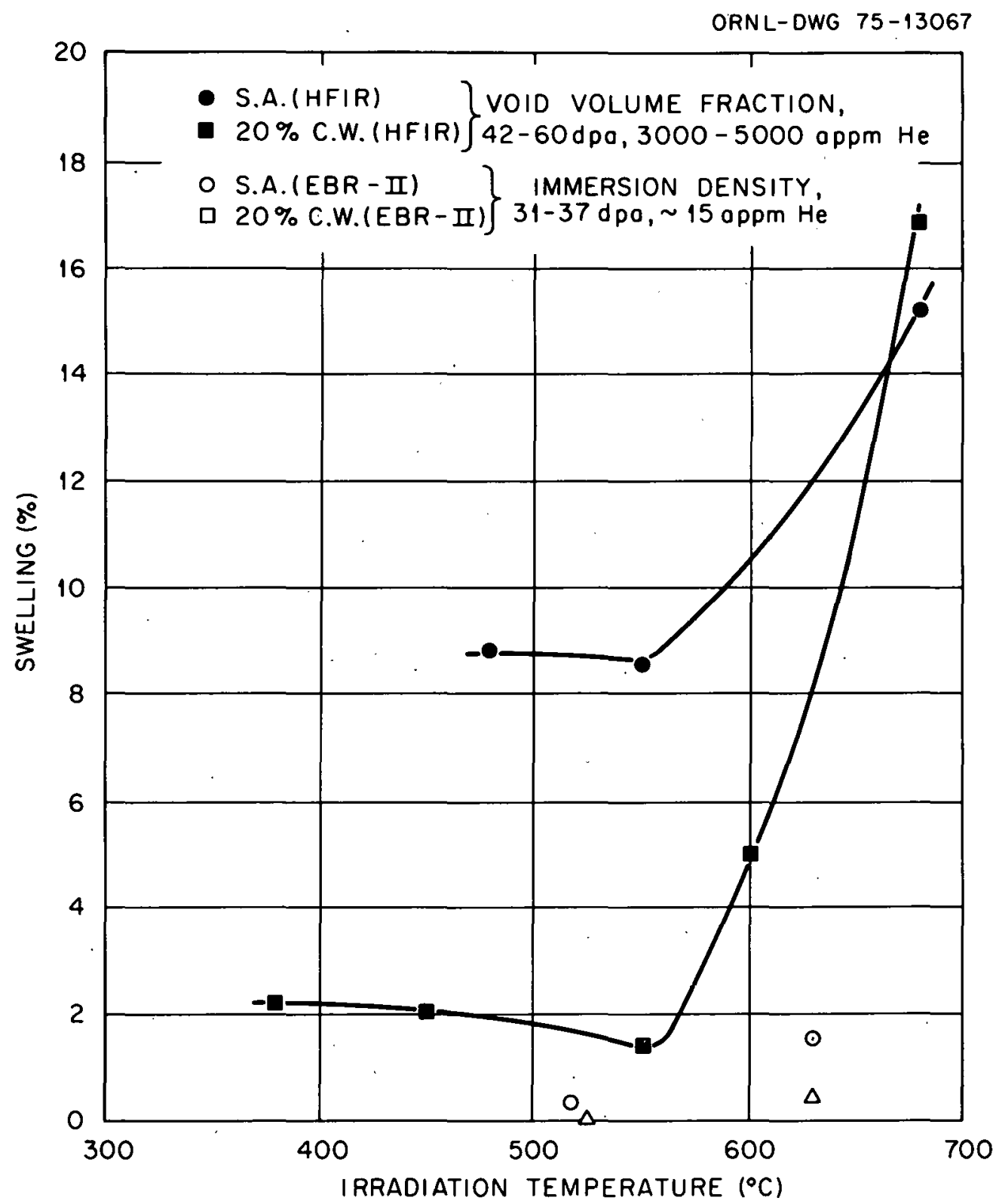

Fig. 10. Swelling of cold worked and annealed type 316 stainless steel in HFIR to $40-60 \mathrm{dpa}$ and $3000-4300 \mathrm{appm} \mathrm{He}$. 


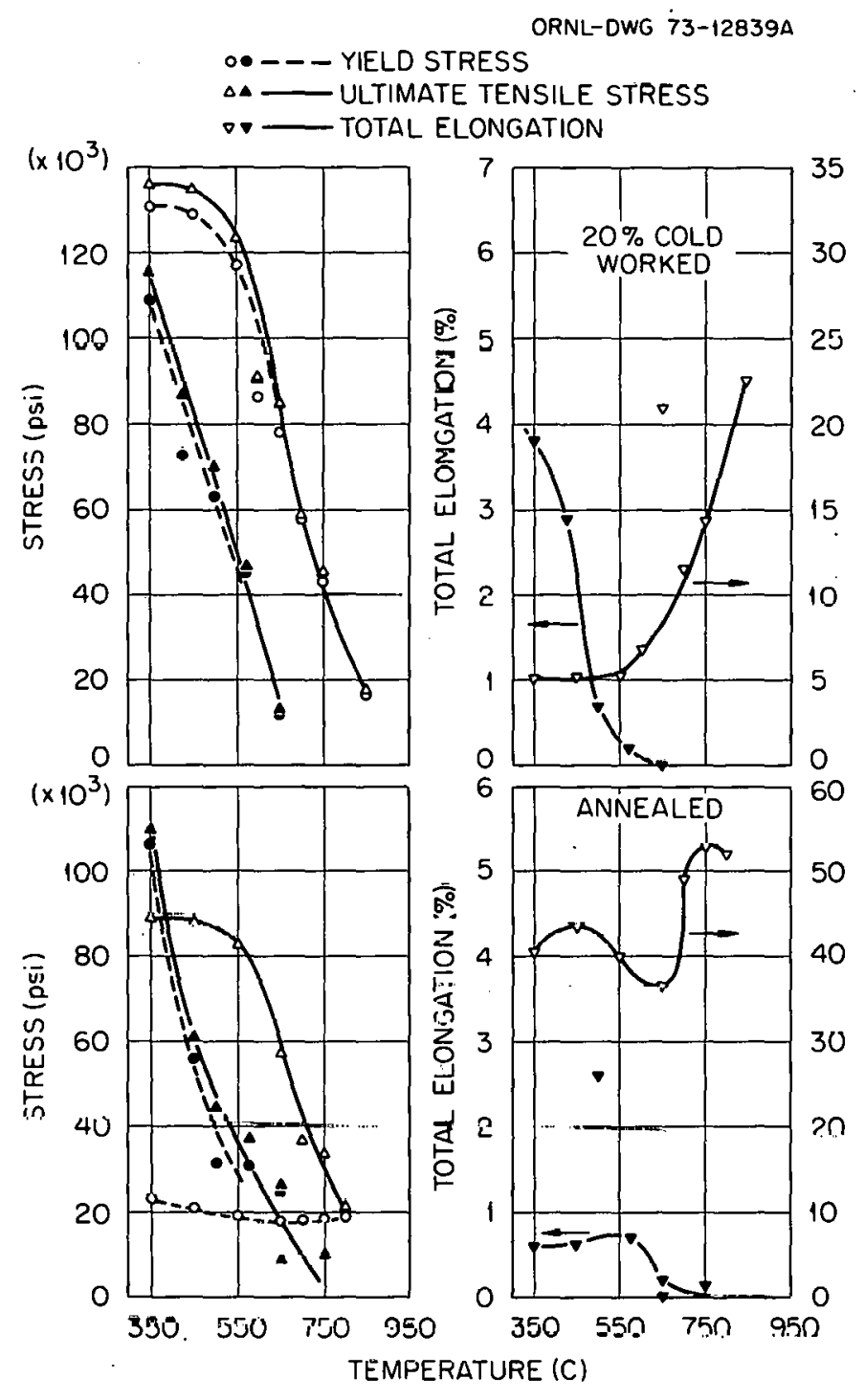

Fig. 11. Tensile properties of type 316 stainless steel after irradiation in HFIR to 40-60 dpa and 30004300 appm He. Data are plotted at test temperatures; irradiation temperatures were slightly higher than test temperatures lor each te'st poinl. The open pointa arr for unirradiated samples, and the closed points are for irradiated samples. 


\section{THERMAL-HYDRAULIC ANALYSIS}

\subsection{THE COOLANTS}

No clear-cut optimum choice of coolant for fusion reactor blankets can be made at this time. However, based on the excellent survey work of H. E. McCoy on coolants, ${ }^{7}$ at least two candidates warrant further study.

1) The salt candidates - HITEC, sodium hydroxide, and chlorides - appear to have promise for operation based on the guidelines of low pressure and good heat transfer characteristics. The sodiumpotassium-nitrate-nitrite salt mixture HITEC has been used commercially and limited property data are available. HITEC is a eutectic mixture of water-soluble inorganic salts: potassium nitrate, $53 \%$; sodium nitrite, $40 \%$; and sodium nitrate, $7 \% .8$ Much further experimental work is needed on this class of salts in the areas of corrosion and stability before a final assessment can be made of their potential usefulness for fusion applications.

2) In terms of stability and compatibility, helium is the coolant with the most potential, but it must be shown that helium can remove the heat from the first wall without imposing intolerable thermal stresses.

Helium and HITEC are particularly interesting as coolants because they are at almost opposite poles - one inert but operating at high pressure, the other reactive and more fragile but able to operate at low pressure.

\subsection{THE HEAT TRANSFER MODEL}

For our calculations, we consider the front leg of a cassette blanket, using a single tube of diameter $d$ and length $L$ as shown in Fig. 12 .

The tube is heated by the alpha energy source on the plasma side $\left(q_{i n c}\right)$ and by the neutron heating of the lithium moderator $\left(q_{N L}\right)$ of thickness $t$ on the back side. Additional heating is generated in the tube wall $\left(q_{N T}\right)$ and in lié cuuldill $\left(\mathrm{u}_{\mathrm{NC}}\right)$.
The energy bal.ance model assumes that we create an adiabatic surface $A$ so that the heat transfer calculations for the front leg of the coolant tube can be separated from those for the back leg. The adiabatic surface is created using the series of evacuated small-diameter tubes made of niobium or vanadium used for tritium recovery (discussed in Sect. 6). Establishing the proper temperature for these tubes so that tritium recovery can be accomplished is also a necessary part of the heat transfer calculations.

Calculations are done in two successive steps. The first step, for the front leg of the tube, establishes the bulk of the requirements such as acceptable tube diameters, flow rates, pumping power, preliminary stress analysis, etc. The second step, for the back leg, satisfies the total energy balance of the cassette by calculating the value of $t_{2}$. We focus here on the first step.

The total energy deposition in the front leg of the tube is

$$
\begin{aligned}
Q_{T O T} & =q_{i n C}\left(L \cdot d_{0} \cdot t\right) \\
& +P_{N T}\left[L \pi \cdot 0.25\left(d_{0}{ }^{2}-d_{i}{ }^{2}\right)\right] \\
& +P_{N C}\left(L \pi \cdot 0.25 d_{i}{ }^{2}\right),
\end{aligned}
$$

where $P_{N L}, P_{N T}$, and $P_{N C}$ are the local power density in the lithium; tube wall, and coolant, respectively.

From attenuation data and neutronic runs on a representative $1 i$ thium/stainless steel blanket, we have established that for the internal heat generation in the lithium, 9

$P_{(y) N L}=4.62 \exp \left(\frac{-y}{0.385}\right) \mathrm{MW} / \mathrm{m}^{3}$

when the wall loading is $1.0 \mathrm{MW} / \mathrm{m}^{2}$.

Furthermore, to a close approximation, the internal heat generation in the coolant tube material (stainless steel) is 
ORNL / DWG / FED - 77362

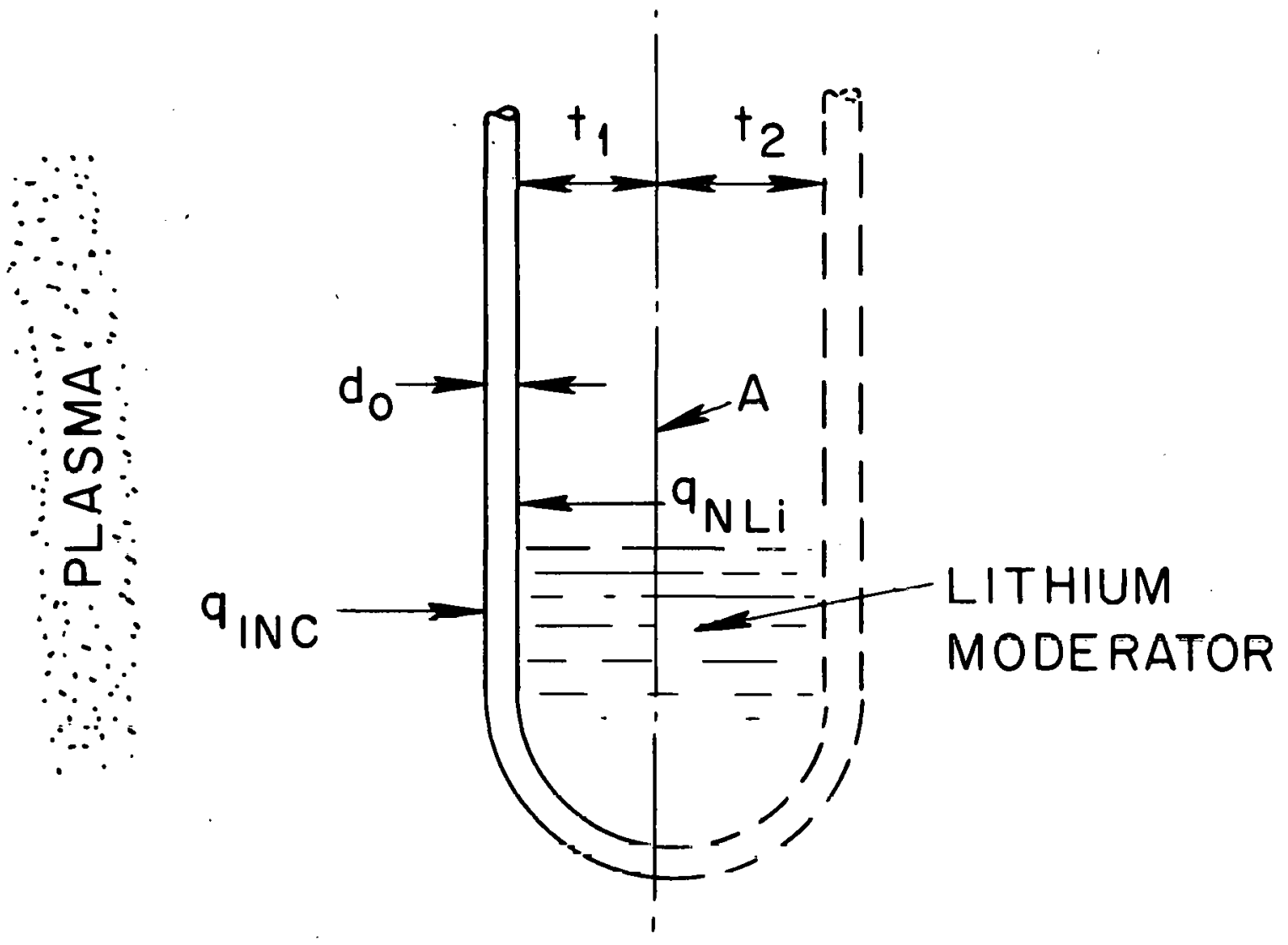

Fig. 12. Tube from front leg of cassette blanket used for heat transfer calculations. 
$P_{(y) N T}=13.1 \exp \left(\frac{-y}{0.385}\right)$.

For helium the internal heat generation is

$P_{(y) N C}=0 ;$

for the sait,

$$
P_{(y) N C}=9.24 \exp \left(\frac{-\dot{y}}{0.385}\right) \text {. }
$$

The $q_{\text {inc }}$ is functionally related to the neutron wall loading $W_{L}$ by the ratio of neutron to alpha energy and by the use of a divertor and its efficiency. With a $D-T$ reactor, the functiona) relationship comes from

$D+T \rightarrow 14.1 \operatorname{MeV}(n)+3.5 \operatorname{MeV}(\alpha)$,

so that without a divertor the alpha energy in one form or another must end up on the wal1; that is,

$q_{\text {inc }}=\frac{3.5}{14.1} w_{L}=0.25 W_{L}$.

The value of $W_{L}$ for reactors of interest at this time ranges from 1.0 to $\sim 4 \mathrm{MW} / \mathrm{m}^{2}$. With the use of a completely effective divertor, the least value of $q_{i n c}$ would be caused by radiation (bremsstrahlung). As a parameter the range of $q_{\text {inc may be }}$

$0.1 \mathrm{MW} / \mathrm{m}^{2}<\mathrm{q}_{\text {iIC }}<1.0 \mathrm{MW} / \mathrm{m}^{2}$.

We use $1.5 \mathrm{MW} / \mathrm{m}^{2}$ as a maximum value instead of $1.0 \mathrm{MW} / \mathrm{m}^{2}$ to allow for both flux peaking due to asymmetry and values somewhat higher than 4.0 $\mathrm{MW} / \mathrm{m}^{2}$ for $W_{L}$. We will assume for this analysis that there is no divertor which is the most critical, most difficult case for both heat transfer and problems of stress.

For numerous reasons, the wall loading parameter $W_{L}$ is quite important - it strongly influences economics, radiation damage, etc. Therefore, we will use $W_{L}$ as a control parameter and write other quantities in terms of it as suggested by Fig. 13.

There is some advantage in setting $q_{N L}$ $\leqslant q_{\text {inc }}$. We do not want the cassette to be too thick nor can we allow the temperature of the lithium at the adiabatic surface $A$ to be too high. If the lithium becomes too hot, convection currents could be set up that could overcome the MHD effects which freeze the lithium. This could cause hot lithium to be dumped on the relatively cool wall of the coolant tube, introducing possible cyclic fatigue problems. Figure 14 shows two cases, $q_{N L}=1 / 2 q_{\text {inc }}$ and $q_{N L}=q_{\text {inc }}$. We choose the first case for our discussion. Using the inequality of the first case, we establish the value of $t$, the thickness of the lithium that will be required to furnish the necessary heat input $a_{N L}$.

We do not know at this point what values of tube diameter are appropriate. This is another of the principal parameters. We use $d_{0}$, the outside diameter, as the reference. It is likely that the range of $d_{0}$ will be

$0.005 m \leqslant d_{0} \leqslant 0.04 m$.

The value of $\delta$, the tube wall thickness, is a function of $d_{0}$ determined by both heat transfer and stress. Generaliy,

$\delta \simeq 0.05 \mathrm{~d}_{0}$

The value of $d_{j}$, the inside diameter, is then explicitly determined by

$d_{i}=0.9 d_{0}$.

There are two precautions to note. The value of $\delta$ may be smaller than is commercially feasible for the smaller diameter tubes; it is also possible that $\delta$ will be larger than necessary. At any rate, when we converge on what is a reasonable solution or set of solutions for heat transfer and stress, we may wish to refine $\delta$. 
ORNL / DWG / FED - 77363

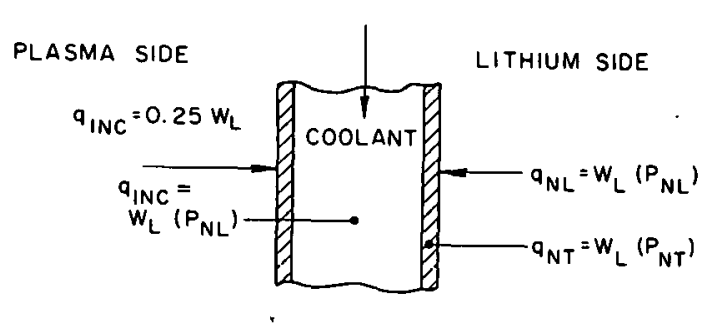

Fig. 13. Heating parameters in terms of the wall loading parameter $W_{L}$.

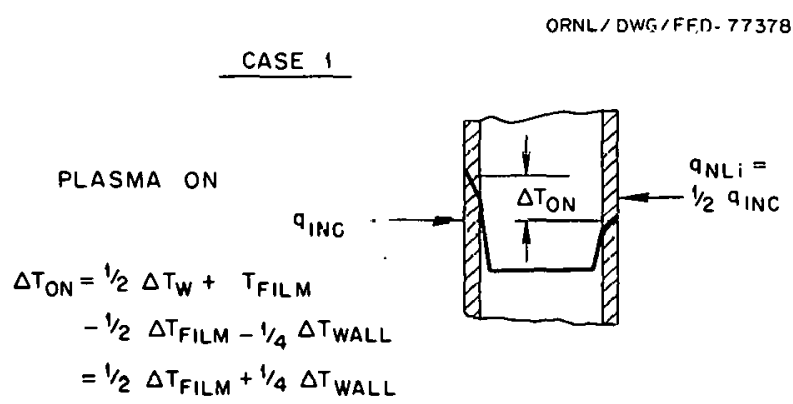

PLASMA OFF

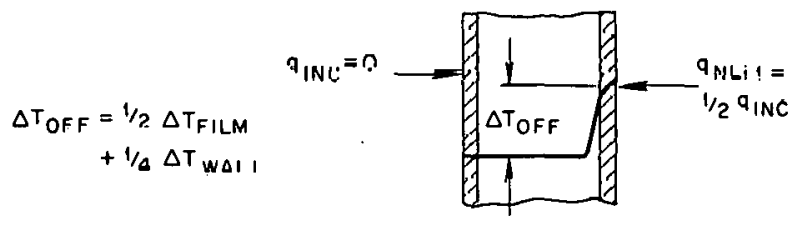

CA3E 2

PLASMA ON

$\Delta T_{\text {ON }}=0$

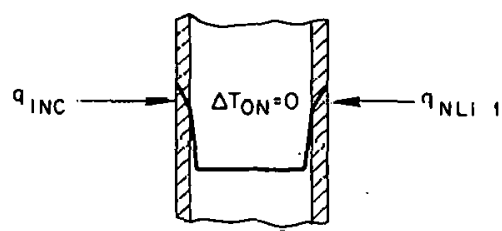

PI. SMM DFF

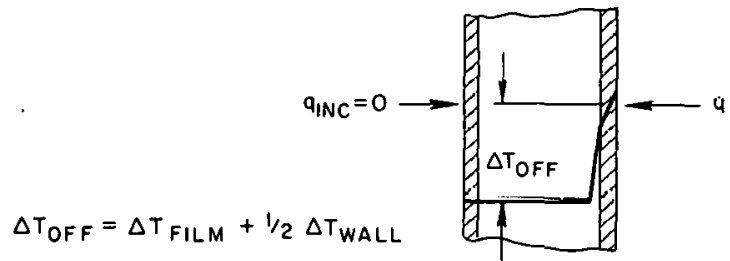

\footnotetext{
Fig. 14. Temperatures for $q_{\mathrm{NL}}=1 / 2 \mathrm{q}_{\text {inc }}$
(Case 1) and $\mathrm{q}_{\mathrm{NL}}=q_{\text {inc }}$ (Case 2).
} 
The value of $t$, the thickness of lithium needed to produce the appropriate $q_{N L}$, will be large enough so that Eq. (2) must be integrated,

$q_{N L}=\int_{y_{0}}^{y_{1}} 4.62 \exp \left(\frac{-y}{0.385}\right) d y$,

$q_{N L}=\int_{y_{0}}^{y_{1}} 1.78 \exp \left(\frac{-y}{0.385}\right) M W / m^{2}$.

When we include in the equation the wall loading factor, $W_{L}$, the tube length, $L$, and $i$ ts diameter, $d_{0}$, we have the energy input to the coolant from the lithium. For a tube width this may be written as

$q_{N L}=\left(y_{y_{0}}^{y_{1}} 1.78 \exp \frac{-y}{0.385}\right) W_{L} \cdot L \cdot d_{0}$.

For the heat generation in the tube wall for tube diameters that are relatively small, it is sufficiently accurate to write the energy contribution to the coolant as

$q_{N T}=\left[13.1 \exp \left(\frac{-y_{c}}{0.385}\right)\right]\left(\frac{0.19 d_{0}{ }^{2}}{4}\right) \pi \cdot L \cdot W_{L},(10)$

where

$y_{c}=$ distance to center line of coolant tube, For the heat generation in the HITEC salt coolant for relatively small tube diameters, the contribution of coolant energy to total energy input when $d_{i}=0.9 d_{0}$ is

$q_{N C}=\left[9.24 \exp \left(\frac{-y}{0.385}\right)\right]\left(\frac{0.81 d_{0}^{2}}{4}\right) \pi W_{L} \cdot L$.

We assume a unit length of $1 \mathrm{~m}$ for the tube length, $L$.

The properties of helium ${ }^{10}$ and HITEC ${ }^{8}$ which we will require are shown in Appendix 1 . The reference density $\rho$ for the helium used in our calculations is $0.14 \mathrm{~kg} / \mathrm{m}^{3}$ at $350 \mathrm{~K}$ and $1 \mathrm{~atm}$. We use the perfect gas law to determine $o$ for other pressures and temperatures and a mean. density $\bar{\rho}$ determined at the first quarter-length of the U-shaped tube.
Generaliy in the cassette blanket, the overall length $L$ of the tube will be $28 \mathrm{~m}$. At the point where $L=4 \mathrm{~m}$ (at the bend), there is a radiation damage constraint on the tube wall temperature, $T_{\text {wmax }} \lesssim 400^{\circ} \mathrm{C}(2700 \mathrm{~K})$. The combined value of film drop, $\Delta T_{f i l m}$, and the temperature drop across the wall, $\Delta T_{\text {wall }}$, is yet to be determined, but we will guess initially that the greatest value is $2100 \mathrm{~K}$. Therefore, $T_{B M}$ must not exceed $2600 \mathrm{~K}$.

For the helium coolant, a reasonable inlet temperature to the blanket, $T_{B I N}$, is $350 \mathrm{~K}$ with a helium/water external heat exchanger driving a steam cycle. The outlet temperature is taken as $750 \mathrm{~K}$. Figure 15 helps to clarify the energy balance assumptions.

The pressure of the helium is assumed to be a parameter. It is likely that the range of pressure will be

$20 \mathrm{~atm}<\mathrm{p}<80 \mathrm{~atm}$.

For any calculation where the front leg is $\simeq 4 \mathrm{~m}$ and we input as a parameter the change in temperature $\Delta T$ per meter for the coolant, the mean density of the helium is

$\bar{\rho}=\left[\rho_{350 K} \times \frac{350 K}{(350 K+2 \Delta T)}\right] \times p_{\text {atm }}$.

With the heat loading as specified in Fig. 15, the maximum $\Delta T$ per meter of length for the front leg could be $75 \mathrm{~K} / \mathrm{m}$.

For the salt, a bulk fluid inlet temperature $T_{B I N}$ is specified by the melting point plus some margin of safety,

$$
\begin{aligned}
\mathrm{T}_{\mathrm{BIN}} & \geqslant \mathrm{T}_{\mathrm{mp}}+50^{\circ} \mathrm{C} \\
& \geqslant 142^{\circ} \mathrm{C}+50^{\circ} \mathrm{C} \geqslant 415 \mathrm{~K} .
\end{aligned}
$$

The outlet temperature is limited by dissociation and thermal instability to $\sim 700 \mathrm{~K}$. The maximum temperature $T_{B M}$ at the midpoint of the tube for the salt is therefore

$T_{B M}=(700 K-415 K) \times \frac{1.5}{2}+415 K \simeq 630 k$. 


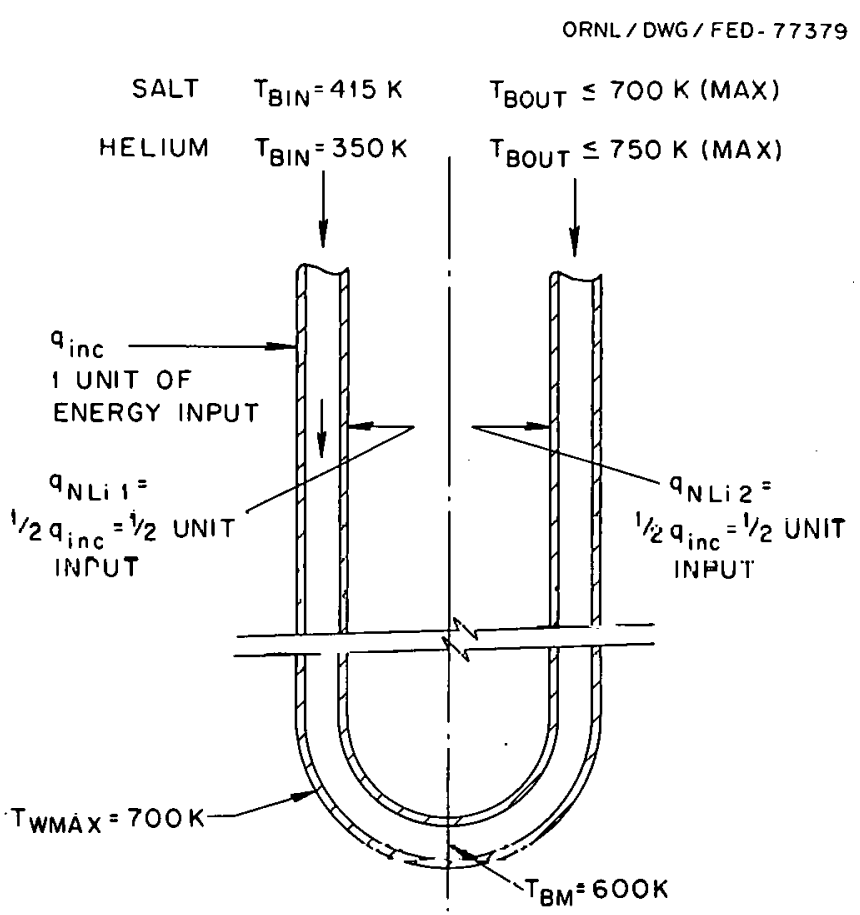

Fig. 15. Assumptions for the energy balance in a cassette coolant tube.

\subsection{SOME ILLUSTRATIVE DATA}

The heat transfer calculations are given in Appendix 2 and output data for different wall loadings and tube diameters are given in Appendix 3 for illustration. The data given are for helium at $60 \mathrm{~atm}$ with $\Delta \mathrm{T}=20^{\circ} \mathrm{C} / \mathrm{m}$ and for the salt at $7 \mathrm{~atm}$ with $\Delta T=10^{\circ} \mathrm{C} / \mathrm{m}$. Other pressures and temperature changes would also be appropriate and better cases could possibly be cited; however, for the values chosen there is adequate design space for both helium and the salt as coolants.

We may now use the acceptable values in this compilation to determine their acceptability from a structural stress standpoint.

As a high pressure coolant, helium will be more limited by stress than salt. In this case, we use as our starting point the higher wall loadings and an acceptable fraction of thermal power for pumping power. The pumping power must be limited to $n, 1 \%$ of the thermal rower because of

1) plant efficiency (assumed $232 \%$ ) and

2) allowance for additional coolant tube lengths outside the blanket - approximately a factor of two.

Thus, in terms of electrical power,

$\% \mathrm{PP}_{\text {elec }}=\frac{1 \%}{0.32} \times 2=6.25 \%$.

This is a reasonable valuc, although a lower value would be better for a commercial machine. It could be perhaps twice as high for demonstration purposes. Figure 16 shows that with these $1 \%$ and $2 \%$ constraints on pumping power, tube diameters in the range $3 \mathrm{~cm} \leqslant d_{0} \leqslant 5 \mathrm{~cm}$ will be required for wall loadings greater than $2 \mathrm{MW} / \mathrm{m}^{2}$ for helium. 


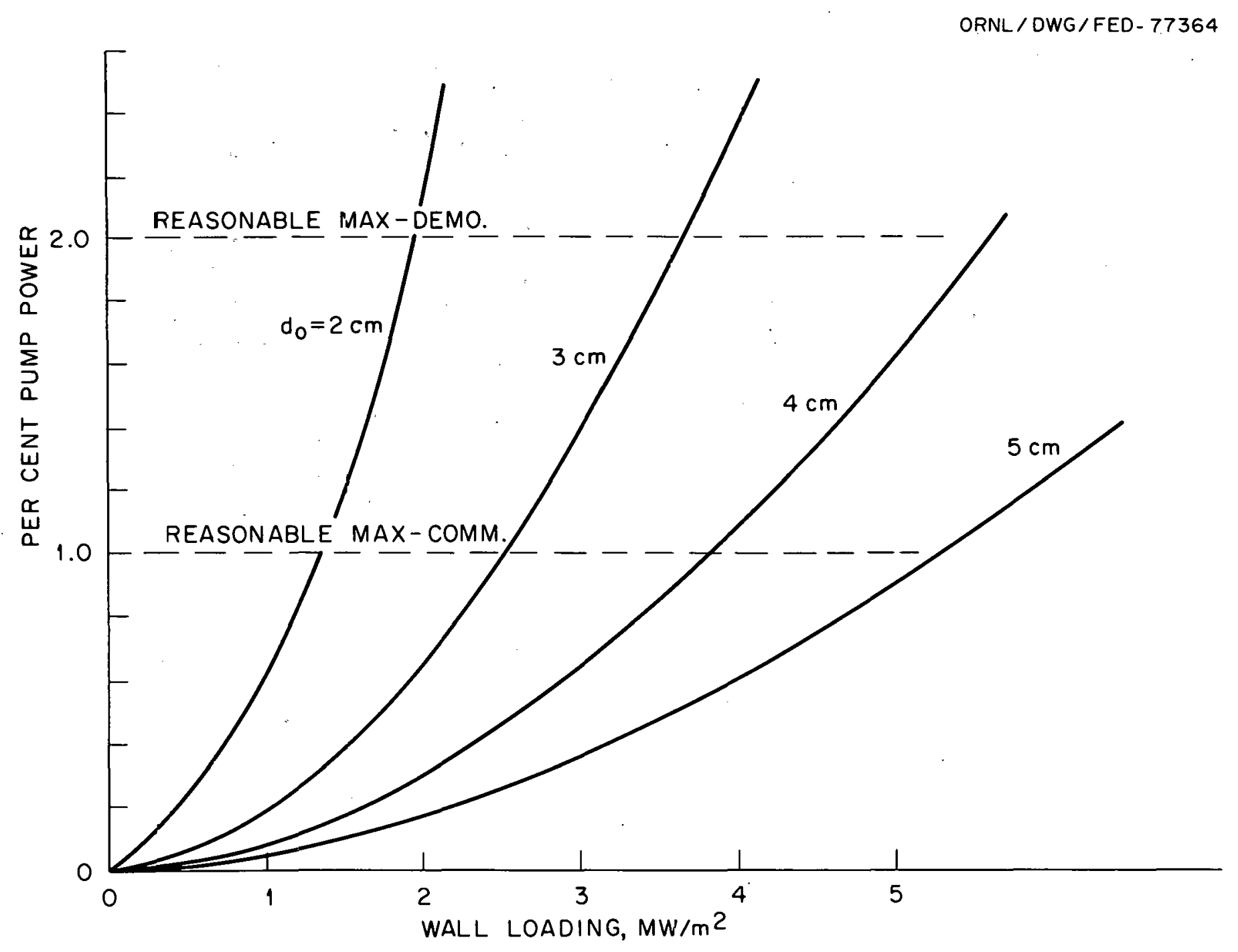

Fig. 16. Pumping power vs wall loading for various tube diameters using helium at 60 atm. Temperature rise of coolant $=20^{\circ} \mathrm{C} / \mathrm{m}$. 
5. THE STRUCTURAL MODEL

\subsection{GENERAL COMMENTS ON STRESS ANALYSIS}

The three stresses to be calculated are

1) the diametral stress, $\sigma_{B}$, dealing with tube bending due to unequal heating from front to back; .

2) local thermal stresses in the tube wall, $\sigma_{T} ;$ and

3) pressure stresses from the coolant flow, $\sigma_{H}$ and $\sigma_{L}$.

The stresses that arise in assemblies such as the cassette module are complicated by uncertainty about geometry and fabrication. The cassette is a relatively simple structure, but the stresses are cyclic because the tokamak is the reference case and the state of stress may be influenced by time in a radiation field or in a region where surface effects such as sputtering may exist. A proper analysis should include a three-dimensional survey (plus time). It would probably be even more appropriate to build and test a model. However, a one-dimensional analysis seems in order for general shakedown purposes and to see where operating regimes are likely to be. The design should stand up under one-dimensional analysis before more detailed study is in order.

\subsection{DEFORMATION AND BENDING STRESS IN} NONUNIFORMLY HEATED TUBES

During a burn cycle, the $q_{\text {inc }}$ from radiant or alpha energy is buffered or balanced by the $q_{N L}$ from the neutron-heated lithium. During the burn cycle, if $q_{i n c} \neq q_{N L}$ tube deformation takes place because of the temperature difference across the tube diameter. If the tube were unrestrained, it would bow in an arc.
After the burn the $q_{\text {inc }}$ disappears, but due to the heat capacity of the lithium $q_{N L}$ is effectively undiminished in the first few seconds so that there is a new temperature gradient from front to back of the tube, as illustrated in Fig. 14, and the tube bows differently, either with a new radius $r$ or in a different direction.

To assess the bending stress, we consider a unit length of tubing of diameter d. subjected t.n heating from one side so that there is some differential growth,

$\Delta s=\alpha \Delta T$.

The tube develops a radius of curvature $r$. We wish to determine $r$ as a function of $d$, the tube diameter, and $\Lambda s$, the differential growth due to the differential temperature. We know that for $\operatorname{arcs} s=r \theta$ and here

$r=\frac{s+\Delta s}{\theta}$,

$r=\frac{1.0+\alpha \Delta T}{\theta}$

The $\alpha$ term is the coefficient of thermal expansion of the material. The tube diameter $d$ is a parameter which allows $r$ to be calculated. The tube wall thickness $\delta$ is taken to be a function of $d$ so that hoop stress and longitudinal stress are constant, i.e.,

$\delta=0.05 \mathrm{~d}$.

The $\Delta T$ represents llow much holter one side of the tube is than the other (the diametral difference). For Case 1 (shown in Fig. 14),

$\Delta T=\frac{1}{2} \Delta T_{f i 1 m}+\frac{1}{4} \Delta T_{\text {wall }}$. 
From Fig. 17

$\tan \frac{\theta}{2}=\frac{\alpha \Delta T s}{2 d}$

$\frac{\theta}{2}=\tan ^{-1} \frac{\alpha \Delta T s}{2 d}$

$\theta_{\text {radians }}=2 \tan ^{-1} \frac{\alpha \Delta \mathrm{Ts}}{2 \mathrm{~d}_{0}} \frac{\pi}{180}$.

The radius of curvature of the tube due to nonuniform heating is

$r=\frac{1.0+\alpha \Delta T}{\theta}$

We require $b$, the displacement of the tube, to determine the stress. From Fig. 18,

$\cos \phi=\frac{a}{r}=\frac{r-b}{r}$.

Almost certainly, in an operational situation the tube cannot be allowed to deform, and if it is constrained to remain straight, stresses will be generated because of the nonuniform heating. These stresses may be calculated assuming the tube is a cantilevered beam with an end coupling, as shown in Fig. 19. Then having determined b, the deflection of the beam, we may determine the stress as follows. The equation for the deflection is

$b=\frac{1}{2} \frac{M L^{2}}{E I} ;$

the moment is

$M=\frac{2 E I b}{L^{2}} \quad ;$

and the bending stress is

$\sigma_{B}=\frac{M c}{I}=\frac{2 E b C}{L^{2}}$.

To this stress we must add the local thermal stress across the tube wall, $\sigma_{T}$, the hopop stress, $\sigma_{H}$, and the longitudinal stress, $\sigma_{L}$. The thermal stress across the thickness of the tube $\tilde{\delta}$ is

$\sigma_{T}=\frac{E_{\alpha \Delta T} T_{\text {wal }}}{2(1-v)}$, where the temperature drop across the wall, $\Delta \mathrm{T}_{\text {wall }}$, is

$\Delta T_{\text {wall }}=\frac{2 q_{i n c}}{k \pi}$.

The hoop stress and the longitudinal stress are

$\sigma_{H}=\frac{P-R}{t}$

and

$\sigma_{L}=\frac{P^{-} R}{2 t}$

\subsubsection{The Stress Levels}

We may now calculate the principal stresses $\sigma_{z}, \sigma_{R}$, and $\sigma_{\theta}$. Figure 20 and the data in Table 2 indicate the makeup of these principal stresses. The illustrative values shown in the figure are for a wall loading of $3 \mathrm{MW} / \mathrm{m}^{2}$, a tube diameter of $4 \mathrm{~cm}$, a temperature rise in the helium coolant of $20^{\circ} \mathrm{C} / \mathrm{m}$, and a pressure of $60 \mathrm{~atm}$. Table 2 is a compilation of stresses on the plasma side of the tube. The stresses on the lithium side are somewhat less.

\subsubsection{Cyclic Stress Intensities}

These stresses are to be evaluated undèr cyclic behavior. This is the significance of the last column in Table 2, where

$S_{1=2}=\sigma_{z}-\sigma_{R}$,

$S_{2-3}=\sigma_{R}-\sigma_{\theta}$,

$\sigma_{3-1}=\sigma_{\theta}-\sigma_{z}$.

A A portion of the American Society of Mechanical Engineers (ASME) design code is included in Appendix 4 to explain the stress analysis.

The stress intensity with which we will be concerned is the largest of the stress differences. By the ASME boiler code,11 we are 


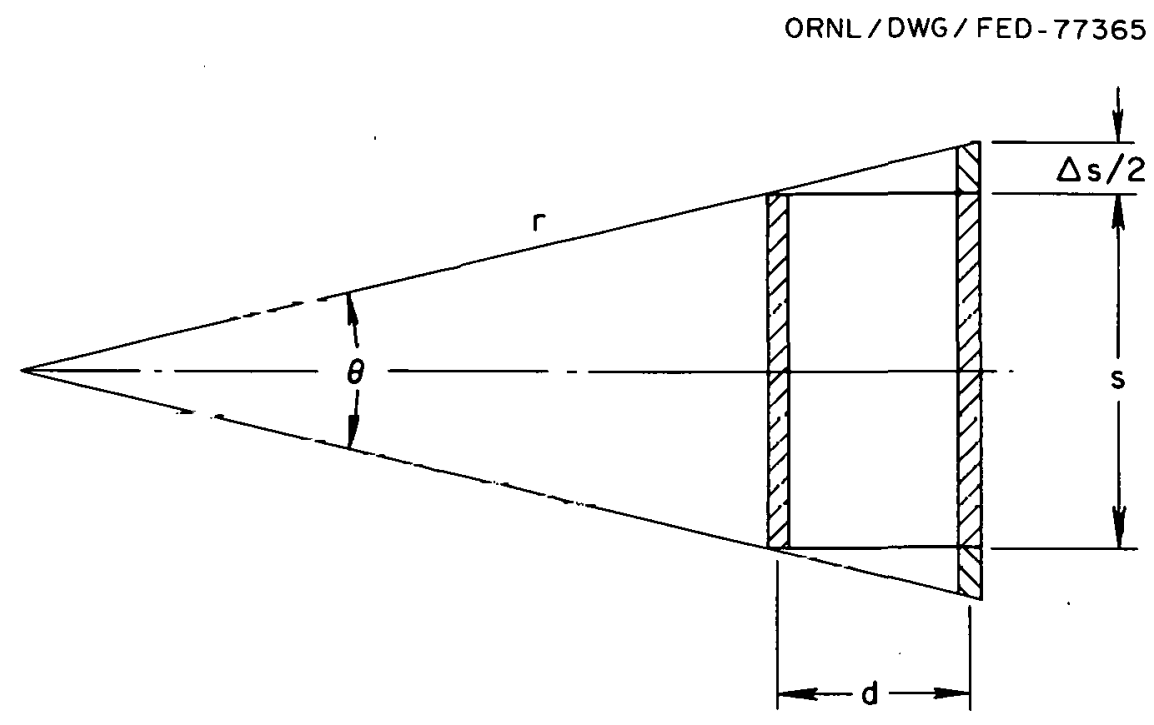

Fig. 17. Radius of curvature $r$ determined as function of tube diameter $d$ and differential growth $\Delta s$.

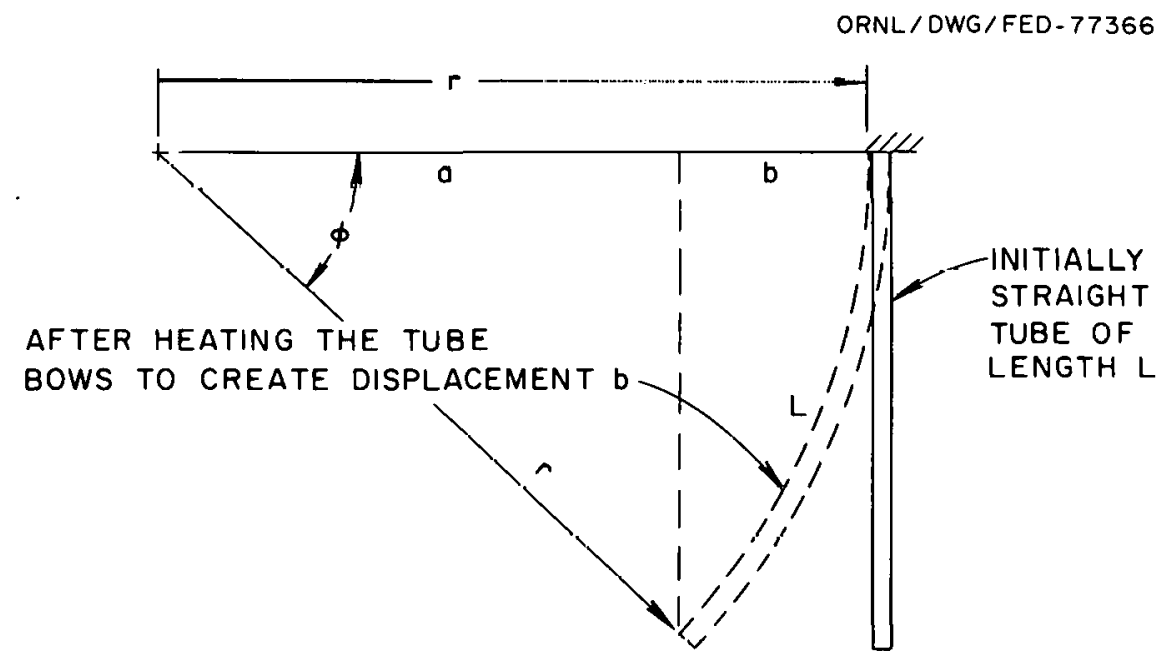

Fig. 18. Calculation of the deflection, b, of a tube subjected to nonuniform heating. 
ORNL / DWG / FED - 77367

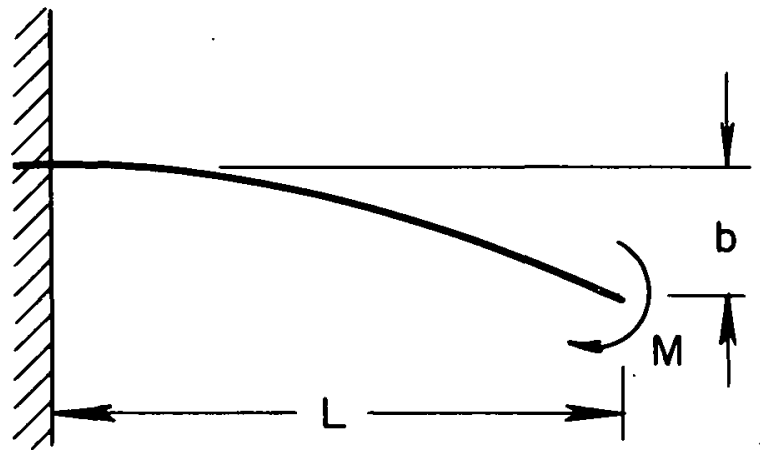

Fig. 19. Tube deflection, $b$, created by nonuni form heating.

ORNL / DWG / FED - 77368

PLASMA SIDE

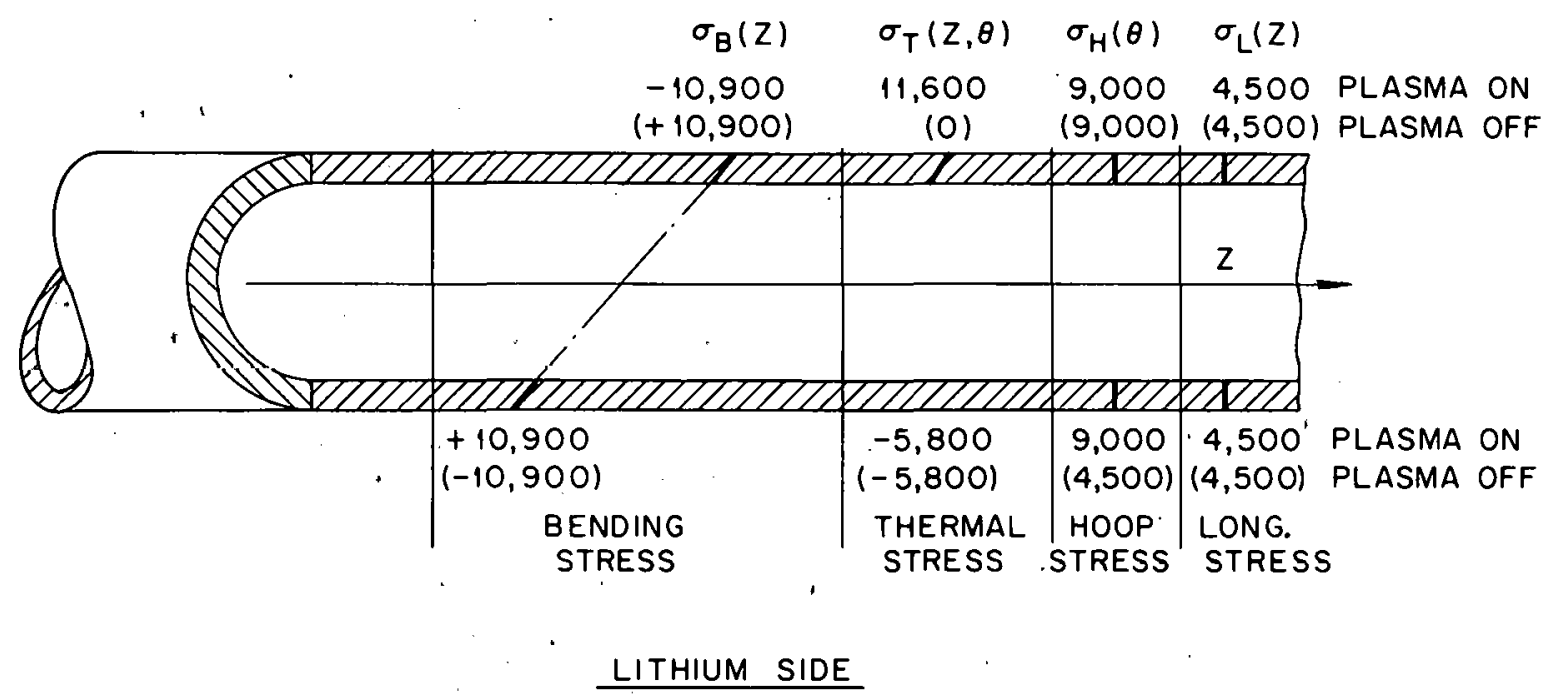

: Fig. 20. Components of stress in a tube subjected to a wall loading of $3 \mathrm{MW} / \mathrm{m}^{2}$ with $\mathrm{q}_{\mathrm{NL}}=$ $1 / 2 q_{\text {inc }}$ for helium coolant at $60 \mathrm{~atm}$. . 
Table 2. Principal stresses on the plasma side of the tube

\begin{tabular}{|c|c|c|c|c|c|}
\hline & $\sigma$ & $z$ & $\sigma_{\theta}$ & $\sigma_{R}$ & Maximum $S_{i j}$ \\
\hline \multirow[t]{4}{*}{ Plasma on } & $\sigma_{B}=$ & $-10,900$ & $\sigma_{r}=-11,600$ & 0 & 33,400 \\
\hline & $\sigma_{T}=$ & $-11,600$ & $\sigma_{H}=+9,000$ & & \\
\hline & $\sigma_{L}=$ & $-4,500$ & & & \\
\hline & $\Sigma_{z}=$ & $-18,000$ & $\Sigma_{0}=-2,600$ & & \\
\hline \multirow[t]{7}{*}{ Plasma off } & $\sigma_{B}=$ & $+10,900$ & $\sigma_{r}=+11,600$ & & \\
\hline & $\sigma_{T}=$ & 0 & $\sigma_{H}=+9,000$ & & \\
\hline & $\sigma_{L}=$ & $+4,500$ & & & \\
\hline & & $+15,400$ & 20,600 & & \\
\hline & Range & $=15,400$ & Range $=20,600$ & & \\
\hline & & $+18,000$ & $+2,600$ & & \\
\hline & & $-33,400$ & - 23,200 & & \\
\hline
\end{tabular}

allowed an alternating stress that is halt the maximum stress difference,

$S_{a l t}=0.5\left(S_{i j}\right)_{\text {MAX }}$

$=16,700$ psi for the illustrative case.

For any one reactor design we may estimate the number of cycles per year and assign a desired number of years of life to establish the total number of cycles to which a part will be subjected. For instance, we may decide that a reasonable life span is 5 years, based on radiation damage. For tokamaks it is hoped that the burn time will be around $1000 \mathrm{sec}$, so the number of cycles will be $21.5 \times 10^{5}$ maximum. For this value the allowable stress would be 35,000 psi when $E$, the modulus of elasticity, is $26 \times 10^{6}$ psi. Correcting for $E=24 \times 10^{6} \mathrm{psi}$ at $500^{\circ} \mathrm{C}$, the value of $S_{A}$ is $\sim 32,000$. [This value is obtained from the ASME boiler code (see Appendix 4).] This $S_{A}$, when compared to the value of 16,700 psi in our case, provides a safety margin of 22 .
A set of data on stresses for hel ium at 60 atm is plotted in Fig. 21 as a function of wall loading for various tube diameters. Pumping power limits of 1 and $2 \%$ and the limit on alternating stress $(32,000 \mathrm{psi})$ are aiso shown. Within these boundaries, it can be seen that there is a reasonable operating regime for helium at high wall loadings. (The reader may refer to Fig. 16 for an illustration of pumping power vs wall loading for selected tube diameters.)

\subsection{STRESSES IN THE TUBE AS A UNIT}

The preceding calculations have indicated the stress levels that would arise if a simple straight tube subjected to heating from one side only was constrained to remain straight. The constraint against bending was not spectfled, but is built in between the front and back portions of the U-shaped tube as a result of the tube bend of radius $R$ in the assembly. The following example and the additional analyses in 


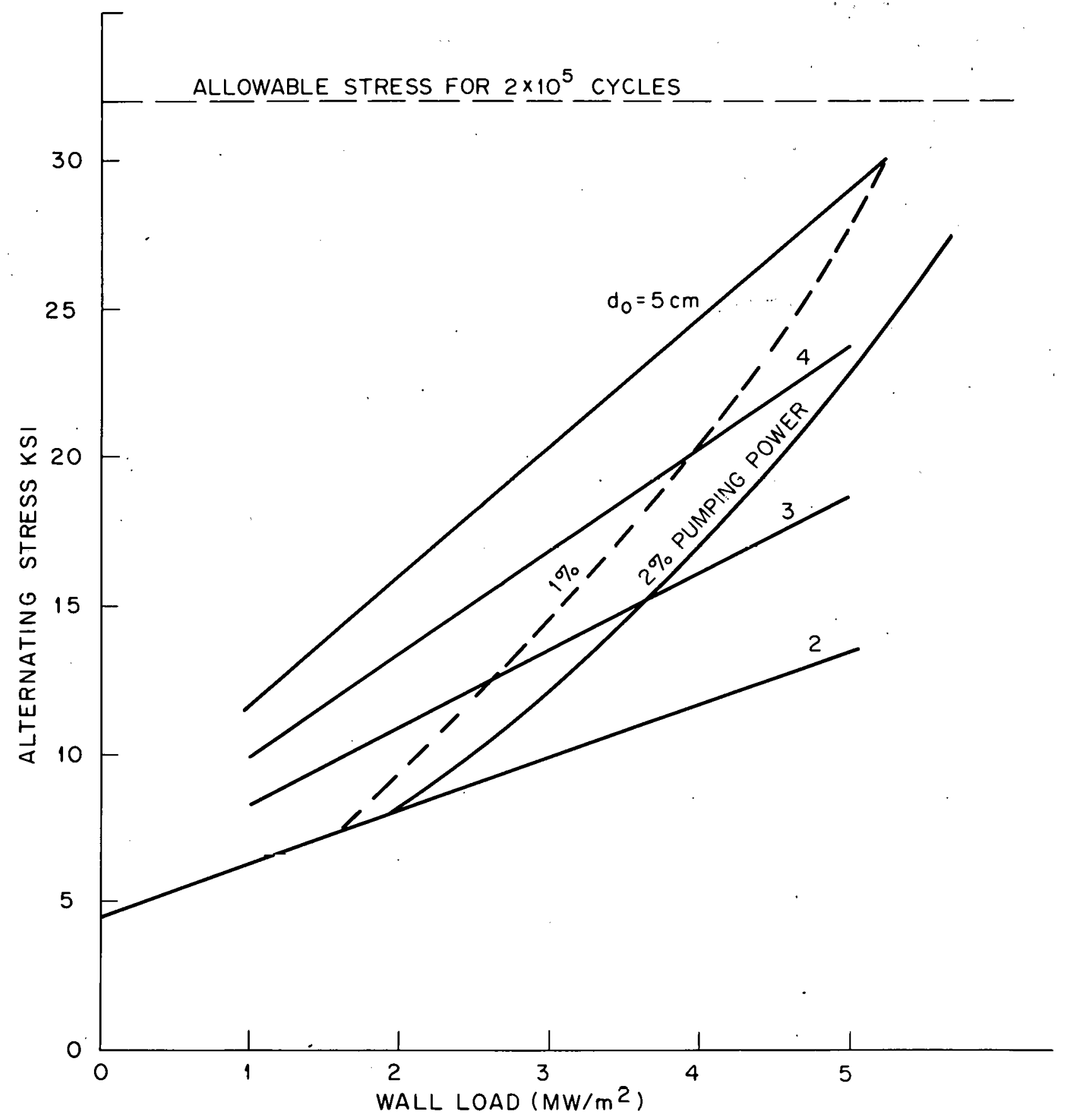

Fig. 21. Alternating stress vs wall loading for various tube diameters using helium coolant at $60 \mathrm{~atm}$. The acceptable operating range is bounded by allowable stress and allowable pumping power. 
Appendix 5 take this constraint into account. The form and the equations for the analyses were provided by John Mayhall of Oak Ridge National Laboratory.

By proper combination we may reduce Mayhall's $5 \times 5$ matrix (derived in Appendix 5) to one that is $2 \times 2$, as we are primarily interested in deterunining the moment, $M$, and the shear, $V$, contained in the stress equation

$$
\sigma_{\max }=\frac{M+V_{2}}{\pi r^{2} t}
$$

After substituting the influence coefficients the equations are:

$$
\begin{aligned}
\left(\frac{\ell}{\mathrm{EI}}+\right. & \left.+\frac{\pi \mathrm{R}}{2 \mathrm{EI}}\right) M+\left[\frac{\ell^{2}}{2 \mathrm{EI}}-\frac{\mathrm{R}^{2}}{\mathrm{EI}}\left(\frac{\pi}{2}-1\right)\right] V \\
& =\frac{l \alpha \Delta \mathrm{T}}{2 r}-\frac{\pi \mathrm{R}}{2 r} \alpha \Delta \mathrm{T},
\end{aligned}
$$

$$
\begin{aligned}
{\left[\frac{\ell^{2}}{2 E I}\right.} & \left.+\frac{R^{2}}{E I}\left(\frac{\pi}{2}-1\right)\right] M+\left[\frac{\ell^{3}}{3 E I}-\frac{R^{3}}{E I}\left(\frac{3 \pi}{4}-2\right)\right] V \\
& =\frac{2 r}{\alpha \Delta T}\left[1-\cos \left(\frac{\ell \alpha \Delta T}{2 r} \frac{180}{\pi}\right)\right] \\
& =\frac{\alpha\left(T_{H}+T_{C}\right) R}{2} .
\end{aligned}
$$

We will assume from our previous calculations that

$$
\begin{aligned}
\ell & =4.0 \mathrm{~m} \\
R & =0.07 \mathrm{~m} \\
r & =0.015 \mathrm{~m} \\
t & =0.0015 \mathrm{~m} \\
\Delta T & =51^{\circ} \mathrm{C} \\
\alpha & =18 \times 10^{-6} \mathrm{~m} / \mathrm{m} \\
E & =24 \times 10^{6} \mathrm{psi} .
\end{aligned}
$$

The resulting stress is 12,400 psi or 8.55 $\times 10^{7} \mathrm{~Pa}$. With intermediate supports the effective length, $\ell$, may be decreased and these stresses diminished. However, the stress is acceptable as it stands. 


\section{TRITIUM PROCESSING}

\subsection{HEATING OF THE LITHIUM}

For any one set of conditions of incident energy, heat transfer, etc., we establish $t_{1}$ and $t_{2}$, the distances from the coolant tubes to the adiabatic surface $A$ (see Fig. 12). The values of t may be determined from Eq. (9), which is rewritten here as

$q_{N L}=\left[\left.\right|_{y_{0}} ^{y_{1}} 1.78 \times 10^{6} \exp \left(\frac{-y}{0.385}\right)\right] W_{L}$.

We need the relationship between $q_{i n c}$ and $W_{L}$. For the assumptions previously made, we know that $q_{N L}=0.5 q_{i n c}$ and $q_{i n c}=0.25 w_{L}$. Also from the figure, $y_{0}$ is first zero and then equal to $t_{1}$. Thus, in two steps we may determine that $t_{1}=$ $0.03 \mathrm{~m}$ and $t_{2}=0.045 \mathrm{~m}$.

It is interesting to note that with $0.03-\mathrm{m}$ diam coolant tubes (which satisfy pumping power and cyclic stress requirements for helium as a coolant), the thickness of the cassette is 0.14 $\mathrm{m}$, allowing $20.0005 \mathrm{~m}$ for the thickness of the adiabatic niobium tube surface. This is a desirable thickness in terms of both damage attenuation and ease of changing. With this size, the innermost cassette may be changed as a single unit, two units could be changed, or a double cassette could be changed.

From Appendix 6, we have the temperature distribution within the lithium of thickness $L$ (when $x<L$ )

$t_{x}-t_{1}=\frac{Q_{0}}{k \mu^{2}}\left(e^{-\mu x}-\mu x e^{-\mu L}+1\right)$.

We take as an example the Demonstration Power Reactor (Demo) model, which has the parameters $\bar{\varphi}_{0}=4.62 \mathrm{MW} / \mathrm{m}^{3}$ when wall load is $1 \mathrm{~mW} / \mathrm{ml}^{2}$, $\mu=1 / 0.385=2.597 \mathrm{~m}^{-1}$,

$\mathrm{L}=0.03 \mathrm{~m}$,

$k=60 \mathrm{~W} / \mathrm{m}^{\circ} \mathrm{C}$ for $1 \mathrm{ithium}$ at an average temperature of $700^{\circ} \mathrm{C}$,

and an assumed wall loading of $3 \mathrm{MW} / \mathrm{m}^{2}$. Then

$$
\begin{aligned}
t_{L}-t_{1} & =\frac{4.62 \times 10^{6} \times 3}{60 \times 2.597^{2}}\left(-e^{-0.03 \cdot 2.597}\right. \\
& -2.597 \times 0.03 \times \mathrm{e}^{-0.03 \cdot 2.597+1)} \\
& =3.425 \times 10^{4}\left(2.88 \times 10^{-3}\right) ; \\
t_{L}-t_{1} & =98.7^{\circ} \mathrm{C} \approx 100^{\circ} \mathrm{C} .
\end{aligned}
$$

This is a fairly modest temperature rise, considering that the wall loading of $3 \mathrm{MW} / \mathrm{m}^{2}$ is substantial. We may wish to consider some asymmetry in the flux distribution and assume that a peak flux of $4.5 \mathrm{MW} / \mathrm{m}^{2}$ is possible. Figure 22 shows a plot of the temperature gradient in the lithium as a function of increasing $L$. Notice that the lithium temperature at $L$ rises rather abruptly as the thickness of the zone increases. For instance, had we wished the thickness to be $0.06 \mathrm{~m}$ instead of $0.03 \mathrm{~m}$, the temperature gradient would have been about $500^{\circ} \mathrm{C}$. This would increase the rate of tritium diffusion through the niobium but could be troublesome since, as the gradient increases, the probability of convective mixing in the lithium increases. That is, if the MHD forces prohibit the convective mixing until the convective forces overcome the MHD forces, it is possible that the convective mixing could become cyclic, periodically dumping hot lithium on the 316 stainless steel coolant tube. This would introduce a new cyclic fatigue problem. Therefore, it appears better to keep this temperature gradient fairly low.

\subsection{TRITIUM PRODUCTION AND RECOVERY}

Tritium is produced in the lithium by the following reactions:

$n+{ }^{7} L i+n^{1}+T-2.47 \mathrm{MeV}$

and

$\mathrm{n}+{ }^{6} \mathrm{Li} \rightarrow \mathrm{T}+{ }^{4} \mathrm{He}+4.8 \mathrm{MeV}$. 


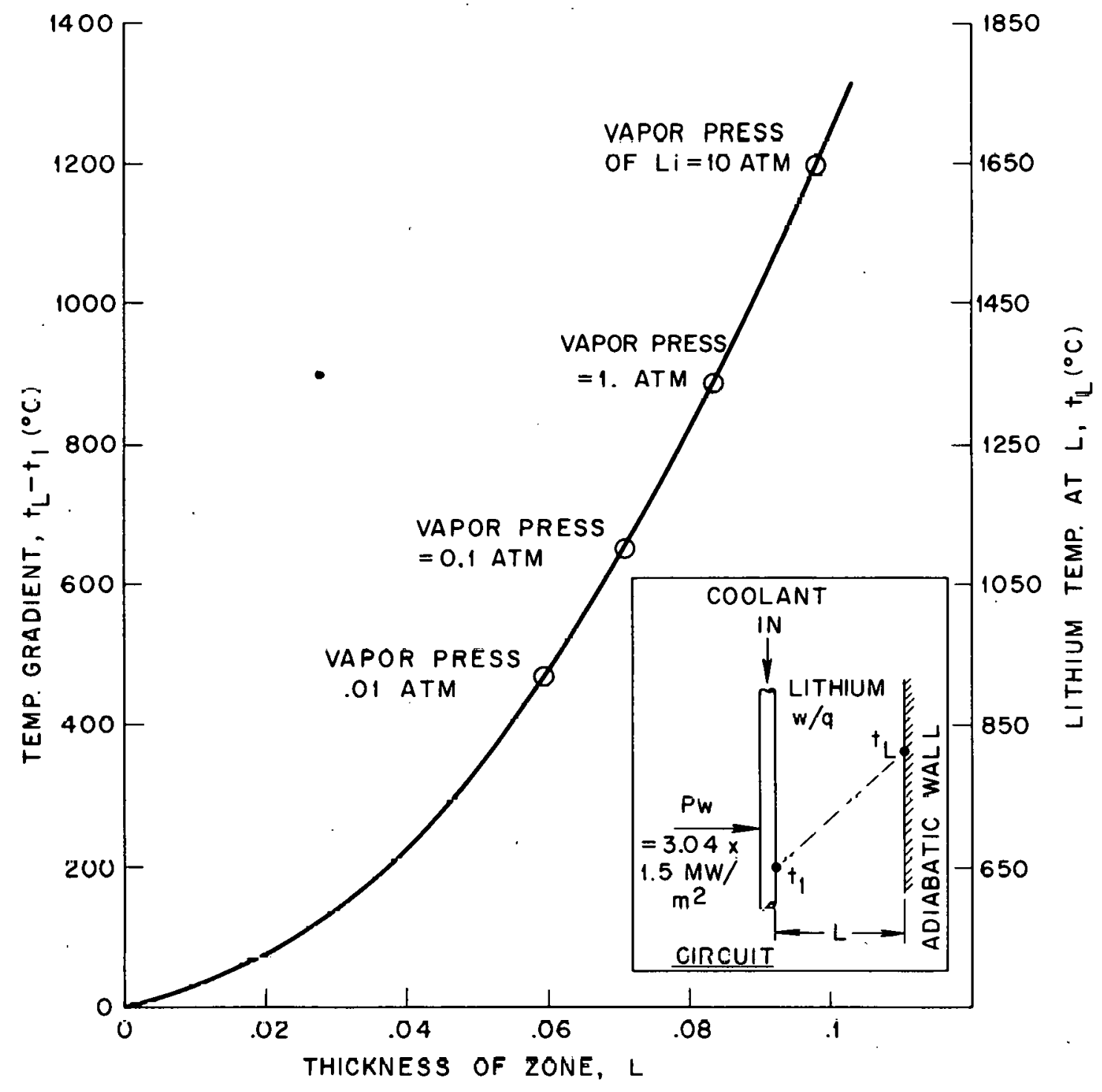

Fig. 22. Temperature gradient in lithium with internal heat generation due to a neutron wall load of $3 \mathrm{MW} / \mathrm{m}^{2} \times 1.5$ to account for the peak flux. 
For the D-T reaction, the energy production is equal to $17.6 \mathrm{MeV}$ from the fusion reaction itself plus some quantity of additional energy generated as a consequence of exothermic reactions in the blanket (such as that of a neutron with ${ }^{6} L i$ ). The total energy is conservatively $\sim 20 \mathrm{MeV}$ per source neutron. Given this total energy production for each D-T reaction, the tritium consumption $T_{\text {con }}$ can be calculated from

$T_{\text {con }}=\frac{P}{E} \times \frac{M}{N_{0}} \times 6.25 \times 10^{12} \mathrm{~g} / \mathrm{sec}$,

where

$P=$ thermal power (watts)

$E=$ energy production (megaelectron volts per fusion reaction)

$M=$ mass of tritium ion (grams per gram molecule)

$N_{0}=$ Avogadro's number $\left(6.025 \times 10^{23}\right.$ molecules per gram molecule)

and. 1 watt $=6.25 \times 10^{12} \mathrm{MeV} / \mathrm{sec}$. Thus for each thermal megawatt, the tritium consumption is

$$
\begin{aligned}
T_{\text {con }} & =\frac{1 \times 10^{6}}{20} \times \frac{3}{6.025 \times 10^{23}} \times 6.25 \times 10^{12} \\
& =1.55 \times 10^{-6} \mathrm{~g} / \mathrm{MW}-\mathrm{sec} .
\end{aligned}
$$

For convenience, at standard temperature and pressure (STP) in the diffusion calculations which follow Eq. (33) is rewritten as

$\mathrm{T}_{\text {con }}^{\prime}=1.155 \times 10^{-2} \mathrm{~cm}^{3}(\mathrm{STP}) / \mathrm{MW}-\mathrm{sec}$.
The rate of permeation of tritium through the adiabatic tube surface may be determined by the Richardson equation,

$$
F=\frac{C A}{d \sqrt{3}}\left(p_{1}^{1 / 2}-p_{2}^{1 / 2}\right) \exp \left(-\frac{Q}{R T}\right) \text {, }
$$

where

$F=$ permeation rate $\left(\mathrm{cm}^{3} / \mathrm{hr}\right.$ at STP $)$

$C=$ permeation constant for system $\left[\mathrm{cm}^{3}\right.$ (STP) $\left.\mathrm{mm} / \mathrm{hr} \mathrm{cm}^{2} \mathrm{~atm}^{1 / 2}\right]$

$A=$ available area for diffusion $\left(\mathrm{cm}^{2}\right)$

$d=$ thickness of tube wall (mm)

$P_{1}=$ partial pressure of tritum on lithium side of tube (atm)

$P_{2}=$ partial pressure of tritium on heat-pipe side of tube (atm)

$T=$ gas temperature (degrees Kelvin)

$R=$ universal gas constant ( $1.9864 \mathrm{cal} / \mathrm{mole} \mathrm{K})$

$Q=$ activation energy of diffusion (cal/mole)

and $\sqrt{3}$ takes into account the mass difference between $n$ and hydrogen. The activation energy $Q$ and the permeation constant $C$ are given for selected materials in Table 3 . We are particularly interested in niobium and in type 316 stainless steel; the first has high permeation, which could be used in tritium recovery, and the second has low permeation, which could be used to ensure that the tritium does not go where it is not wanted. For convenience, the permeation equation

Table 3. Activation energies for diffusion and permeation constants

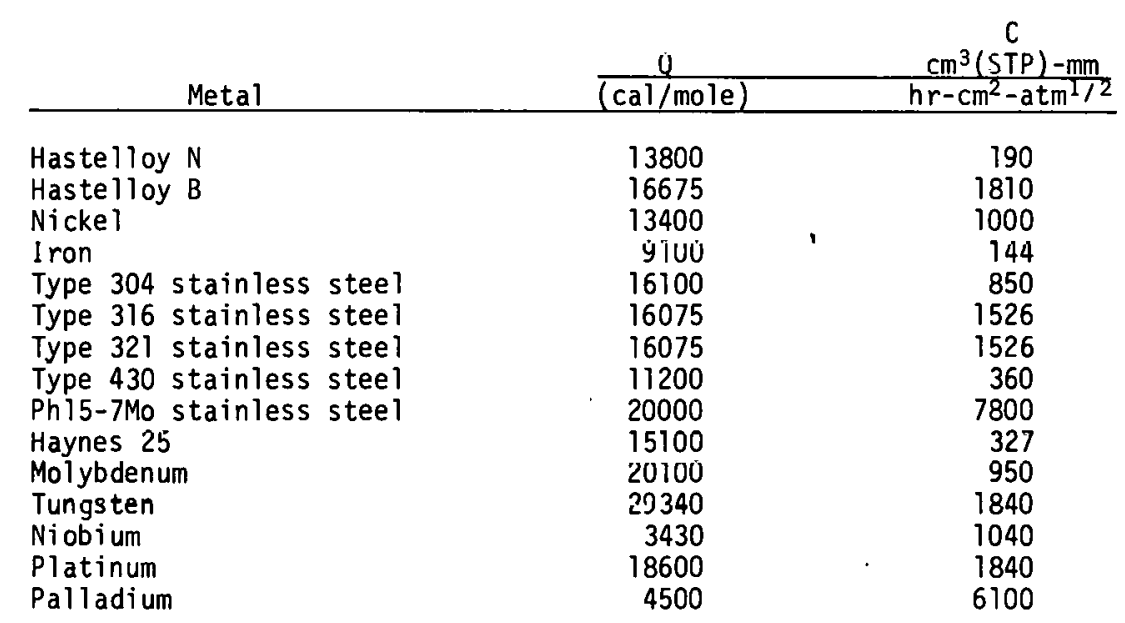


may be written with time in seconds and pressure in torr as

$$
\begin{aligned}
F_{S T}=\frac{C A}{d \sqrt{3}}\left(P_{1}^{1 / 2}\right. & \left.-P_{2}^{1 / 2}\right) \exp \left(-\frac{Q}{R T}\right) \\
& \times 10^{-5} \mathrm{~cm}^{-3 / \text { sec }} .
\end{aligned}
$$

\subsubsection{An Example: Partial Pressure Requirements}

We may equate the consumed tritium with the tritium diffused through the adiabatic wall by combining Ës. (34) and (36). This allows us to determine either the required surface area of the niobium or the partial pressure that will result with a given area. For a square meter of cassette, we have

$$
\begin{array}{r}
1.155^{\circ} \times 10^{-2} \times W_{L}=\frac{C A}{d \sqrt{3}}\left(P_{1}^{1 / 2}-P_{2}^{1 / 2}\right) \\
\exp \left(\frac{-Q}{R T}\right) \times 10^{-5} .
\end{array}
$$

We assume the following parameters:

$$
\begin{aligned}
& W_{L}=4 \mathrm{MW} / \mathrm{m}^{2} \\
& P_{2}=0 \\
& T \simeq 723 \mathrm{~K} \\
& C=1040 \\
& Q=3430 \\
& d=0.25 \mathrm{~mm}
\end{aligned}
$$

and a surface area $A$ for each cassette of $\pi \mathrm{m}^{2}$ per square meter. With a typical cassette thickness of $20.14 \mathrm{~m}$, it is likely that at least four or five cassettes will be required for proper overall neutron moderation. In this case, A will be not less than $4 \pi \mathrm{m}^{2}$ per square meter of blanket facing the plasma. Thus,

$$
\begin{aligned}
P_{1}^{1 / 2} & =\frac{1.155 \times 10^{3} \times W_{L} \times d \sqrt{3}}{C A \exp \left(\frac{-Q}{R T}\right)} \\
& =\frac{1.155 \times 10^{3} \times 4 \times 0.25 \sqrt{3}}{1040.4 \pi \times 10^{4} \times 0.107}
\end{aligned}
$$

$$
\begin{aligned}
& P_{1}^{1 / 2}=1.43 \times 10^{-4} ; \\
& P_{1}=2 \times 10^{-8} \text { torr } .
\end{aligned}
$$

Evidently, there is no problem in attaining either adequate temperatures or adequate area, as evidenced by the low requirement of only $2 \times 10^{-8}$ torr for the tritium driving pressure force. The problem is that the downstream pressure must be finite rather than the zero that we assumed. We may more correctly assume that the differential pressure relationship should be

$P_{1}^{1 / 2}-P_{2}^{1 / 2}=1.43 \times 10^{-4}$.

If we consider tritium holdup as a limiting criterion, then for a holdup of $210 \mathrm{~kg}$ in the total blanket the value of $P_{1} \simeq 10^{-6}$ torr. Thus

$-P_{2}^{1 / 2}=1.43 \times 10^{-4}-1 \times 10^{-3}$

and

$P_{2}=7.34 \times 10^{-7}$ torr $\approx 1 \times 10^{-6}$ torr.

\subsubsection{Removing the Tritiuin tu an ExLepuld Reglon}

This $10^{-6}$ torr is probably not a reasonable pressure to achieve when pumping on a inng tube ( $4 \mathrm{~m}$ ) of small diameter $(20.005 \mathrm{~m})$ with a closed end. If this vacuum pumbing should prove to he a problem, a continuous tube with a flow of some carrier gas could be substituted. The carrier gas could have entrained in it lithium vapor or the vapor of some salt at low partial pressure. The vapor would scavenge the inner surface of the niobium tube wall, cleaning off contaminants and assuring good permeation, and would also react with the tritium tor its transport and removal. The effective pressure $P_{2}$ would be very low. 


\section{CONCLUSIONS AND RECOMMENDATIONS}

\subsection{HELIUM AND HITEC AS COOLANTS}

It is difficult to make direct comparisons between helium and the salt HITEC as coolants for reactor blankets. However, the following considerations are noted.

The use of helium produces higher stresses than those produced using HITEC but there does appear to be adequate design space for the helium. While the necessary pumping power is trivial for HITEC, for helium it must always be a consideration. Thus, with helium we are always committed to high pressures and substantial pumping power; these are its two major deficiencies. HITEC's melting point of $142^{\circ} \mathrm{C}$ poses substantial problems in the initial charging of the system and in the formulation of procedures to follow in case of unplanned blanket cooldown. HITEC cannot be used at temperatures much above $700 \mathrm{~K}$, and its thermal stability is a matter of concern. Its radiation stability must also be verified. HITEC is a strong oxidizer and reacts exothermically with lithium; also, with its high energy capture, it degrades the ability of the lithium to breed tritium.

In the area of mechanical considerations, a method of remote disconnection for helium lines is far simpler than it would be for HITEC lines. If a leak which vented to the plasma occurred in the blanket cassette, there would be no quick way to turn off the HITEC - a gravity head alone could cause the fluid to flow for a substantial time, perhaps hours - while a faulty helium line could be evacuated and the flow stopped very quickly (provided that a cassette can be equipped with a pressure transducer capable of isolating the leak or detecting a leak rate). Also, the problems of cleanup following a helium leak must clearly be significantly less than those following a leak of HITEC.

Al1. things considered, my personal conviction is that helium is the better choice. I believe, however, that HITEC and that class of fluids offer excellent heat transfer properties at low pressure - a significant advantage - and should be studied further to answer and resolve some of the questions posed here.

\subsection{FURTHER ANALYSIS AND MODEL TESTING}

In the design of fusion reactors, we are not yet cognizant of the total problem; however, we are making good progress at present. Blanket designs, for instance, are beginning to yield to the pressures of studies which include all influencing parameters instead of ignoring important issues. We are approaching designs that with some refinement will satisfy the total criteria of assembly, disassembly, integrity, breeding, technology, and physics; models of these designs should be fabricated and tested.

The cassette represents one of these designs. It is recommended that more rigorous analyses be accomplished, particulariy in the area of mechanics of materials. These should be both analytical and practical. The initial model testing could be done on single modules or portions of modules, but eventually should proceed to the scale testing of a representative sector of a reactor and should include testing in a simulated fusion environment. These activities could be pursued in concert with other ongoing studies, such as the Large Coil Program at ORNL. The data obtained in this way would then be ready to integrate into the overall plan for commercial feasibility indicated by the ORNL Fusion Power Demonstration Study.

\subsection{THE CASSETTE AND THE VACUUM BUILDING}

The cassette blanket concept fits in well with another concept introduced in the ORNL Fusion Power Demonstration Study ${ }^{2}$ - that of housing the entire reactor in a vacuum building. 12 The vacuum building approach liberates the blanket from the requirements of absolute vacuum integrity during and after assembly; the building envelops the total blanket in a 
vacuum. Complex mechanical seais or welds, almost precluding disassembly and replacement, are no longer required.

Not only the cassette blanket design but also blanket designs in general should benefit from the vacuum building approach. We may be able to use existing facilities which are large enough to accommodate a reactor, such as the facility at Plum Brook, Ohio (described in Ref. 12).

7.4 A FINAL CAVEAT: THE NEED FOR A FAIL-SAFE BLANKET

There are serious considerations in the design of fusion reactor blankets which have only been alluded to in this report. One of these considerations is the need for an assessment of the consequences of a lithium or coolant leak that vents to the plasma. Such a leak could be catastrophic. A pinhole leak no larger than the period at the end of this sentence, with only a static head driving force, would extinguish the plasma in milliseconds and unfortunately continue to vent for hours. The cassette design with helium as the coolant circumvents this problem by encapsulating the lithium with helium. More work is required in evaluation of this area, but the cassette design appears to present a workable, fail-safe blanket. 


\section{REFERENCES}

1. W. Wells (Oak Ridge National Laboratory), personal communication, August 25, 1976.

2. D. Steiner et al., ORNL Fusion Power Demonstration Study: Interim Report, ORNL/TM5813, Oak Ridge National Laboratory, Oak Ridge, Tennessee (March 1977).

3. R. T. Santoro (Oak Ridge National Laboratory), personal communication, January 24 , 1977.

4. M. A. Hoffman et al., Review of Heat Thansber Problems Associated with Magnetically Confined Fusion Reactor Concepts, UCRL78036, Lawrence Livermore Laboratory, Livermore, California (April 1976).

5. E. E. Bloom et al., "Temperature and Fluence Limits for a Type 316 Stainless Steel CTR First Wall," Trans. Am. Nucl. Soc. 22, 178179.

6. J. L. Scott, "Blanket Structure," Sect. 5 in ORNL Fusion Power Demonstration Study: Interim Report, ORNL/TM-5813, Oak Ridge National Laboratory, Oak Ridge, Tennessee (March 1977).

7. H. E. McCoy, "Blanket Coolant," Sect. 6 in ORNL Fusion Power Demonstration Study: Interim Report, ORNL/TM-5813, Oak Ridge National Laboratory, Oak Ridge, Tennessee (March 1977).
8. HITEC Heat Transfer Salt: Properties, Uses, Storage, and Handling, Industrial Chemicals Department, E. I. DuPont de Nemours \& Co., Aiken, South Carolina.

9. R. T. Santoro (Oak Ridge National Laboratory), personal communication, December 1976.

10. E. R. Eckert and R. M. Drake, Analysis of Heat and Mass Transfer, McGraw-Hill Book Co., New York, 1972.

11. ASME Boiler and Pressure Vessel Code, Section III. Nuclear Power Plant Components, Subsections NA: General Requirements and NB: Class 1 Components, American Society of Mechanical Engineers, New York, 1974 :

12. R. W. Werner, ORNL Fusion Power Demonstration Study: Arguments for a Vacuum Building in which to Enclose a Fusion Reactor, ORNL/ TM-5664, Oak Ridge National Laboratory, Oak Ridge, Tennessee (December 1976). 
APPENDIX 1

PROPERTIES OF HELIUM AND HITEC

Table Al.1. Properties of HITEC at $400^{\circ} \mathrm{C}$

$\begin{array}{ll}\text { Melting point, mp } & 142^{\circ} \mathrm{C} \\ \text { Specific heat, } C_{p} & 1.54 \times 10^{3} \mathrm{~W} \cdot \mathrm{sec} / \mathrm{kg} \cdot \mathrm{K} \\ \text { Density, } \beta & 1.68 \times 10^{3} \mathrm{~kg} / \mathrm{m}^{3} \\ \text { Viscosity, } \mu & 3 \times 10^{-3} \mathrm{~kg} / \mathrm{m}-\mathrm{sec} \\ \text { Thermal conductivity, } k & 0.6 \mathrm{~W} / \mathrm{m} \cdot \mathrm{K}\end{array}$

Table A1.2. Property values of helium at atmospheric pressure

\begin{tabular}{|c|c|c|c|c|c|c|c|}
\hline $\begin{array}{l}\text { Tempera- } \\
\text { ture (K) }\end{array}$ & $\begin{array}{l}\text { Density, } \\
\rho\left(\mathrm{kg} / \mathrm{m}^{3}\right)\end{array}$ & $\begin{array}{l}\text { Specific } \\
\text { heat, c } \\
\text { (Wsec/ } \\
\text { kg K) }\end{array}$ & $\begin{array}{l}\text { Viscosity } \\
\text { (dynamic), } \\
\mu(\text { ky/llsec })\end{array}$ & $\begin{array}{l}\text { Viscosity } \\
\text { (kinemat- } \\
\text { |c), v }\left(m I^{3} /\right. \\
\text { sec) }\end{array}$ & $\begin{array}{l}\text { Thermal } \\
\text { conduc- } \\
\text { l|vily, } \\
k(W / m k)\end{array}$ & $\begin{array}{l}\text { Thermal } \\
\text { diffu- } \\
\text { s|v|lyy, } \\
\alpha=k / C_{p} \rho \\
\left(m^{2} / \mathrm{sec}\right)\end{array}$ & $\begin{array}{l}\text { Prandl } \\
\text { number, } \\
\mathrm{Pr} \\
\left(\mu \mathrm{C}_{\mathrm{p}} / \mathrm{k}\right)\end{array}$ \\
\hline 3 & & $5.200 \times 10^{3}$ & $8.42 \times 10^{-7}$ & & 0.0106 & & \\
\hline 33 & 1.4657 & 5.200 & 50.2 & $3.42 \times 10^{-4}$ & 0.0353 & $0.04625 \times 10^{-4}$ & 0.74 \\
\hline 144 & 3.3799 & 5.200 & 125.5 & 37.11 & 0.0928 & $0.52 \% 5$ & 0.70 \\
\hline 200 & 0.2435 & 5.200 & 156.6 & 61.38 & 0.1177 & 0.9288 & 0.694 \\
\hline 255 & 0.1908 & 5.200 & 181.7 & 95.50 & 0.1357 & 1.3675 & 0.70 \\
\hline 366 & 0.13280 & 5.200 & 230.5 & 173.6 & 0.1691 & 2.419 & 0.71 \\
\hline 477 & 0.10204 & 5.200 & 275.0 & 269.3 & 0.197 & 3.716 & 0.72 \\
\hline 589 & 0.08282 & 5.200 & 311.3 & 375.8 & 0.225 & 5.215 & 0.72 \\
\hline 700 & 0.07032 & 5.200 & 347.5 & 491.2 & 0.251 & 6.661 & 0.72 \\
\hline $80 n$ & 0.0602 .3 & 5.200 & 387.7 & 6.34 .4 & 0.275 & 8.774 & $0.7 ?$ \\
\hline 900 & 0.05286 & 5.200 & 413.6 & 781.3 & 0.298 & 10.831 & 0.72 \\
\hline
\end{tabular}


APPENDIX 2

CALCULATIONAL PROCEDURE FOR HEAT TRANSFER

We specify as input parameters the following:

$\mathrm{d}_{0}=0.005 \mathrm{~m}, 0.04 \mathrm{~m}, 0.005 \mathrm{~m}$ steps

$W_{L}=5 \times 10^{5} \mathrm{~W} / \mathrm{m}^{2}, 5 \times 10^{6} \mathrm{~W} / \mathrm{m}^{2}, 5 \times 10^{5} \mathrm{~W} / \mathrm{m}^{2}$ steps

$P($ pressure $)=10 \mathrm{~atm}, 60 \mathrm{~atm}, 10 \mathrm{~atm}$ steps for hel ium

$=7 \mathrm{~atm}$ (constant) for salt

$q_{\text {inc }}=0.25 \times W_{L}\left(W / m^{2}\right)$

$q_{N L}=0.5 q_{i n c}\left(w / m^{2}\right)$

$d_{i}=0.9 d_{0}(\mathrm{~m})$

$\Delta T=10 \mathrm{k} / \mathrm{m}, 60 \mathrm{k} / \mathrm{m}, 10 \mathrm{k} / \mathrm{m}$ s teps.

The following output data are determined.

1) Heat into the coolant, Q, per meter of tube length

$$
\begin{aligned}
Q_{\text {TOTAL }}= & W_{L} d_{0}\left(q_{i n C}+q_{N L}\right)+W_{L}\left(Q_{N T}+Q_{N C}\right) \\
= & W_{L} d_{0}(0.25+0.125)+W_{L}\left[13.1 \exp \left(\frac{-y_{C}}{0.385}\right)\right. \\
& \left.\times \frac{0.19 \pi d_{0}^{2}}{4}\right]+W_{L}\left[9.24 \exp \left(\frac{-y_{C}}{0.385}\right)\right. \\
& \left.\times \frac{0.81 \pi d_{0}^{2}}{4}\right], \\
Q_{\text {TOTAL }}= & W_{L} d_{0}\left[0.375+\left(1.955 d_{0}+5.87 d_{0}\right)\right] \\
& \exp \left(\frac{-y c}{0.385}\right) .
\end{aligned}
$$

For salt,

$Q_{\text {TOTAL }}=W_{L} d_{0}\left[0.375+7.83 d_{0} \exp \left(\frac{-y_{c}}{0.385}\right)\right]$.

For helium,

$Q_{\text {TOTAL }}=W_{L} d_{0}\left[0.375+1.955 d_{0} \exp \left(\frac{-y_{C}}{0.385}\right)\right]$.

2) The mass flow rate $\dot{m}$, in kilograms per second, for helium, .

$\dot{m}_{H}=\frac{Q}{C \rho \Delta T}=\frac{Q}{5.2 \times 10^{3} \times \Delta T}$,

and for salt,

$\dot{\mathrm{m}}_{\mathrm{S}}=\frac{Q}{1.54 \times 10^{3} \times \Delta \mathrm{T}}$.
3) The flow velocity, $v$, in meters per second, for helium,

$V_{H}=\dot{m} / \rho A=4 \dot{m} / \pi \cdot 0.81 d_{0}^{2} \ddot{\rho P} \quad$,

where

$\bar{\rho}=(0.14 \cdot 350) /(350+20 \mathrm{~T})$

and $P$ is atmospheric pressure, and for salt,

$V_{S}=4 \dot{m} / \pi \cdot 0.81 d_{0}^{2} \rho_{S}$.

4) The Reynolds number, $N_{R}$,

$N_{R}=\frac{d_{i} V \cdot \rho}{\mu}$

For helium,

$N_{R H}=\frac{0.9 d_{0} V_{H} \overline{\rho p}}{2.75 \times 10^{-7}}$;

for salt,

$N_{R S}=\frac{0.9 d_{0} V_{S} \rho_{S}}{3 \times 10^{-3}}$

5) The friction factor, f, which for smooth tubes is proportional to the Stanton number (Ref. 1), $\mathrm{N}_{\mathrm{S}}$,

$f=1.5 \mathrm{~N}_{\mathrm{S}}$.

The Stanton number for smooth tubes may be written as

$N_{S}=\alpha\left(N_{P}\right)^{-2 / 3}\left(N_{R}\right)^{-00 \cdot 2}$.

where $\alpha=0.023$; thus

$f=0.0345\left(N_{p}\right)^{-2 / 3}\left(N_{R}\right)^{-0.2}$.

The value of $N_{p}$ is 0.72 for helium and 7.7 for the salt; therefore, for helium

$f_{H}=0.043\left(N_{R}\right)^{-0.2}$ 
and for salt

$$
f_{S}=0.011\left(N_{R}\right)^{-0.2} .
$$

6) The pressure drop, $\Delta P$, in newtons per square meter,

$\Delta P=\frac{2 f \dot{m}^{2} L}{\rho d}\left(\frac{\pi d_{i} 2}{4}\right)^{-2}$,

where $\rho=\bar{\rho}$ for helium and $\rho=\rho_{S}$

for salt. In terms of $d_{0}$,

$\Delta P_{I I}=\frac{2 f_{1.1} \dot{m}^{2}}{p} \frac{L}{d}\left(\frac{n .81 \pi r_{0}^{2}}{4}\right)^{-2}$

and

$\Delta P_{S}=\frac{2 f_{S} \dot{m}^{2}}{\rho_{S}} \frac{L}{d}\left(\frac{0.81 \pi d_{0}^{2}}{4}\right)^{-2}$

The pressure drop may be expressed in pounds per square inch as

$\Delta P_{p s i}=\Delta P / 6.894 \times 10^{3}$.

7) The pumping power, PP, in watts, $\boldsymbol{P} \boldsymbol{P}=\Delta \dot{\boldsymbol{H}} \cdot \mathbf{G}$.

For helium, $: P P=(\Delta P \dot{m}) /(\bar{\rho} \cdot P)$;

For the salt, $\mu P=\left(\Delta P \dot{m} / \rho_{S}\right.$.

8) The percentage of thermal power used for pumping power, if PP,

$\% P P=\frac{P P}{Q} \times 100 \%$.

(Aं.ं.
9) The Nussult number, Nu. For helium, where the Prandl number $\mathrm{Pr}$ for a constant heat rate is $0.5<\operatorname{Pr}<1.0$,

$\mathrm{Nu}_{\mathrm{H}}=0.222 \cdot \operatorname{Pr} 0.6 \operatorname{Re}^{0.8}$;

(A2.10a)

for the salt, where $\operatorname{Pr}=7.7$,

$N u_{S}=0.0155 \cdot \operatorname{Re}^{0.83} \operatorname{Pr} 0.5$

$=0.043 \mathrm{Re}^{0.83}$.

10) The film coefficient, $\bar{h}$,

$h=N u \cdot \frac{K_{2}}{0.9 d_{0}}$

11) The film drop, $\Delta T_{f i l m}$, in degrees Celsius,

$T_{f i \text { lm }}=T_{w i}-T_{B M}=\frac{q_{i n c} \cdot 2}{\bar{h}_{\pi}}$.

12) The temperature drop across the wall, $\Delta \mathrm{T}_{\text {wall }}$, in degrees Celsius,

$\Delta T_{\text {Wal }}=\frac{q_{\text {inc }} \cdot 2 \cdot 0.05 d_{0}}{K \pi}$.

REFERENCE

1 G R Hopkins and of Melesa=n'Hospital, "Helium Cooling for Fusion Reactors," Nucl. Eng. Ues. 26, 215-230 (19774). 
APPENDIX 3

OUTPUT DATA FOR HELIUM AND HITEC

AT DIFFERENT WALL LOADINGS AND TUBE DIAMETERS

Tables A3.1 through A3.5 present data for helium at $60 \mathrm{~atm}$ and $\Delta T=20^{\circ} \mathrm{C} / \mathrm{m}$ with different wall loadings $\left(1-5 \mathrm{MW} / \mathrm{m}^{2}\right)$ and tube diameters (0.005-0.05 m). Tables A3.6 through A3.10 present data for HITEC at $7 \mathrm{~atm}$ and $\triangle T=10^{\circ} \mathrm{C} / \mathrm{m}$ for wall loadings of $1-5 \mathrm{MW} / \mathrm{m}^{2}$ and tube diameters of 0.005-0.05 $\mathrm{m}$. The data are for the following parameters:

1) heat into the coolant, Q

2) mass flow rate, $\dot{m}$

3) flow velocity, $v$
4) Reynolds number, $N_{R}$

5) pressure drop, $\Delta P$ (in newtons per meter and in pounds per square inch)

6) pumping power, PP

7) percentage of thermal power used for pumping power, \%pp

8) Nussult number, Nu

9) film coefficient, $\bar{h}$

10) film drop, $\Delta T_{\text {film }}$

11) temperature drop across the wall, $\Delta T_{\text {wall }}$ 
Table A3.1. Jutput data for helium at $60 \mathrm{~atm}, \Delta T=20^{\circ} \mathrm{C}$, ard wall loading of $1 \mathrm{MW} / \mathrm{m}^{2}$

\begin{tabular}{|c|c|c|c|c|c|c|c|c|c|c|c|c|}
\hline$d_{0}$ & 7 & $\dot{m}$ & $v$ & $N_{R}$ & $\Delta P$ & $\Delta P$ & PP & qPP & $\mathrm{Nu}$ & $\bar{h}$ & \multicolumn{2}{|c|}{$\Delta T\left({ }^{\circ} \mathrm{C}\right)$} \\
\hline (m) & $(\sqrt[s]{)})$ & $(\mathrm{kg} / \mathrm{sec})$ & $(\mathrm{m} / \mathrm{s} \in \mathrm{c})$ & & $\left(\mathrm{N} / \mathrm{m}^{2}\right)$ & (psi) & (W) & & & & $\mathrm{Fi} \cdot \mathrm{m}$ & Wall \\
\hline 0.005 & 1,923 & 0.0184 & 154 & $2.1 \times 10^{5}$ & $2.65 \times 10^{5}$ & 38.5 & 52 & 33.8 & 329 & $1.31 \times 10^{4}$ & 12.1 & 2.1 \\
\hline 0.010 & 3.945 & 0.0379 & 79 & $2.16 \times 10^{5}$ & $3.46 \times 10^{4}$ & 5.0 & 175 & 4.43 & 335 & $6.7 \times 10^{3}$ & 23.7 & 4.2 \\
\hline 0.015 & 6,064 & 0.0583 & 54 & $2.2 \times 10^{5}$ & $1.07 \times i 0^{4}$ & 1.56 & 83 & 1.37 & 342 & $4.56 \times 10^{3}$ & 34.8 & 6.3 \\
\hline 0.020 & 8.282 & 0.0796 & 415 & $2.27 \times 13^{5}$ & $4.7 \times 10^{3}$ & 0.687 & 50 & 0.604 & 348 & $3.48 \times 10^{3}$ & 45.6 & 8.4 \\
\hline 0.025 & 10.597 & 0.101 & 33.9 & $2.32 \times 13^{5}$ & $2.52 \times 10^{3}$ & 0.366 & 34 & 0.322 & 355 & $2.84 \times 10^{3}$ & 55.9 & 10.4 \\
\hline 0.030. & 13.010 & 0.125 & 28.9 & $2.4 \times 10^{5}$ & $1.52 \times 10^{3}$ & 0.221 & 25.3 & 0.194 & 362 & $2.4 \times 10^{3}$ & 66 & 12.5 \\
\hline 0.035 & 15.520 & 0.149 & 25.4 & $2.43 \times 13^{5}$ & $1.0 \times 10^{3}$ & 0.145 & 19.8 & 0.127 & 368 & $2.1 \times 10^{3}$ & 75.6 & 14.6 \\
\hline 0.040 & 18,129 & 0.179 & 22.7 & $2.5 \times 10^{5}$ & $6.9 \times 10^{2}=$ & 0.101 & 16.1 & $0.08 \varepsilon$ & 374 & $1.87 \times 10^{3}$ & 85 & 16.7 \\
\hline 0.045 & 20,835 & 0.20 & 20.6 & $2.5 \times 10^{5}$ & $5.08 \times 1.3^{2}$ & 0.073 & 13.5 & 0.065 & 381 & $1.7 \times 10^{3}$ & 94 & 18.8 \\
\hline 0.050 & 23.639 & 0.227 & 19.0 & $2.6 \times 10^{5}$ & $3.84 \times 1.3^{2}$ & 0.0558 & 11.6 & 0.05 & 388 & $1.55 \times 10^{3}$ & 102 & 21 \\
\hline
\end{tabular}

Table A3.2. Output data for helium at $60 \mathrm{~atm}, \Delta \mathrm{T}=20^{\circ} \mathrm{C}$, and wall loajing of $2 \mathrm{~mW} / \mathrm{m}^{2}$

\begin{tabular}{|c|c|c|c|c|c|c|c|c|c|c|c|c|}
\hline \multirow{2}{*}{$\begin{array}{c}d_{0} \\
(m)\end{array}$} & \multirow{2}{*}{$\begin{array}{c}Q \\
(W)\end{array}$} & \multirow{2}{*}{$\begin{array}{c}\dot{\mathrm{m}} \\
(\mathrm{kg} / \mathrm{sec})\end{array}$} & \multirow{2}{*}{$\begin{array}{c}V \\
(m / \mathrm{sec})\end{array}$} & \multirow[t]{2}{*}{$N_{R}$} & \multirow{2}{*}{$\begin{array}{c}\Delta P \\
\left(N / m^{2}\right)\end{array}$} & \multirow{2}{*}{$\begin{array}{l}\Delta P \\
(p s i)\end{array}$} & \multirow{2}{*}{$\begin{array}{l}\text { PP } \\
(W)\end{array}$} & \multirow[t]{2}{*}{ qPF } & \multirow[t]{2}{*}{$\mathrm{Nu}$} & \multirow[t]{2}{*}{$\bar{h}$} & \multicolumn{2}{|c|}{$\Delta \mathrm{T}\left({ }^{\circ} \mathrm{C}\right)$} \\
\hline & & & & & & & & & & & Film & Wall \\
\hline 0.005 & 3,848 & 0.037 & 308 & $4.2 \times 10^{5}$ & $9.25 \times 10^{5}$ & 134 & 4539 & 118 & 572 & $2.3 \times 10^{4}$ & 13.9 & 4.2 \\
\hline 0.015 & 12,130 & 0.116 & 108 & $4.4 \times 10^{E}$ & $3.74 \times 10^{4}$ & 5.43 & 579 & 4.77 & 595 & $7.94 \times 10^{3}$ & 40 & 12.5 \\
\hline 0.920 & 16,564 & 0.159 & 83 & $4.5 \times 105$ & $1.64 \times 10^{4}$ & 2.4 & 348 & 2.1 & 607 & $6.07 \times 10^{3}$ & 52.4 & 16.7 \\
\hline 0.025 & 21,194 & 0.203 & 68 & $4.6 \times 10^{5}$ & $8.8 \times 10^{3}$ & 1.27 & 238 & 1.12 & 618 & $4.94 \times 10^{3}$ & 64.3 & 21 \\
\hline 0.035 & 31,041 & 0.298 & 51 & $4.8 \times 10^{5}$ & $3.48 \times 10 \equiv$ & 0.505 & 137 & 0.44 & 641 & $3.65 \times 10^{3}$ & 87 & 29.3 \\
\hline 0.040 & 36,257 & 0.348 & 45.6 & $5.0 \times 10^{5}$ & $2.72 \times 10 \equiv$ & 0.35 & 112 & 0.309 & 652 & $3.26 \times 10^{3}$ & 97.5 & 33.5 \\
\hline 0.045 & 41,670 & 0.4 & $41 . \tilde{c}$ & $5.1 \times 10^{5}$ & $1.77 \times 10 \equiv$ & 0.256 & 94.1 & 0.225 & 663 & $2.95 \times 10^{3}$ & 107.8 & 37.7 \\
\hline 0.050 & 47,277 & 0.45 & 38 & $5.2 \times 10^{5}$ & $1.34 \times 10 \equiv$ & 0.194 & 81 & 0.7 & 675 & $2.7 \times 10^{3}$ & 118 & 42 \\
\hline
\end{tabular}


Table A3.3. Output data for helium at $60 \mathrm{~atm}, \Delta \mathrm{T}=20^{\circ} \mathrm{C}$, and wall loading of $3 \mathrm{sW} / \mathrm{m}^{2}$

\begin{tabular}{|c|c|c|c|c|c|c|c|c|c|c|c|c|}
\hline$d_{0}$ & 0 & $\dot{\mathrm{m}}$ & v & $N_{R}$ & $\Delta \mathrm{P}$ & $\Delta P$ & $\mathrm{PP}$ & qPP & $\mathrm{Nu}$ & $h$ & \multicolumn{2}{|c|}{$\Delta T\left({ }^{\circ} \mathrm{C}\right)$} \\
\hline$\cdot(m)$ & (w) & $(<g / s e c)$ & $\left(m^{\prime} / \mathrm{sec}\right)$ & & $\left(\mathrm{N} / \mathrm{m}^{2}\right)$ & (psi) & $(w)$ & & & & $\mathrm{Film}$ & Wall \\
\hline 0.005 & 5,771 & D. 055 & 462 & $6.3 \times 10^{5}$ & $1.9 \times 10^{6}$ & 278 & $1.41 \times 10^{4}$ & 244 & 792 & $3.17 \times 10^{4}$ & 15 & 6.3 \\
\hline 0.070 & $11,8: 37$ & 3.113 & 237 & $6.5 \times 10^{5}$ & $2.5 \times 10^{5}$ & 36.4 & $3.8 \times 10^{3}$ & 32 & 808 & $1.6 \times 10^{4}$ & 29.5 & 12.5 \\
\hline 0.075 & 18,195 & 0.175 & 162 & $6.6 \times 10^{5}$ & $7.7 \times 10^{4}$ & 11.3 & $1.8 \times 10^{3}$ & 9.9 & 824 & $1.1 \times 10^{4}$ & 43.4 & 18.8 \\
\hline 0.020 & 24,846 & 3.238 & 124 & $6.8 \times 10^{5}$ & $3.42 \times 10^{4}$ & 4.96 & $1.08 \times 10^{3}$ & 4.36 & 839 & $8.4 \times 10^{3}$ & 56.8 & 25 \\
\hline 0.025 & 31,791 & 3.305 & 102 & $6.9 \times 10^{5}$ & $1.82 \times 10^{4}$ & 2.65 & 740 & 2.33 & 855 & $6.8 \times 10^{3}$ & 69.7 & 31.4 \\
\hline 0.030 & 39,029 & 1.375 & 87 & $7.1 \times 10^{5}$ & $1.1 \times 10^{4}$ & 1.59 & 548 & 1.4 & 871 & $5.8 \times 10^{3}$ & 82 & 37.7 \\
\hline 0.035 & 46,561 & 1.447 & 76.2 & $7.3 \times 10^{5}$ & $7.2 \times 10^{3}$ & 1.04 & 428 & 0.92 & 887 & $5.06 \times 10^{3}$ & 94 & 44 \\
\hline 0.040 & 54,386 & 10.523 & 68 & $7.5 \times 10^{5}$ & $5.03 \times 10^{3}$ & 0.73 & 349 & 0.64 & 902 & $4.5 \times 10^{3}$ & 106 & 50.2 \\
\hline 0.045 & 62,504 & 0.6 & 62 & $7.6 \times 10^{5}$ & $3.67 \times 10^{3}$ & 0.54 & 292 & 0.468 & 918 & $4.1 \times 10^{3}$ & 117 & .56 .5 \\
\hline 0.050 & 70,916 & 0.68 & 57 & $7.8 \times 10^{5}$ & $2.78 \times 10^{3}$ & 0.4 & 251 & 0.354 & 933 & $3.7 \times 10^{3}$ & 128 & 63 \\
\hline
\end{tabular}

Table A3.4. Output data for helium at $60 \mathrm{~atm}, \Delta T=20^{\circ} \mathrm{C}$, and wall loading of $4 \mathrm{~mW} / \mathrm{m}^{2}$

\begin{tabular}{|c|c|c|c|c|c|c|c|c|c|c|c|c|}
\hline$d_{0}$ & $Q$ & $\dot{\mathrm{m}}$ & $v$ & $N_{R}$ & $\Delta \mathrm{P}$ & $\Delta \mathrm{P}$ & pp & qpp & $\mathrm{Nu}$ & $\bar{h}$ & \multicolumn{2}{|c|}{$\Delta \mathrm{T}\left({ }^{\circ} \mathrm{C}\right)$} \\
\hline$(\mathrm{m})$ & (W) & $(\mathrm{kg} / \mathrm{sec})$ & $(\mathrm{m} / \mathrm{sec})$ & & $\left(\mathrm{N} / \mathrm{m}^{2}\right)$ & (psi) & (W) & & & & Film & Wall \\
\hline 0.005 & 7,695 & 0.074 & 617 & $8.4 \times 10^{5}$ & $3.2 \times 10^{6}$ & 467 & 31,600 & 410 & 996 & $4 \times 10^{4}$ & 16 & 8.4 \\
\hline C.010 & 15,782 & 0.151 & 316 & $8.6 \times 10^{5}$ & $4.2 \times 10^{5}$ & 61 & 8,479 & 54 & 1017 & $2 \times 10^{4}$ & 31.2 & 16.7 \\
\hline 0.015 & 24,260 & 0.233 & 216 & $8.8 \times 10^{5}$ & $1.3 \times 10^{5}$ & 19 & $.4,036$ & 16.6 & 1037 & $1.4 \times 10^{4}$ & 46 & 25.1 \\
\hline$C .020$ & 33,128 & 0.318 & 166 & $9 \times 10^{5}$ & $5.74 \times 10^{4}$ & 8.3 & 2,427 & 7.3 & 1057 & $1.05 \times 10^{4}$ & 60.2 & 33.5 \\
\hline 0.025 & 42,388 & 0.407 & 136 & $9.3 \times 10^{5}$ & $3.06 \times 10^{4}$ & 4.44 & $1,6.58$ & 3.91 & 1077 & $8.6 \times 10^{3}$ & 73.8 & 42 \\
\hline 0.030 & 52,039 & 0.50 & 116 & $9.5 \times 10^{5}$ & $1.85 \times 10^{4}$ & 2.68 & 1,227 & 2.35 & 1097 & $7.3 \times 10^{3}$ & 87 & 50.2 \\
\hline 0.035 & 62,081 & 0.596 & 101 & $9.7 \times 10^{5}$ & $1.2 \times 10^{4}$ & 1.75 & 960 & 1.54 & 1116 & $6.4 \times 10^{3}$ & 99.7 & 58.6 \\
\hline 0.040 & 72,515 & 0.697 & 91 & $9.9 \times 10^{5}$ & $8.4 \times 10^{3}$ & 1.22 & 781 & 1.07 & 1136 & $5.7 \times 10^{3}$ & 112 & 67 \\
\hline 0.045 & 83,339 & 0.80 & 82.5 & $1 \times 10^{6}$ & $6.1 \times 10^{3}$ & 0.894 & 655 & 0.786 & 1156 & $5.2 \times 10^{3}$ & 124 & 75 \\
\hline 0.050 & 94,555 & 0.91 & 75.8 & $1 \times 10^{6}$ & $4.6 \times 10^{3}$ & 0.676 & 5.62 & 0.595 & 1175 & $4.7 \times 10^{3}$ & 135 & 84 \\
\hline
\end{tabular}


Table A3.5. Output ciaza for helium at $60 \mathrm{~atm}, \Delta T=20^{\circ} \mathrm{C}$, ard wall loading of $5 \mathrm{MW} / \mathrm{m}^{2}$

\begin{tabular}{|c|c|c|c|c|c|c|c|c|c|c|c|c|}
\hline$d_{0}$ & $Q$. & $\dot{m}$ & v & $v_{R}$ & $\angle P$ & $\Delta \mathrm{P}$ & PP & Epp & $\mathrm{Nu}$ & $\bar{h}$ & \multicolumn{2}{|c|}{$\Delta \mathrm{T}\left({ }^{\circ} \mathrm{C}\right)$} \\
\hline$(m)$ & (W) & $(\mathrm{kg} / \mathrm{sec})$ & $(\mathrm{m} / \mathrm{sec})$ & & $\left(\mathrm{i} / \mathrm{m}^{2}\right)$ & (psi) & (W) & & & & Film & Wall \\
\hline 0.005 & 9,619 & 0.092 & 771 & $1 \times 10^{6}$ & $4.8 \times 10^{6}$ & 698 & $5.9 \times 10^{4}$ & 6.4 & $119 i$ & $4.7 \times 10^{4}$ & 16.7 & 10.4 \\
\hline 0.010 & 19,728 & 0.189 & 395 & $1.1 \times 10^{6}$ & $6.3 \times 10^{5}$ & 91.3 & $1.58 \times 10^{4}$ & $B C .2$ & 1216 & $2.4 \times 10^{3}$ & 32.7 & 21 \\
\hline 0.015 & 30,325 & 0.29 & 270 & $1.1 \times 10^{6}$ & $1.95 \times 10^{5}$ & 28.2 & $7.5 \times 10^{3}$ & 24.3 & 1240 & $1.65 \times 10^{4}$ & 48.1 & 31.4 \\
\hline 0.020 & 41,410 & 0.398 & 207 & $1.1 \times 10^{6}$ & $8.6 \times 10^{4}$ & 12.4 & $4.5 \times 10^{3}$ & 16.9 & 1264 & $1.26 \times 10^{4}$ & 63 & 42 \\
\hline 0.025 & 52,985 & 0.51 & 170 & $1.16 \times 10^{\epsilon}$ & $4.6 \times 10^{4}$ & 6.6 & $3.09 \times 10^{3}$ & E. B & 1287 & $1.03 \times 10^{4}$ & 77 & 52 \\
\hline 0.030 & 65,049 & 0.62 & 145 & $1.2 \times 10^{6}$ & & 4 & $2.3 \times 10^{3}$ & $\Xi .5 \bar{c}$ & 1311 & $8.7 \times 10^{3}$ & 91 & 63 \\
\hline 0.035 & 77,600 & 0.746 & 127 & $1.2 \times 10^{6}$ & $1.87 \times 10^{4}$ & 2.62 & $1.8 \times 10^{3}$ & 2.3 & 1335 & $7.6 \times 10^{3}$ & 104 & 73.2 \\
\hline 0.040 & 90,643 & 0.87 & 113 & $1.24 \times 10^{8}$ & $1.25 \times 10^{4}$ & 1.83 & $1.46 \times 10^{3}$ & 1.61 & 1358 & $6.8 \times 10^{3}$ & 117 & 84 \\
\hline 0.045 & 104,170 & 1.0 & 103 & $1.3 \times 10^{6}$ & $9.2 \times 10^{3}$ & 1.33 & $1.22 \times 10^{3}$ & 1.17 & 1382 & $6.1 \times 10^{3}$ & 129 & 94 \\
\hline 0.050 & 118,190 & 1.13 & 95 & $1.3 \times 10^{6}$ & $6.97 \times 10^{3}$ & 1.01 & $1.05 \times 10^{3}$ & $(1.89$ & 1405 & $5.6 \times 10^{3}$ & 141 & 105 \\
\hline
\end{tabular}

Table A3.6. Output data for salt at $7 \mathrm{~atm}, \Delta \mathrm{T}=10^{\circ} \mathrm{C} / \mathrm{m}$, and wall loading of $1 \mathrm{~ms} / \mathrm{m}^{2}$

\begin{tabular}{|c|c|c|c|c|c|c|c|c|c|c|c|c|}
\hline$d_{0}$ & 0 & $\dot{\mathrm{m}}$ & v & $N_{2}$ & $\Delta \mathrm{P}$ & $\Delta P$ & PP & qPP & Iu & $\bar{h}$ & \multicolumn{2}{|c|}{$\Delta T\left({ }^{\circ} \mathrm{C}\right)$} \\
\hline$(m)$ & $(W)$ & $(\mathrm{kg} / \mathrm{s} \equiv \mathrm{C})$ & $(\mathrm{m} / \mathrm{sec})$ & & $\left(\mathrm{N} / \mathrm{m}^{2}\right)$ & (psi) & $(w)$ & & & & Filn & Wall \\
\hline 0.005 & 2,070 & 0.1375 & 5.6 & 12,581 & $28,29 ?$ & 4.1 & 2.26 & 0.110 & 109 & 14,589 & 11 & 2.1 \\
\hline 0.010 & 4,533 & 0.2974 & 2.75 & 13,380 & 4,161 & 0.6 & 0.73 & 0.016 & $11 \equiv$ & 7,862 & 20 & 4.2 \\
\hline 0.015 & 7,386 & 0.48 & 1.59 & 15, 1579 & 1.431 & 0.2 & 0.4 & 0.005 & $12 \equiv$ & 5,615 & $28 . \Xi$ & 6.3 \\
\hline 0.020 & 10,632 & 0.69 & 1.6 .1 & $16, \geq 78$ & 692 & 0.1 & 0.284 & 0.0027 & 137 & 4,487 & 35.5 & 8.4 \\
\hline 0.025 & 14,269 & 1.925 & 1.39 & 17,777 & 403 & 0.058 & 0.222 & 0.0016 & $14 \equiv$ & 3,808 & 42 & 10.5 \\
\hline 0.030 & 18,298 & T1. 188 & 1.23 & 18,577 & 263 & 0.038 & 0.186 & 0.001 & 151 & $.3,353$ & 47.4 & 12.6 \\
\hline 0.035 & 22,718 & 1.475 & 1.12 & 19,376 & 185 & 0.027 & 0.16 & 0.0007 & $15 \equiv$ & 3,026 & 52.5 & 14.6 \\
\hline 0.040 & 27,530 & 1.78 & 1.04 & 21,375 & 138 & 0.020 & 0.146 & 0.0005 & 165 & 2,780 & 57.2 & 16.6 \\
\hline 0.045 & 32,734 & $\equiv .125$ & 0.932 & 22,274 & 107 & 0.0155 & 0.135 & 0.0004 & $0 T E$ & 2,587 & 61.5 & 18.8 \\
\hline 0.050 & 38,329 & $\Xi .48$ & 0.93 & 23,474 & 85.7 & 0.012 & 0.127 & 0.0003 & $18=$ & 2,432 & 65.4 & 21 \\
\hline
\end{tabular}


Tlable A3.7. Output data for salt at $7 \mathrm{~atm}, \Delta \mathrm{T}=10^{\circ} \mathrm{C} / \mathrm{m}$,

and wall loading of $2 \mathrm{mw} / \mathrm{m}^{2}$

\begin{tabular}{|c|c|c|c|c|c|c|c|c|c|c|c|c|}
\hline$d_{0}$ & $Q$ & $\dot{\mathrm{m}}$ & $v$ & $N_{R}$ & $\Delta P$ & $\Delta P$ & PP & qpp & $\mathrm{Nu}$ & $\bar{h}$ & \multicolumn{2}{|c|}{$\Delta \mathrm{T}\left({ }^{\circ} \mathrm{C}\right)$} \\
\hline & (w) & $(\mathrm{kg} / \mathrm{sec})$ & $(\mathrm{m} / \mathrm{s} \in \mathrm{c})$ & & $\left(\mathrm{N} / \mathrm{m}^{2}\right)$ & $(p s i)$ & (W) & & & & Film & Wall \\
\hline 0.005 & 4.141 & 0.268 & 10 & 25,363 & 98,525 & 14.3 & 15.77 & 0.38 & 194 & 25,936 & 12.3 & 4.2 \\
\hline 0.010 & 9,066 & 0.588 & 5.5 & 27,761 & 14,490 & 2.1 & $5.1^{\circ}$ & 0.056 & 209 & 13,977 & 22.7 & 8.4 \\
\hline 0.015 & 14.773 & 0.96 & 3.98 & 30,159 & 4,983 & 0.72 & 2.84 & 0.02 & 224 & 9,981 & 32 & 12.6 \\
\hline $0: 020$ & 21.264 & 1.38 & 3.3 & 32,557 & $2,412^{\circ}$ & 0.35 & 1.98 & 0.009 & 240 & 7,977 & 40 & 16.7 \\
\hline 0.025 & 28.538 & 1.85 & $2.7 \pi$ & 34,955 & 1,404 & 0.20 & 1.55 & 0.0054 & 254 & 6,770 & 47 & 21 \\
\hline 0.030 & 36.596 & 2.37 & $2.4 i$ & 37,354 & 915 & 0.132 & 1.29 & 0.003 & 268 & 5,960 & 53.4 & 25.1 \\
\hline 0.035 & 45,436 & 2.95 & 2.25 & 39,752 & 645 & 0.093 & 1.13 & 0.0025 & 282 & 5,380 & 59 & 29.3 \\
\hline 0.040 & 55,061 & 3.57 & 2.09 & 42,151 & 480 & 0.07 & 1.02 & 0.0019 & 296 & 4,942 & 64.4 & 33.5 \\
\hline 0.045 & 65,468 & 4.25 & 1.96 & 44,549 & 372 & 0.054 & 0.942 & 0.0014 & 310 & 4,599 & 69.2 & 37.7 \\
\hline 0.050 & 76,659 & 4.98 & 1.86 & 46,948 & 298 & 0.043 & 0.88 & 0.0012 & 324 & 4,323 & 73.6 & 41.9 \\
\hline
\end{tabular}

Talsle A3.8. Output data for salt at $7 \mathrm{~atm}, \Delta T=10^{\circ} \mathrm{c} / \mathrm{m}$, and wall loading of $3 \mathrm{Mw} / \mathrm{m}^{2}$

\begin{tabular}{|c|c|c|c|c|c|c|c|c|c|c|c|c|}
\hline \multirow{2}{*}{$\begin{array}{l}d_{0} \\
(m)\end{array}$} & \multirow{2}{*}{$\begin{array}{c}Q \\
(W)\end{array}$} & \multirow{2}{*}{$\begin{array}{c}\dot{\mathrm{m}} \\
(\mathrm{kg} / \mathrm{sec})\end{array}$} & \multirow{2}{*}{$\begin{array}{c}V \\
(\mathrm{~m} / \mathrm{sec})\end{array}$} & \multirow[t]{2}{*}{$N_{R}$} & \multirow{2}{*}{$\begin{array}{c}\Delta \mathrm{P} \\
\left(\mathrm{N} / \mathrm{m}^{2}\right)\end{array}$} & \multirow{2}{*}{$\begin{array}{l}\Delta P \\
(p s i)\end{array}$} & \multirow{2}{*}{$\begin{array}{l}P P \\
(W)\end{array}$} & \multirow[t]{2}{*}{ qPP } & \multirow[t]{2}{*}{$\mathrm{Nu}$} & \multirow[t]{2}{*}{$\overline{\mathrm{h}}$} & \multicolumn{2}{|c|}{$\Delta T\left({ }^{\circ} \mathrm{C}\right)$} \\
\hline & & & & & & & & & & & Film & Wall \\
\hline 0.005 & 6,212 & 0.4 & 15.1 & 38,045 & 204,414 & 29.6 & 49 & 0.79 & 272 & 36,312 & 13.1 & 6.3 \\
\hline 0.010 & 13,599 & $0: 88$ & $8 . \geq 6$ & 41,642 & $.30,063$ & 4.36 & 15.8 & 0.116 & 293 & 19,570 & 24.4 & 12.6 \\
\hline 0.015 & 22,160 & 1.44 & 5.98 & 45,239 & 10,340 & 1.5 & 8.86 & 0.04 & 314 & 13,975 & 34.2 & 18.8 \\
\hline 0.020 & 31,896 & 2.07 & 4.35 & 48,836 & 5,006 & 0.726 & 6.17 & 0.02 & 335 & 11,168 & 42.7 & 25.1 \\
\hline 0.025 & 42,808 & 2.78 & 4.16 & 52,433 & 2,913 & 0.423 & 4.82 & 0.011 & 355 & 9,477 & 50.4 & 31.4 \\
\hline 0.030 & 54,894 & 3.56 & 3.7 & 56,031 & 1,899 & 0.275 & 4.03 & 0.007 & 375 & 8,345 & 57.2 & 37.7 \\
\hline 0.035 & $6 \varepsilon, 155$ & 4.42 & 3.38 & 59,628 & 1,338 & 0.194 & 3.52 & 0.005 & 395 & 7,532 & 63.4 & 44 \\
\hline 0.040 & $8 \hat{c}, 591$ & 5.36 & 3.73 & 63,226 & 996 & 0.144 & 3.18 & 0.004 & 415 & 6,919 & 69 & 50.2 \\
\hline 0.045 & $9 \varepsilon, 202$ & 6.37 & 2.94 & 66,824 & 772 & 0.112 & 2.93 & 0.003 & 434 & 6,439 & 74.1 & 56.5 \\
\hline 0.050 & 114,989 & 7.46 & 2.79 & 70,422 & 619 & 0.09 & 2.75 & 0.0024 & 454 & 6,053 & 78.9 & 62.8 \\
\hline
\end{tabular}


Table A3.9. Outpu: datz for salt at $7 \mathrm{~atm}, \Delta \mathrm{T}=10^{\circ} \mathrm{C} / \mathrm{m}$, and wall luacing of $4 \mathrm{MW} / \mathrm{m}^{2}$

\begin{tabular}{|c|c|c|c|c|c|c|c|c|c|c|c|c|}
\hline \multirow{2}{*}{$\begin{array}{l}d_{0} \\
(m)\end{array}$} & \multirow{2}{*}{$\begin{array}{c}Q \\
(N)\end{array}$} & \multirow{2}{*}{$\begin{array}{c}\dot{n} \\
(\mathrm{~kg} / \mathrm{sec})\end{array}$} & \multirow{2}{*}{$\begin{array}{c}V \\
(n \cdot \sec )\end{array}$} & \multirow[t]{2}{*}{$N_{R}$} & \multirow{2}{*}{$\begin{array}{c}\Delta^{2} \\
\left(N / n^{2}\right)\end{array}$} & \multirow{2}{*}{$\begin{array}{c}\Delta p \\
(p s i)\end{array}$} & \multirow{2}{*}{$\begin{array}{l}P P \\
(W)\end{array}$} & \multirow[t]{2}{*}{ qPp } & \multirow[t]{2}{*}{$\mathrm{NL}$} & \multirow[t]{2}{*}{$\bar{h}$} & \multicolumn{2}{|c|}{$\Delta T\left({ }^{\circ} \mathrm{C}\right)$} \\
\hline & & & & & & & & & & & $\mathrm{Film}$ & Wall \\
\hline 0.005 & 8,283 & 0.5 .37 & 20.1 & 50,727 & 340,0100 & 49.7 & 109.8 & 1.32 & $34 E$ & 46,105 & 13.8 & 8.4 \\
\hline 0.010 & 18,132 & 1.17 & 11 & 55,523 & 50,457 & 7.32 & 35.36 & 0.19 & $37 c$ & 24,848 & 25.6 & 16.7 \\
\hline 0.015 & 29,547 & 1.90 & 7.97 & 60,319 & 17,354 & 2.52 & 19.8 & 0.067 & $40 C$ & 17,744 & 36 & 25.1. \\
\hline 0.020 & 42,529 & $2 . T 5$ & $6.4 E$ & 6,115 & 8,432 & 1.22 & 13.8 & 0.032 & 425 & 14,180 & 45 & 33.5 \\
\hline 0.025 & 57,077 & 3.7 & 5.5 & 6,911 & 4,839 & 0.71 & 10.8 & 0.02 & 451 & 12,034 & .53 & 41.1 \\
\hline 0.030 & 73,192 & 4.75 & 4.94 & 74,708 & 3,138 & 0.46 & 9.02 & 0.0123 & $47 \%$ & 10,596 & 60.1 & 50.2 \\
\hline 0.035 & 90,873 & 5.9 & 4.5 & 79,505 & 2,275 & 0.32 & 7.88 & 0.0087 & $50 \bar{c}$ & 9,563 & 66.5 & 58.6 \\
\hline 0.040 & 110,122 & 7.15 & 4.18 & 84,302 & 1,671 & 0.24 & 7.1 & 0.0065 & $52 i$ & 8,785 & 72.4 & 67 \\
\hline 0.045 & 130,937 & 8.5 & 3.9 & $\$, 100$ & 1,237 & 0.188 & 6.5 & 0.005 & 551 & 8,176 & 77.8 & 75.4 \\
\hline 0.050 & 153,319 & 9.9 & 3.72 & 93,397 & 1,039 & 0.15 & 6.15 & 0.004 & $57 \epsilon$ & 7,686 & 82.8 & 83.7 \\
\hline
\end{tabular}

Tatle A3 10. Output deta for salt at $7 \mathrm{~atm}, \Delta \mathrm{T}=10^{\circ} \mathrm{C} / \mathrm{m}$, and wall coating of $5 \mathrm{MW} / \mathrm{m}^{2}$

\begin{tabular}{|c|c|c|c|c|c|c|c|c|c|c|c|c|}
\hline \multirow{2}{*}{$\begin{array}{l}d_{0} \\
(m)\end{array}$} & \multirow{2}{*}{$\begin{array}{c}Q \\
(W)\end{array}$} & \multirow{2}{*}{$\begin{array}{c}\dot{m} \\
(k g / s e c)\end{array}$} & \multirow{2}{*}{$\begin{array}{c}l \\
(\mathrm{~m} / \mathrm{sec})\end{array}$} & \multirow[t]{2}{*}{$N_{R}$} & \multirow{2}{*}{$\begin{array}{c}\angle B \\
\left(N / n^{2}\right)\end{array}$} & \multirow{2}{*}{$\begin{array}{c}\Delta P \\
(p s i) .\end{array}$} & \multirow{2}{*}{$\begin{array}{l}P P \\
(W)\end{array}$} & \multirow[t]{2}{*}{ qPP } & \multirow[t]{2}{*}{$\mathrm{Nu}$} & \multirow[t]{2}{*}{$\bar{h}$} & \multicolumn{2}{|c|}{$\Delta T\left({ }^{\circ} \mathrm{C}\right)$} \\
\hline & & & & & & & & & & & Film & Wall \\
\hline 0.005 & 10,353 & $3.6^{\circ}$ & 25.1 & 63,409 & 500,000 & 74.4 & 205 & 1.98 & 415 & 55,487 & 14.3 & 10.5 \\
\hline 0.010 & 22,665 & $1.4^{7}$ & 13.7 & 69,404 & 75,398 & 10.9 & 66 & 0.29 & 443 & 29,903 & 26.6 & 20.9 \\
\hline 0.015 & 36,934 & 2.4 & 9.97 & 5,398 & 25,933 & 3.76 & 37 & 0.10 & 480 & 21,354 & 37.3 & 31.4 \\
\hline 0.020 & $53, i 61$ & 3.45 & 8.07 & 81,394 & 12,555 & 1.82 & 25.8 & 0.048 & 512 & 17,066 & 46.6 & 41.8 \\
\hline 0.025 & 71,346 & 4.63 & 6.93 & 87,389 & 7,305 & 1.05 & 20.1 & 0.028 & 543 & 14,482 & 55 & 52.3 \\
\hline 0.030 & 490, ו9 & 5.94 & 6.17 & 93,385 & $4, .764$ & 0.69 & 16.8 & 0.0184 & 577 & 12,752 & 62.4 & 62.8 \\
\hline 0.035 & 113,592 & $7.3^{7}$ & 5.63 & 99,381 & 3,355 & 0.486 & 14.7 & 0.013 & 607 & 11,509 & 69.1 & 73.3 \\
\hline 0.040 & 137,652 & 3.9 & 5.2 & 105,377 & $2,<98$ & 0.362 & 13.2 & 0.0047 & 637 & 10,573 & 75.2 & 83.7 \\
\hline 0.045 & 163,671 & 13.6 & 4.9 & 11,374 & $1, \subseteq 38$ & 0.28 & 12.2 & 0.0075 & 667 & 9,840 & $80: 9$ & 94.2 \\
\hline 0.050 & 191,649 & 12.4 & 4.65 & 17,371 & 1,553 & 0.22 & 11.5 & 0.006 & 693 & 9,250 & 86 & 105 \\
\hline
\end{tabular}


APPENDIX 4

SELECTIONS FROM THE ASME BOILER CODE ON ALTERNATING STRESSES

The following material provides information on stress and stress analysis which is useful in analyzing the requirements for fusion reactors. 
ASME BOILER AND PRESSURE VESSEL CODE An American National Standard

\section{SECTION III-DIVISION 1}

Rules for Construction of

Nuclear Power Plant Components

\section{SUBSECTION NB \\ Class 1 Components}

1974 EDITION

July 1,1974

ASME BOILER AND PRESSURE. VESSEL COMMITTEE SUBCOMMITTEE UN NUCLEAR PUWEK

THE AMERICAN SOCIETY OF MECHANICAL ENGINEERS UNITED ENGINEERING CENTER 
(a) Principal Stresses-Consider the values of the three principal stresses at the point versus time for the complete stress cycle taking into account both the gross and local structural discontinuities and the thermal effects which vary during the cycle. These are designated as $\sigma_{1}, \sigma_{2}$, and $\sigma_{3}$ for later identification.

(b) Stress Differences-Determine the stress differences $S_{12}=\sigma_{1}-\sigma_{2} . S_{23}=\sigma_{2}-\sigma_{3}, S_{31}=\sigma_{3}-\sigma_{1}$ versus time for the complete cycle. In what follows, the symbol $S_{i j}$ is used to represent any one of these three stress differences.

(c) Alternating Stress Intensity-Determine the extremes of the range through which each stress difference $\left(S_{i j}\right)$ fluctuates and find the absolute magnitude of this range for each $S_{i j}$. Call this magnitude $S_{r i j}$ and let $S_{\mathrm{alt} i j}=0.5 S_{r i j}$. The alternating stress intensity, $S_{\mathrm{alt}}$, is the largest of the $S_{\mathrm{alt} i j}$ 's.

NB-3216.2 Varying Principal Stress Direction. For any case in which the directions of the principal stresses at the point being considered do change during the stress cycle, it is necessary to use the more general procedure of (a) through (e) belcw.

(a) Consider the values of the six stress components, $\sigma_{t}, \sigma_{l}, \sigma_{n} \tau_{l l}, \tau_{l m} \tau_{r l}$, versus time for the complete stress cycle, taking into account both the gross and local structural discontinuities and the thermal effects which vary during the cycle.

(b) Choose a point in time when the conditions are one of the extremes for the cycle (either maximum or minimum, algebraically) and identify the stress components at this time by the subscript $i$. In most cases it will be possible to choose at least one time during the cycle when the conditions are known to be extreme. In some cases it may be necessary to try different points in time to find the one which results in the largest value of alternating stress intensity.

(c) Subtract each of the six stress components, $\sigma_{t i}$, $\sigma_{l i}$, from the corresponaing stress components, $\sigma_{l}, \sigma_{l}$, etc., at each point in time during cycle and call the resulting components, $\sigma^{\prime}{ }^{\prime}, \sigma^{\prime}$, etc.

(d) At each point in time during the cycle, calculate the principal stresses, $\sigma^{\prime}{ }_{1}, \sigma_{2}^{\prime}, \sigma^{\prime}{ }_{3}$, derived from the six stress components, $\sigma^{\prime}{ }^{\prime}, \sigma^{\prime}$, etc. Note that the directions of the principal stresses may change during the cycle but each principal stress retains its identity as it rotates.

(e) Determine the stress differences $S_{12}^{\prime}=\sigma^{\prime}{ }_{1} \sigma_{2}^{\prime}$, $S_{23}^{\prime}=\sigma_{2}^{\prime}-\sigma_{3}^{\prime}, S_{31}^{\prime}=\sigma_{3}^{\prime}-\sigma_{1}^{\prime}$, versus time for the complete cycle and find the largest absolute magnitude of any stress difference at any time. The alternating stress intensity, $S_{\mathrm{al}}$, is one-half of this magnitude. 


\section{NB-3214 Stress Analysis}

A detailed stress analysis of all major structural components shall be prepared in sufficient detail to show that each of the stress limitations of NB-3220 and NB-3230 is satisfied when the component is subjected to the loadings of NB-3110. As an aid to the evaluation of these stresses, formulas, and methods for the solution of certain recurring problems have been placed in Appendix A.

\section{NB-3215 Derivation of Stress Intensitics}

One requirement for the acceptability of a design is that the calculated stress intensities shall not exceed specified allowable limits. These limits differ depending on the stress category from which the stress intensity is derived. This paragraph describes the procedure for the calculation of the stress intensities which are subject to the specified limits. The steps in the procedure are stipulated in the following subparagraphs.

(a) At the point on the component which is being investigated, choose an orthogonal set of coordinates such as tangential, longitudinal, and radial, and designate them by the subscripts $t, l$, and $r$. The stress components in these directions are then designated $\sigma_{10}$ $\sigma_{l}$, and $\sigma_{r}$ for direct stresses and $\tau_{l r} \tau_{l r}$ and $\tau_{r l}$ for shearing stresses.

(b) Calculate the stress components for each type of loading to which the part will be subjected and assign each set of stress values to one or a group of the following categories: ${ }^{1}$

(l) General primary membrane stress, $P_{m}$ (NB3213.8):

'See Tables NB-3217-1 and NB-3217-2 and Nute $I$ of Figure NB3221-1.
(2) Local primary membrane stress, $P_{L}$ (NB3213.10);

(3) Primary bending stress, $P_{b}$ (NB-3213.7 and NB-3213.8);

(4) Expansion stress, $P_{c}$ (NB-3213.20);

(5) Secondary stress, $Q$ (NB-3213.9);

(6) Peak stress, $F$ (NB-3213.11). NB-3217 provides guidance for this step.

(c) For each category, calculate the algebraic sum $o^{*}$ the $\sigma_{\text {, }}$ 's which result from the different types of loadings and similarly for the other five stress components. Certaln combinations of the categories must also he considered.

(d) Tranelate the etrese componente for the $t, l$, and $r$ directions into principal stresses, $\sigma_{1}, \sigma_{2}$, and $\sigma_{3}$. In many pressure component calculations, the $t, l$, and $r$ directions may be so chosen that the shearing stress components are zero and $\sigma_{1}, \sigma_{2}$, and $\sigma_{3}$ are identical to $\sigma_{t}, \sigma_{l}$, and $\sigma_{r}$.

(e) Calculate the stress differences $S_{12}, S_{23}$, and $S_{31}$ from the relations

$$
\begin{aligned}
& S_{12}=\sigma_{1}-\sigma_{2} \\
& S_{23}=\sigma_{2}-\sigma_{3} \\
& S_{31}=\sigma_{3}-\sigma_{1}
\end{aligned}
$$

The stress intensity, $S$. is the largest absolute value of $S_{12}, S_{23}$, and $S_{31}$.

Note: Membrane stress intensity is derived from the stress components averaged across the thickness of the section. The averaging shall be performed at the component level, in step (b) or (c) above.

\section{NB-3216 Derivation of Stress Differences}

If the specified operation of the component does not meet the conditions of NB-3222.4(d), the ability of the component to withstand the specified cyclic operation without fatigue failure shall be determined as provided in NB-3222.4(e). The determination shall be made on the basis of the stresses at a point of the component and the allowable stress cycles shall be adequate for the specified operation at every point. Only the stress differences due to operational cycles as specified in the Design Specification need be considered.

NB-3216.1 Constant Principal Stress Direction. For any case in which the directions of the principal stresses at the point being considered do not change during the cycle. the steps stipulated in the following subparagraphs shall he taken to determine the alternating stress intensity. 
ASME BOILER AND PRESSURE VESSEL CODE An Amcrican National Standard

\title{
SECTION III-DIVISION 1
}

Rules for Construction of Nuclear Power Plant Components

\author{
SUBSECTION NA \\ General Requirements \\ (Includes All Appendices)
}

1974 EDITION

July 1,1974

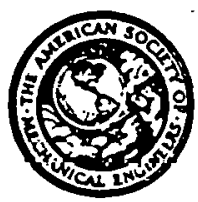

ASME BOILER AND PRESSURE VESSEL COMMITTEE SUBCOMMITTEE ON NUCLEAR POWER 


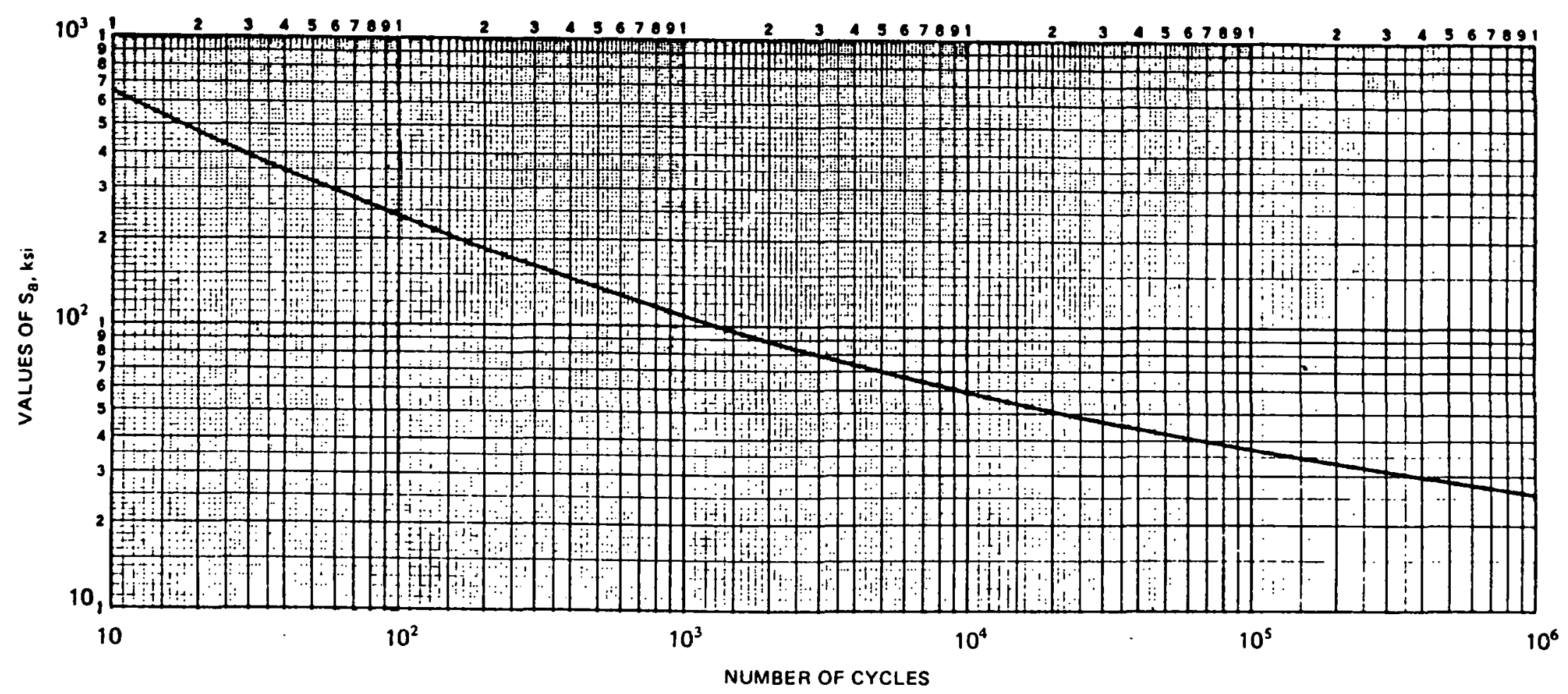

NOTE:

$E=26.0 \times 10^{\circ} \mathrm{psi}$

FIG. 1-9.2 DESIGN FATIGUE CURVE FOR AUSTENITIC STEELS, NICKEL-CHROMIJM-IRON ALLOY, NICKEL-IRON-CHROMIUM ALLOY AND NICKEL-COPPER ALLOY 
APPENDIX 5

STRESSES AT THE BEND OF A

U-SHAPED TUBE

To find the stresses in the U-shaped tube shown in Fig. A5.1, we may consider only half the tube because of symmetry. The conditions shown in Fig. A5.1 (tube free at one end and subjected to nonuniform heating) will result in the tube deformation shown in Fig. A5.2.

The compatibility equations are

$B-\theta_{c}=a M+b V$,

$\theta_{c}-\beta_{2}=e M-f V$,

$\delta_{1}=b M+c V$,

$\delta_{2}=f M-g V$,

and

$\Delta_{1}-\Delta_{2}=\delta_{1}+\vec{\delta}_{2}$,

where $a, b, c, e, f$, and $g$ are influence coefficients and $V, M, \delta_{1}, \delta_{2}$, and $\theta_{c}$ are unknowns. We can calculate the influence coefficients and $B_{1}$, $\beta_{2}, \Delta_{1}$, and $\Delta_{2}$ given the assumption that the tube will bend like a beam and the plane section will remain plane. From Fig. A5.3, we can deduce

$\frac{\rho}{\rho \mathrm{d} \theta}=\frac{r}{\rho \mathrm{d} \theta \frac{\Delta \mathrm{T} \alpha}{2}}$

where $\alpha \equiv$ coefficient of expansion of tube mate-

rial. Thus,

$\rho=\frac{2 r}{\alpha \Delta T}$,

$\dot{B}_{1}=\ell / \rho$,

and

$\Delta_{1}=\rho\left(1-\cos B_{1}\right)$.
For the circular tube illustrated in Fig. A5.4, $e^{\prime}=\frac{2 r}{\alpha \Delta T}$, $\beta_{2}=\frac{\pi R}{2 r} \alpha \Delta T$,

and

$\Delta_{2}=\alpha \frac{\left(T_{H}+T_{C}\right)}{2}$.

We calculate the influence coefficients as.

$$
\begin{aligned}
& a=\frac{\ell}{E I}, b=\frac{\ell^{2}}{2 E I}, c=\frac{\ell^{3}}{3 E I}, e=\frac{\pi R}{2 E I}, \\
& f=\frac{R^{2}}{E I}\left(\frac{\pi}{2}-1\right), g=\frac{R^{3}}{E I}\left(\frac{3 \pi}{4}-2\right),
\end{aligned}
$$

where $E$ is the modulus at average material temperature and $I=\pi r^{3} t$.

Therefore,

$$
\begin{aligned}
& \frac{\ell \alpha \Delta T}{2 r}-\theta_{C}=\frac{\ell}{E I} M+\frac{\ell^{2}}{2 E I} V \\
& -\frac{\pi}{2}\left(1-\frac{\alpha \Delta T}{2} \frac{R}{r}\right)+\theta_{c}=\frac{\pi R}{2 E I} M-\frac{R^{2}}{E I}\left(\frac{\pi}{2}-1\right) V,
\end{aligned}
$$

$\delta_{1}=\frac{\ell^{2}}{2 E I} M+\frac{\ell^{3}}{3 E I} V$,

$\delta_{2}=\frac{R^{2}}{E I}\left(\frac{\pi}{2}-1\right) M-\frac{R^{3}}{E I}\left(\frac{3}{4} \pi-2\right) V$,

and

$\frac{2 r}{\alpha \Delta T}\left[1-\cos \left(\frac{\ell \alpha \Delta T}{2 r}\right)\right]-\alpha \frac{\left(T_{H}+T_{C}\right) R}{2}=\delta_{1}+\delta_{2}$.

We may solve Eqs. (A5.6) through (A5.9) simultaneously and parametrically. We are able to vary $R, t, l, r, \Delta T$ within the system constraints to see what happens to stress. 


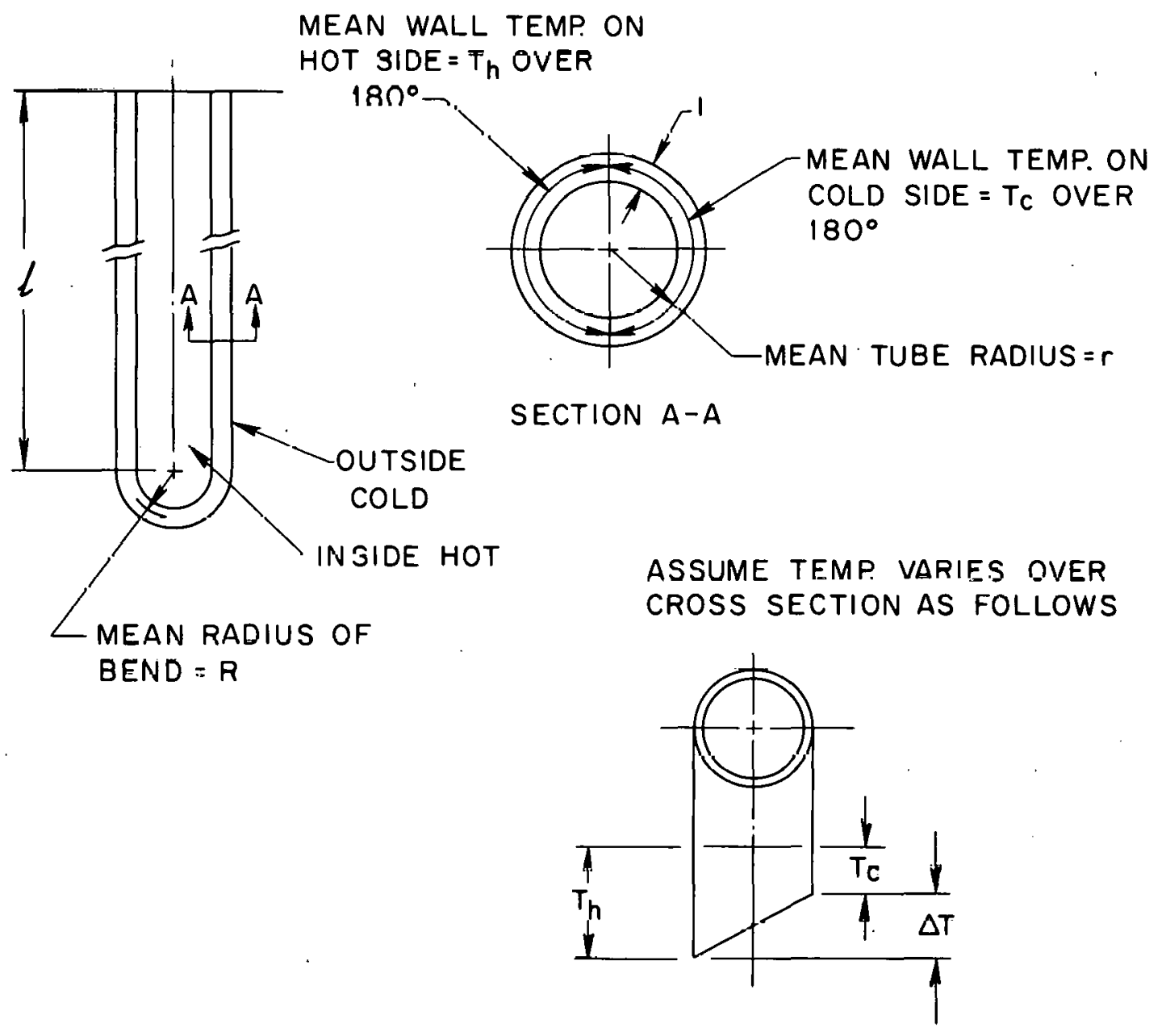

Fig. A5.1. Stresses in a U-shaped tube. 

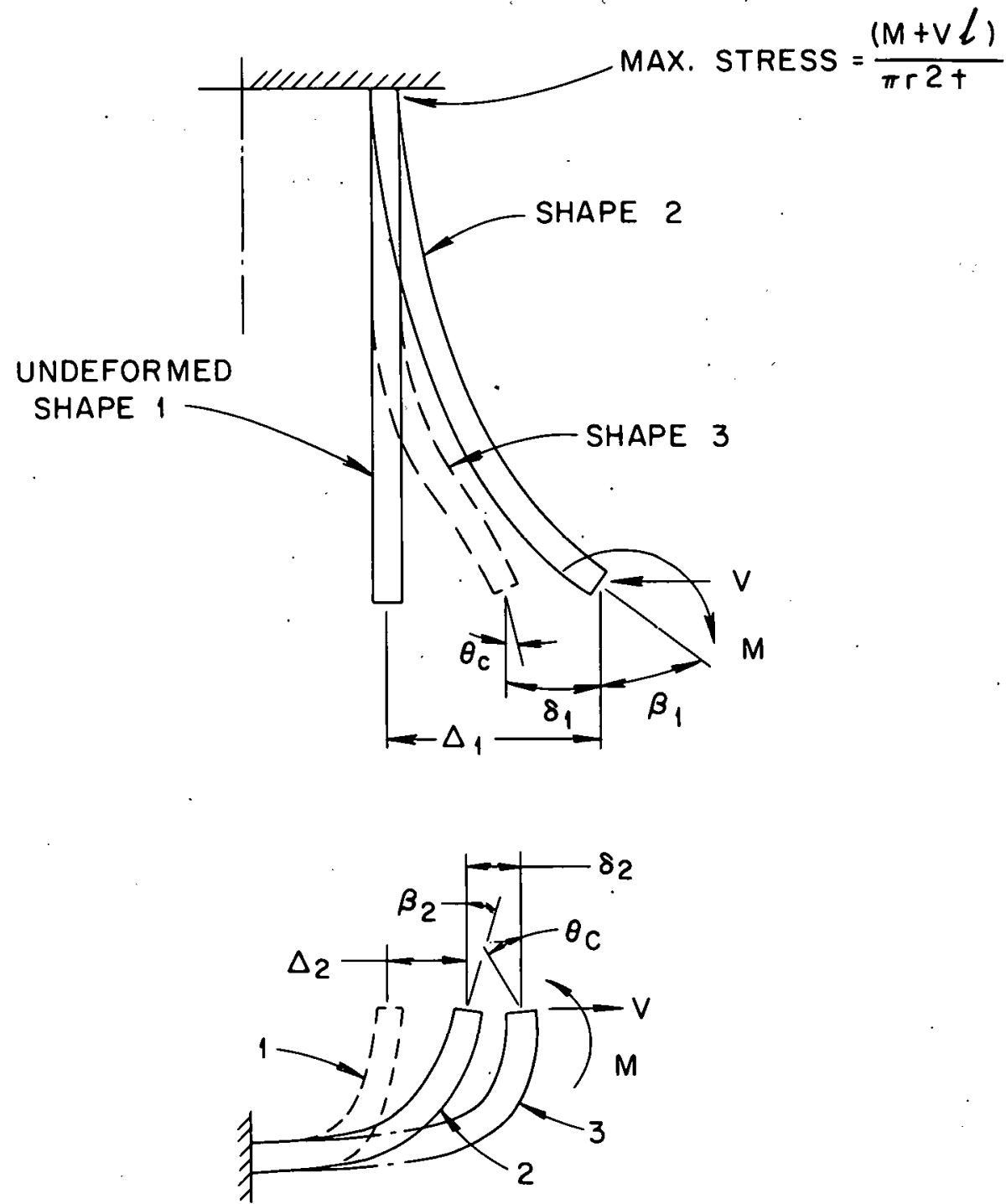

Fig. A5.2. Deformation of U-shaped tube. Shape 2 is the shape the tube would assume if it were free on the end and heated as shown. Shape 3 is the final shape of the tube. $V$ is the internal shear force and $M$ is the moment induced in the tube. 


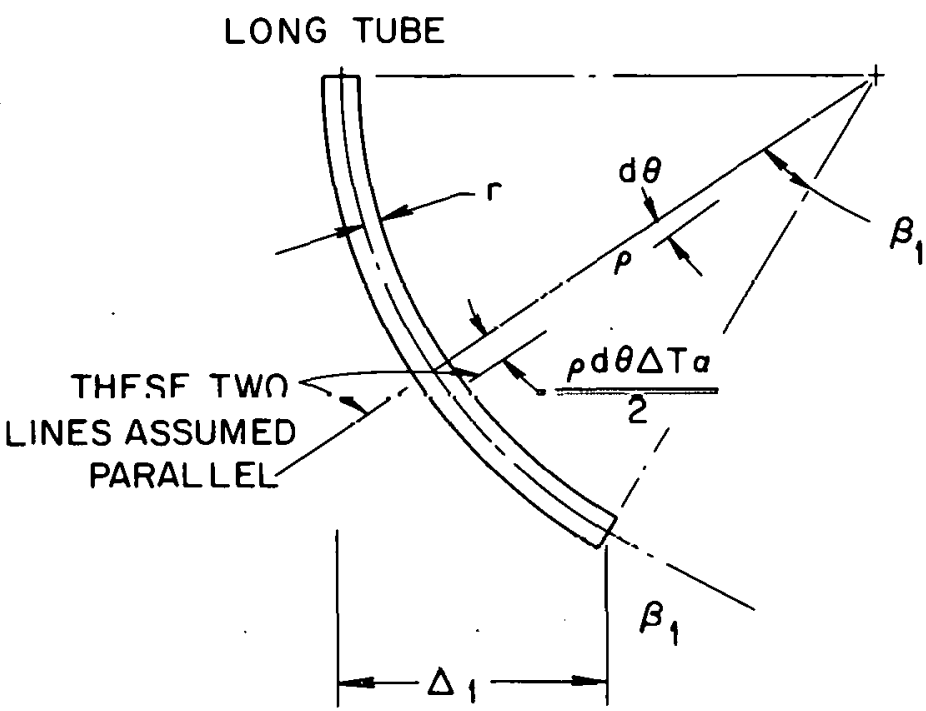

Fig. A5.3. Deformation in a long tube.

ORNL / OWG / FED - T T 370

CIRCULAR TUBE

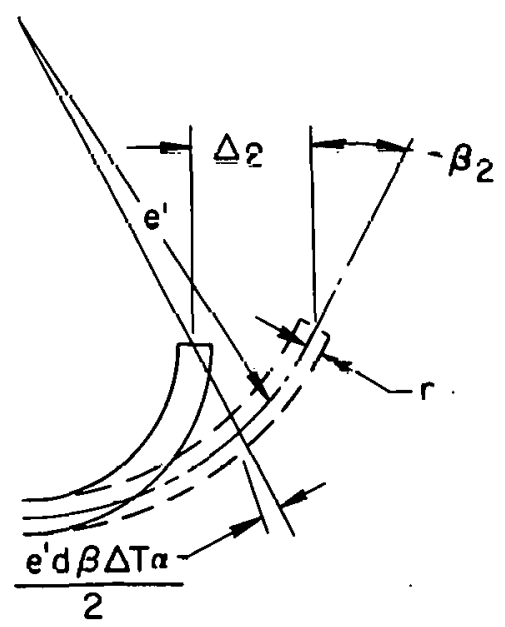

Fig. A5.4. Deformation in a circular tube. 
APPENDIX 6

EQUATION FOR TEMPERATURE PROFILES

IN THE LITHIUM

For steady-state temperatures in a onedimensional system with internal heat sources, $\frac{d^{2} t}{d x^{2}}+\frac{\dot{q}}{k}=0$

For a fusion reactor blanket the internal heat deposition is exponential so that

$\frac{d^{2} t}{d x^{2}}=\frac{-Q_{0} e^{-\mu x}}{k}$,

where

$\dot{q}=Q_{0} e^{-\mu x}$,

$\frac{d t}{d x}=\frac{Q_{0} e^{-\mu x}}{k \mu}+C_{1}$,

$t=\frac{-Q_{0} e^{-\mu x}}{k \mu^{2}}+c_{1} x+c_{2}$

In establishing the temperatures in the lithium in the cassette units, we use the boundary conditions shown in Fig. A6.l and the following definitions:

$t=t_{1}$ at $x=0$,

$t=t_{2}$ at $X=L$,

$d t / d x=0$ at $X=L$.

From these conditions we may calculate $t_{1}$ and $t_{2}$,

$t_{1}=\frac{-Q_{0}}{k \mu^{2}}+c_{2}$
$t_{2}=\frac{-Q_{0} e^{-\mu L}}{k \mu^{2}}+c_{1} L+c_{2}$

where

$c_{1}=\frac{-Q_{0} e^{-\mu L}}{k \mu}$.

Subtracting Eq. (A6.6) from Eq. (A6.7) yields

$t_{2}-t_{1}=\frac{-Q_{0} e^{-\mu L}}{k \mu^{2}}+c_{1} L+\frac{Q_{0}}{k \mu^{2}}$.

Substituting the value of $C_{1}$ [from Eq. (A6.8)] into Eq. (A6.9), we obtain

$t_{2}-t_{1}=\frac{-Q_{0} e^{-\mu L}}{k \mu^{2}}+\left(\frac{-Q_{0} e^{-\mu L}}{k \mu} L\right)+\frac{Q_{0}}{k \mu^{2}}$.

Thus, the temperature at $L$ is

$t_{L}-t_{1}=\frac{Q_{0}}{k \mu^{2}}\left(-e^{-\mu L}-\mu L e^{-\mu L}+1\right)$,

and for the temperature distribution within the region of thickness $L$ (when $X<L$ ) we have

$t-t_{1}=\frac{Q_{0}}{k \mu^{2}}\left(e^{-\mu x}-\mu x e^{-\mu L}+1\right)$.

and 


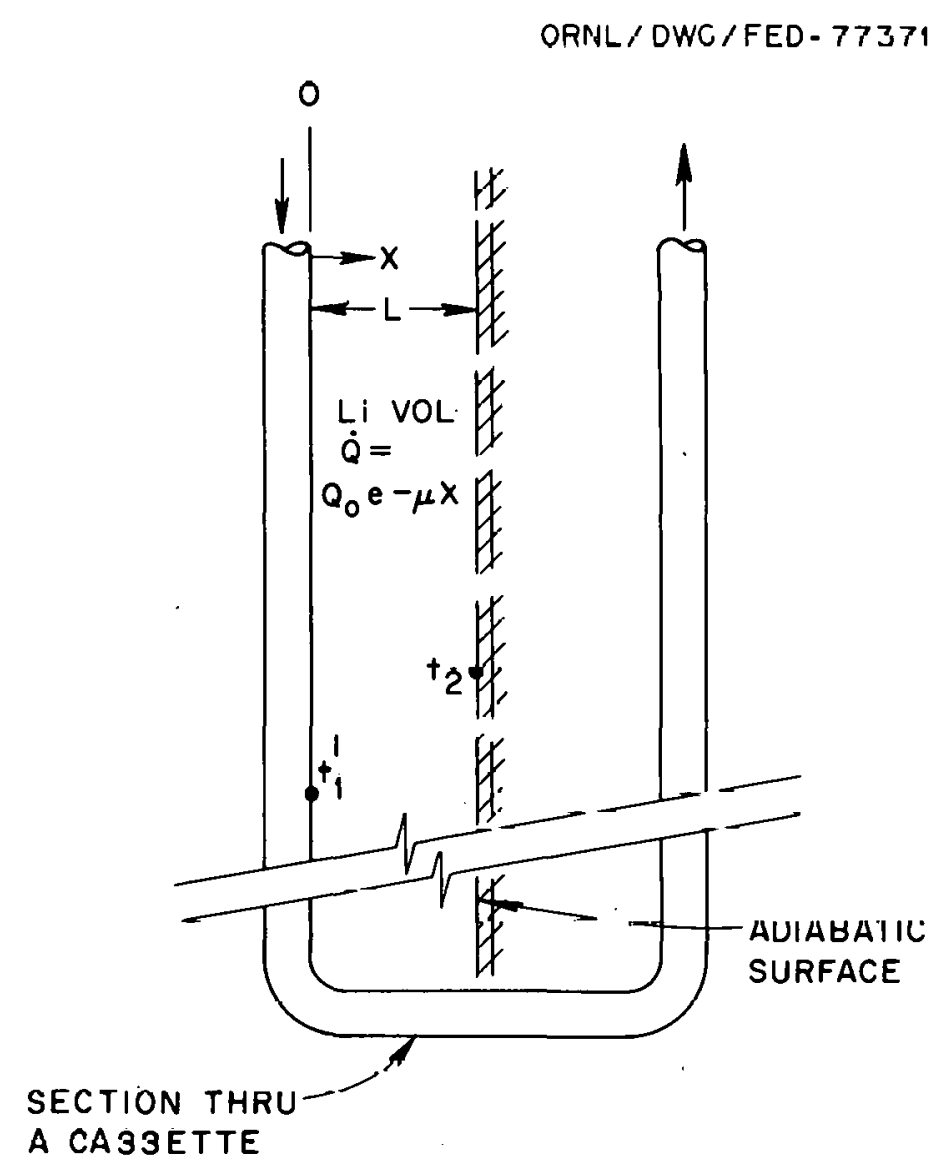

Fig. Ab.i. Boundary conditiuis fur calculating temperatures in lithium. 
INTERNAL DISTRIBUTION

I. R. G. Alsmiller, Jr.

2. B. R. Appleton

3. J. K. Ballou

4. L. A. Berry

5. E. S. Bettis

6. E. H. Bryant

7. J. D. Callen

8. D. D. Cannon

9-10. Central Research Library

11-30. J. F. Clarke

31. R. E. Clausing

32. S. D. Clinton

33. R. J. Colchin

34. F. L. Culler

35. R. A. Dandl

36. S. Datz

37. J. H. DeVan

38. R. A. Dory

39. L. Dresner

40. J. L. Dunlap

41. P. Fisher

42. A. P. Fraas

43-44. Fusion Energy Division Library

45. Fusion Energy Division Reports Office

46. T. A. Gabriel

47. M. L. Grossbeck

48. P. N. Haubenreich

49. J. T. Hogan

50. J. Horak

51. T. J. Huxford

52. G. G. Kelley

53. G. Krist

54. Laboratory Records

55. Laboratory Records - ORNL-RC

56. C. G. Lawson

57. M. S. Lube 11

\author{
58. J. W. Lue \\ 59. F. B. Marcus \\ 60. B. F. Maskewitz \\ 61. J. May \\ 62. P. J. Maziasz \\ 63. W. McAfee \\ 64. H. E. McCoy \\ 65. H. C. McCurdy \\ 66. A. T. Mense \\ 67. R. V. Miskell \\ 68. 0. B. Morgan \\ 69. ORNL Patent Office \\ 70. $Y-K$. M. Peng \\ 71. H. Postma \\ 72. R. L. Reid \\ 73. M. Roberts \\ 74. M. T. Robinson \\ 75. M. W. Rosenthal \\ 76. R. T. Santoro \\ 77. G. Schilling \\ 78. J. L. Scott \\ 79. J. E. Selle \\ 80. T. E. Shannon. \\ 81. P. Spampinato \\ 82. D. Steiner \\ 83. L. D. Stewart \\ 84. W.C.T. Stoddart \\ 85. N. A. Uckan \\ 86. J. S. Watson \\ 87. H. L. Watts \\ 88. W. Wells \\ 89-122. R. Werner \\ 123. F. W. Wiffen \\ 124. H. T. Yeh \\ 125. $Y-12$ Document Reference Section
}

EXTERNAL DISTRIBUTION

126. D. Anthony, General Electric Co., Building 2, Room 447, I River Rd., Schenectady, NY 12345

127. Peper L. Auer, Laboratory of Plasma Studies, Cornell University, 312 Upson Hall, Ithaca, NY 14853

128. C. C. Baker, General Atomic Co., San Diego, CA 92138

129. J. Baublitz, Division of Magnetic Fusion Energy, Energy Research and Development Administration, Washington, $D C$

130. J. Beal, Division of Magnetic Fusion Energy, Energy Research and Development Administration, Washington, UC

131. J.W. Bennett, Division of Reactor Development and Demonstration, Energy Research and Development Administration, Washington, DC 20545

132. R. Blanken, Division of Magnetic Fusion Energy, Energy Research and Development Administration, Washington, DC 20545

133. S. L. Bogart, Division of Magnetic Fusion Energy, Energy Research and Development Administration, Washington, DC 20545

134. Keith A. Brueckner, Department of Physics, University of California at San Diego, La Jolla, CA 92037

135. Sol Buchsbaum, Vice President, Network Planning and Customer Services, Bell Laboratories - Room 2 G 610, Holmdel, NJ 07733

136. R. N. Cherdack, Burns and Roe Inc., 283 Highway 17, Paramus, NJ 07652

137. F. E. Coffman, Division of Magnetic Fusion Energy, Energy Research and Development Administration, Washington, DC 20545

138. M. Cohen, Division of Magnetic Fusion Energy, Energy Research and Development Administration, Washington, DC 20545

139. R. W. Conn, Nuclear Engineering Department, University of Wisconsin, Madison, WI 53706

140. Library, Culham Laboratory, Abingdon, 0xon, 0X14 3DB, United Kingdom

141. E. Dalder, Division of Magnetic Fusion Energy, Energy Research and Development Administration, Washington, DC 20545

142. N. Anne Davies, Division of Magnetic Fusion Energy, Energy Research and Development Administration, Washington, DC 20545 
143. S. 0. Dean, Division of Magnetic Fusion Energy, Energy Research and Development Administration, Washington, DC 20545

144. J. F. Decker, Division of Magnetic Fusion Energy, Energy Research and Development Administration, Washington, DC 20545

145. David A. Dingee, Manager, Fusion Programs, Pacific Northwest Laboratories, Battelle Blvd., Richland, WA 99352

146. T. Edelbaum, Charles Stark Draper Laboratories, 75 Cambridge Pkwy., Cambridge, MA 02142

147. W. R. Ellis, Division of Magnetic Fusion Energy, Energy Research and Development Administration, Washington, DC 20545

148. A. Favale, Grumman Aerospace Corp., Bethpage, NY 11714

149. C. Finfgeld, Division of Magnetic Fusion Energy, Energy Research and Development Administration, Washington, DC 20545

150. C. A. Flanagan, Westinghouse Electric Corp., Fusion Power Systems, P.0. Box 10864, Pittsburgh, PA 15236

151. H. K. Forsen, Exxon Nuclear Co., Bellevue, WA 98004

152. T. K. Fowler, University of California, Lawrence Radiation Laboratory, P.0. Box 808, Livermore, CA 34551

153. J. W. French, Westinghouse Electric Corp., Fusion Power Systems, P.0. Box 10864, Pittsburgh, PA 15236

154. H. P. Furth, Princeton Plasma Physics Laboratory, Princeton University, P.0. Box 451, Princeton, NJ 08540

155. G. Gibson, Westinghouse Electric Corp., Fusion Power Systems, P.0. Box 10864, Pittsburgh, PA 16236

156. B. Gore, Pacific Northwest Laboratories, Battelle Blvd., P.0. Box 999, Richland, WA 99352

157. M. B. Gottlieb, Princeton Plasma Physics Laboratory, Princeton University, P.0. Box 451 , Princeton, NJ 08540

158. W. C. Gough, Electric Power Research Institute, Palo Alto, CA 94304

159. Roy W. Gould, B1dg. 116-81, California Institute of Technology, Pasadena, CA 91109

160. J. Nelson Grace, Division of Magnetic Fusion Energy, Energy Research and Development Administration, Washington, DC 20545

161. Harold Grad, Courant Institute, New York University, 251 Mercer St., New York, NY 10012

162. E. Gregory, AIRCO Inc., Murray Hill, NJ 07974

163. R. Harder, General Atomic Co., San Diego, CA 92138

164. F. M. Heck, Westinghouse Electric Corp., Fusion Power Systems, P.0. Box 10864, Pittsburgh, PA 15236

165. C. Henning, Division of Magnetic Fusion Energy, Energy Research and Development Administration, Washingtori, DC 20545

166. G. Hess, Division of Magnetic Fusion Energy, [nergy Research and Development Administration, Washington, DC 20545

167. G. Hopkins, General Atomic Co., P.0. Box 608, San Diego, CA 92138

168. Anthony Hsu, Division of Magnetic Fusion Energy. Energy Research and Development Administration, Washington, DC 20545

16y. Hénry Hurwitz, General Electric Company, Kesearch and Development Center, Bui1ding K-1, Radiation, P.0. Box 8, Schenectady, NY 12301

170. A. J. Imtink, Jr., Carnegie-Mellon University, Pittsburgh, PA 15213

171. Institute for Energy Analys is, P.0. Box 117, Oak Ridge, TN 37830

172. N. E. Johnson, Mechanics Research Inc., Oak Ridge, TN 37830

173. C. K. Jones, Westinghouse Electric Corp., Research and Development Laboratory, 1130 Beulah Rd., Pittshurgh, PA 15235

174. E. E. Kintner, Division of Magnetic Fusion Energy, Energy Research and Development Administration, Washington, DC 20545

175. D. Kiein, Westinghouse Electric Corp., Fusion Power Systems, P.0. Box 10864, Pittsburgh, PA 15236

176. R. Kostoff, Division of Magnetic Fusion Energy, Energy Research and Development Administration, Washington, DC 20545

177. G. Kulcinski, Nuclear Engineering Dept., University of Wisconsin, Madison, WI 53706

178. K. Kummer, Materials and Process, McDonnell Douglas, P.0. Box 516, St. Louis, M0 63156

179. L. M. Lidsky, Dept. of Nuclear Engineering, Massachusetts Institute of Technology, Cambridge, MA 02139

180. M. Lotker, Advanced Energy Conversion Research, Northeastern Utilities Service Co., P.0. Box 270, Hartford, CT 06101

181. Bruce J. Mann, Chief, Evaluation Branch, LVF, Environmental Monitoring and Support Lab.. P.O. Box 15027, Las Vegas, NV 89114

182. V. A. Maroni, CTR Program, 208 W1 15, Argonne National Laboratory, 9700 S. Cass Ave., Argonne, IL 60439

183. R. Mason, Division of Magnetic Fusion Energy, Energy Research and Development Administration, Washington, DC 20545

184. D. G. McAlees, Exxon Nuclear Corporation, Research and Technology Center, Laser Enrichment Department, 2955 George Washington Way, Richland, WA 99352

185. R. Mills, Princeton Plasma Physics Laboratory, Princeton University, P.0. Box 451, Princeton, NJ 08540 
186. K. Moses, Division of Magnetic Fusion Energy, Energy Research and Development Administration, Washington, DC 20545

187. M. Murphy, Division of Magnetic Fusion Energy, Energy Research and Development Administration, Washington, DC 20545

188. J. 0. Neff, Division of Magnetic Fusion Energy, Energy Research and Development Administration, Washington, DC 20545

189. T. Ohkawa, General Atomic Co., San Diego, CA 92112

190. J. Powe 11, Brookhaven National Laboratory, Upton, Long Island, NY 11973

191. Plasma Physics Library, Princeton Plasma Physics Laboratory, Princeton University, P.0. Box 451 , Princeton, NJ 08540

192. J. Purce11, General Atomic Co., San Diego, CA 92112

193. Research and Technical Support Division, ERDA-ORO, P.0. Box E, Oak Ridge, TN 37830

194. T. Reuther, Division of Magnetic Fusion Energy, Energy Research and Development Administration, Washington, DC 20545

195. F. L. Ribe, Los Alamos Scientific Laboratory, P. O. Box 1663, Los Alamos, NM 87544

196. D. J. Rose, Department of Nuclear Engineering, Massachusetts Institute of Technology, Cambridge, MA 02139

197. M. N. Rosenbluth, School of Natural Sciences, Princeton University, P.0. Box 451, Princeton, NJ 08540

198. C. Rosner, Intermagnetics General Corp., Charles Industrial Park, New Karner Road, Guilderland, NY 12084

199. P. Sager, General Atomic Co., San Diego, CA 92112

200. Z. M. Shapiro, Westinghouse Electric Corp., Fusion Power Systems, P.0. Box 10864, Pittsburgh, PA 15236

201. Weston M. Stacey, Jr., ANL-CTR Program, Bldg. 208, Argonne National Laboratory, 9700 S. Cass Ave., Argonne, IL 60439

202. G. Siegle, Tennessee Valley Authority, 1360 Commerce Union Bank B1dg., Chattanooga, TN 37401

203. J. Stekly, Magnetic Corp. of America, 179. Bear Hill Rd., Wal tham, MA 02154

204. C. Taylor, Controlled Thermonuclear Research, Mail Code L-382, Lawrence Livermore Labratory, P.0. Box 808, Livermore, CA 94550

205. K. Thomassen, CTR Division, Mail Stop 640, P.0. Box 1663, Los Alamos, NM 87544

206. B. Twining, Division of Magnetic Fusion Energy, Energy Research and Development Administration, Washington, DC 20545

207. T. C. Varljen, Westinghouse Electric Corp., Fusion Power Systems, P.0. Box 10864, Pittsburgh, PA 09864

208. S. Waddle, ERDA-ORO, P.0. Box E, Oak Ridge, TN 37830

209. S. T. Wang, CTR Program, 208 Wi15, Argonne National Laboratory, 9700 S. Cass Ave., Argonne, IL 60439

210. H. J. Willenberg, Senior Research Scientist, Battelle Pacific Northwest Laboratories, Battelle Boulevard, Richland, WA 99352

211. J. Willis, Division of Magnetic Fusion Energy, Energy Research and Development Administration, Washington, DC 20545

212. W. Wilkes, Mound Laboratories, Miamiburg, $\mathrm{OH} 45432$

213. J. M. Williams, Division of Magnetic Fusion Energy, Energy Research and Development Administration, Washington, DC 20545

214. Herbert H. Woodson, Department of Electrical Engineering, University of Texas, Austin, TX 78712

215. E. Ziurys, Division of Magnetic Fusion Energy, Energy Research and Development Administration, Washington, DC 20545

216. K. Zwilsky, Division of Magnetic Fusion Energy, Energy Research and Development Administration, Washington, DC 20545

217-243. Technical Information Center, P.0. Box 62, Oak Ridge, TN 37830 